\title{
Government Consumption and Investment: Does the Composition of Purchases Affect the Multiplier?*
}

\author{
Christoph E. Boehm \\ U.T. Austin
}

February 1, 2019

\begin{abstract}
I show that a large and conventional class of macroeconomic models predicts that short-lived government investment shocks have a smaller fiscal multiplier than government consumption shocks. I test this prediction in a panel of OECD countries using real-time forecasts of government consumption and investment to purify changes in purchases of their predicted components. Consistent with theory, I estimate a government investment multiplier near zero and a government consumption multiplier of approximately 0.8. These findings suggest that fiscal stimulus packages which contain large government investment components may not be as effective at stimulating aggregate demand as commonly thought.
\end{abstract}

JEL Codes: E32, E62, E63

Keywords: Fiscal multiplier, Durable goods, Investment, Government spending, Government investment, Government consumption

\footnotetext{
*Department of Economics, Austin, TX 78712. Email: chris.e.boehm@gmail.com. This paper supersedes the paper Government Spending and Durable Goods (Boehm, 2016). Declarations of interest: none. I would like to thank Chris House, Oli Coibion, Matthew Shapiro, Stefan Nagel, Joshua Hausman, and Edward Ionides for valuable comments, suggestions, and support. I also thank Saroj Bhattarai, Charlie Brown, Matias Cattaneo, Aaron Flaaen, Jordi Galí, Simon Gilchrist, Andy Glover, Jim Hamilton, Miles Kimball, David Lagakos, Andrei Levchenko, Karel Mertens, Emi Nakamura, Pablo Ottonello, Nitya Pandalai-Nayar, Valerie Ramey, Dimitrije Ruzic, Richard Ryan, Jeff Smith, Isaac Sorkin, Johannes Wieland, and Justin Wolfers for helpful conversations as well as the participants of the seminars at Michigan, UIUC, the Bank of Canada, the Federal Reserve Board, CREI, Warwick, Cambridge, INSEAD, IIES, the Boston Fed, Notre Dame, Columbia, UT Austin, the San Francisco Fed, UCSD, Oregon, the Dallas Fed, the EGSC in St. Louis, the Fall 2015 Midwest Macro Meeting, and the 85th SEA Annual Meetings.
} 


\section{Introduction}

During the Great Recession, a number of governments around the world enacted fiscal stimulus packages to combat the decline in economic activity. A common feature of these policies was a significant share of spending on long-lived investment goods. In the U.S., for instance, the American Recovery and Reinvestment Act contained provisions to raise spending in excess of 70 billion dollars on infrastructure and transportation. ${ }^{1}$ In other countries infrastructure investment also constituted a significant fraction of stimulus spending, most notably China with approximately 40 percent (International Labour Organization, 2011). More generally, government investment features prominently in debates on fiscal stimulus where it is typically assumed to be highly effective. For instance, Paul Krugman wrote in his New York Times column on June 6, 2016 that "the simplest, most effective answer to a downturn would be fiscal stimulus - preferably government spending on much-needed infrastructure, ..." (Krugman, 2016).

This paper studies the fiscal multiplier associated with government investment and compares it to the multiplier of government consumption spending. I first show that a large and conventional class of macroeconomic models predicts that the government investment multiplier is small-typically below 20 cents on the dollar. This contrasts with the government consumption multiplier which is between 0.6 and 1 under standard assumptions on parameters. Motivated by this prediction, I estimate government consumption and investment multipliers in a panel of OECD countries. The data broadly supports the theory's predictions: I estimate a government consumption multiplier of around 0.8 and a government investment multiplier near zero. These findings suggest that government investment may not be as effective at raising output as is commonly assumed.

I begin in Section 2 by comparing the consumption and investment multiplier in a two-sector model. The model predicts that the investment multiplier is small because private investment falls drastically after government investment shocks. This high degree of crowding out is driven by the high intertemporal elasticity of substitution of investment demand which has been shown to be a feature of a large class of macroeconomic models (e.g., Mankiw, 1985, Erceg and Levin, 2006, Barsky, House, and Kimball, 2007, House and Shapiro, 2008, House, 2014, Barsky et al., 2015). Since a higher intertemporal elasticity of substitution is associated with a smaller wealth

${ }^{1}$ This information is taken from http://www.recovery.gov/arra/Transparency/fundingoverview/Pages/ fundingbreakdown.aspx. Since the website is now offline, I accessed a cached version (from 01/04/2014) via https://archive.org/ 
effect, temporary government investment shocks provide essentially no incentive for households to increase their labor supply.

In Section 3 I test this prediction, using data from the OECD's Statistics and Projections Database. This database not only includes separate series for government consumption and investment, but also real-time forecasts of these two components of spending. Building on Blanchard and Perotti (2002), Auerbach and Gorodnichenko (2012, 2013), Ramey and Zubairy (2017), and Miyamoto, Nguyen, and Sergeyev (2017), I develop a method to estimate separate multipliers for government consumption and investment. To address the concern that shocks identified with this scheme could be anticipated (Ramey, 2011b), I use the OECD's real-time forecasts to purge changes in purchases of their predicted components. Further, I restrict myself to the use of quarterly data (as in Ilzetzki, Mendoza, and Végh, 2013), because the identification assumption requires that the government does not respond to changing economic conditions within the same period.

I estimate a government consumption multiplier of approximately 0.8 and a government investment multiplier near zero. As predicted by the model, the difference between these two multipliers is driven in large part by the fact that private investment falls after government investment shocks, but not after government consumption shocks. Private consumption remains broadly unchanged after either of the two shocks.

The model predicts that private investment is crowded out through a rise in the own real interest rate of the investment goods sector. To test this hypothesis, I construct real interest rates using real-time forecasts of the sector-specific inflation rates from the OECD's Statistics and Projections database. Consistent with the model, there is evidence of a temporary rise in the own real interest rate of investment after a shock to government investment. The own real interest rate in the consumption goods sector responds insignificantly to a government consumption shock. ${ }^{2}$

Because actual multipliers for government consumption and investment multipliers could differ for a number of reasons which are not explicitly considered in the model, I show that empirically the difference between the multipliers is not driven by alternative financing schemes, different monetary policy responses or different exchange rate responses. Net exports fall after both government consumption and government investment shocks, but not differentially so. I also test whether the government consumption and investment multipliers depend on whether the economy is at the

\footnotetext{
${ }^{2}$ Theory suggests that private sector spending could also be crowded in or out via alternative mechanisms. Michaillat (2014), for instance, develops a model in which greater tightness crowds out private sector employment.
} 
zero lower bound (ZLB) (e.g. Christiano, Eichenbaum, and Rebelo, 2011, Woodford, 2011) and 2) the state of the business cycle (e.g. Auerbach and Gorodnichenko, 2012, 2013). There is some evidence for larger multipliers at the ZLB, in particular for government investment. No robust differences emerge when I estimate separate multipliers for alternative states of the business cycle.

An implication of these different multipliers is that the multiplier for total government purchases, which is commonly estimated in the literature, can suffer from external validity problems. Building on earlier work by Kraay (2012), I show in Section 4 that the multiplier for total purchases is approximately a weighted average of the government consumption and investment multipliers. Broadly speaking, the weights reflect the composition of purchases. Since this composition can differ across applications, the multiplier for total purchases can vary - even if the multipliers of government consumption and investment remain unchanged. For instance, if an actual stimulus program has a different composition of government consumption and investment than the identifying variation for the estimated multiplier, then this estimate will provide misleading guidance for policy. Similarly, one would not expect that estimates for the multiplier of total purchases are necessarily comparable across samples and identification schemes.

This paper builds on a large literature on the effects of government spending. Influential theoretical work such as Aiyagari, Christiano, and Eichenbaum (1992) and Baxter and King (1993) emphasizes that the wealth effect is critical for determining the size of the fiscal multiplier and that investment is crowded out after temporary shocks to government purchases. That the effects of government purchases depend on the persistence of the shock is known since at least Barro (1981). Hall (2009) shows in a simple static model that the fiscal multiplier is decreasing in the intertemporal elasticity of substitution. In his model the multiplier tends to zero as the intertemporal elasticity of substitution approaches infinity. I show that the same result holds approximately in the model I present below. ${ }^{3}$ Cogan et al. (2010), Leeper, Walker, and Yang (2010), and Leeper, Traum, and Walker (2017) document in quantitative models that private investment typically falls after an increase in government purchases. Neither of these papers studies government investment separately from government consumption in a two sector model.

The theoretical prediction that investment is crowded out after increases in the sum of government consumption and investment is commonly confirmed in the data. Ramey and Shapiro (1998), Blanchard and Perotti (2002), Mountford and Uhlig (2009), Barro and Redlick (2011),

\footnotetext{
${ }^{3}$ In his discussion of Hall's paper, House (2009) argues that falling investment after fiscal expansions is critical for determining the output responses in standard models.
} 
Ramey (2011b), and others all find that investment falls after such a shock. ${ }^{4}$ Relative to these papers, I argue that one should, if possible, distinguish between these two types of spending since government investment is more likely to crowd out private investment than government consumption.

Another strand of literature argues that public investment accumulates into a productive public capital stock (e.g. Aschauer, 1989a, 1989b, Pereira, 2000, Kamps, 2005). ${ }^{5}$ Motivated by this hypothesis Voss (2002), Perotti (2004), Pappa (2010), and others estimate separate multipliers for government consumption and government investment. Voss (2002) and Perotti (2004) find that government investment is associated with a small multiplier because private investment falls. While Perotti (2004, p. 26) views this evidence as a "puzzle", I show below that a standard two-sector model predicts precisely that. The findings in Pappa (2010) are mixed. Neither of these papers makes a connection to the high intertemporal elasticity of substitution of investment. Perotti (2008) and Ramey (2011a) summarize the literature on the effects of government purchases. ${ }^{6}$ I provide concluding comments in Section 5.

\section{Theoretical Analysis}

I present a two sector New Keynesian model to study the effectiveness of government consumption and investment at raising output. Since the objective of the model is to motivate the empirical analysis below, and not to make quantitative predictions, I keep the environment simple and stylized. The only deviation from a standard two sector model is that the government capital stock is productive as in Baxter and King (1993), among others. After describing the model, I lay out the main claim that under a conventional set of assumptions the government investment multiplier is small. I then discuss the mechanism and its robustness.

\footnotetext{
${ }^{4}$ Edelberg, Eichenbaum, and Fisher (1999) find that residential investment falls but nonresidential investment increases.

${ }^{5}$ There is a large literature on the productivity of government investment. For instance, Fisher and Turnovsky (1998) study the relationship between private and public capital in a model with congestion. Eden and Kraay (2014) estimate that in a sample of low-income countries public investment crowds in private investment. Bouakez, Guillard, and Roulleau-Pasdeloup (2017) study public investment at the zero lower bound and find that it is associated with large multipliers.

${ }^{6}$ A recent literature uses state-level variation to estimate fiscal multipliers. For instance, Cohen, Coval, and Malloy (2011) find that private investment is crowded out after fiscal expansions although this finding is contested in Snyder and Welch (2017). Leduc and Wilson (2012) estimate large multipliers for public infrastructure spending, particularly at long horizons. Since Nakamura and Steinsson (2014) show that such cross-sectional multipliers are not easily mapped to an aggregate multiplier, it is not clear whether the findings in Leduc and Wilson (2012) conflict with the estimates in this paper. Chodorow-Reich (2017) summarizes the literature on cross-sectional multipliers.
} 


\subsection{Model setup}

Consumers Time is discrete and consumers' life time utility is given by

$$
E_{0} \sum_{t=0}^{\infty} \beta^{t}\left[\frac{\left(c_{t}^{h}\right)^{1-\frac{1}{\sigma}}}{1-\frac{1}{\sigma}}+\chi \frac{\left(c_{t}^{g}\right)^{1-\frac{1}{\sigma}}}{1-\frac{1}{\sigma}}-\phi \frac{n_{t}^{1+\frac{1}{\eta}}}{1+\frac{1}{\eta}}\right]
$$

Here, $c^{h}$ denotes the household's nondurable goods consumption and $c^{g}$ is government consumption. I adopt the common assumption that $c^{g}$ enters additively in the utility function, so that it does not affect the equilibrium through complementarity or substitutability with private consumption. The labor aggregate $n$ is composed of labor in the consumption goods sector $n^{c}$ and labor in the investment sector $n^{x}$ according to

$$
n_{t}=\left[\left(n_{t}^{c}\right)^{\frac{\eta+\mu}{\eta}}+\left(n_{t}^{x}\right)^{\frac{\eta+\mu}{\eta}}\right]^{\frac{\eta}{\eta+\mu}}
$$

Note that this specification nests two canonical cases, depending on the choice of $\mu \in[0,1]$. For $\mu=0$, labor is fully mobile between sectors, and for $\mu=1$, labor is perfectly immobile and enters separably in the utility function.

Households own the capital stocks of the two sectors and maximize (1) subject to the labor aggregator (2), the nominal budget constraint

$$
b_{t}+p_{t}^{c} c_{t}^{h}+p_{t}^{x}\left(x_{t}^{c}+x_{t}^{x}\right)=b_{t-1}\left(1+i_{t-1}\right)+\pi_{t}-\tau_{t}^{l}+\sum_{s \in\{c, x\}} w_{t}^{s} n_{t}^{s}+r_{k, t}^{s} k_{t}^{s},
$$

the accumulation equations

$$
k_{t+1}^{s}=k_{t}^{s}(1-\delta)+\vartheta\left(\frac{x_{t}^{s}}{k_{t}^{s}}\right) k_{t}^{s}, \quad s \in\{c, x\}
$$

and a no-Ponzi condition. $x_{t}^{s}$ is investment in sector $s$ and $\vartheta\left(\frac{x_{t}^{s}}{k_{t}^{s}}\right) k_{t}^{s}$ an adjustment cost function satisfying $\vartheta\left(\frac{x}{k}\right)=\frac{x}{k}, \vartheta^{\prime}\left(\frac{x}{k}\right)=1$, and $\vartheta^{\prime \prime}\left(\frac{x}{k}\right)=-\zeta$ in the steady state. The remaining notation is as follows: $b_{t}$ is a nominal bond, $i_{t}$ the nominal interest rate, $\pi_{t}$ are profits, and $\tau_{t}^{l}$ is a lump-sum tax which the government uses to finance both types of expenditures.

Let $\lambda_{t}$ be the multiplier on the nominal budget constraint and $\lambda_{t} \gamma_{t}^{s}$ the multiplier on the accumulation equation in sector $s$, that is, $\gamma_{t}^{s}$ is the dollar value of one unit of installed capital in 
sector $s$. Then optimal behavior requires that

$$
\begin{gathered}
\left(c_{t}^{h}\right)^{-\frac{1}{\sigma}}=p_{c, t} \lambda_{t} \\
\phi\left(n_{t}\right)^{\frac{1-\mu}{\eta}}\left(n_{t}^{s}\right)^{\frac{\mu}{\eta}}=\lambda_{t} w_{t}^{s}, s \in\{c, x\} \\
p_{t}^{x}=\gamma_{t}^{s} \vartheta^{\prime}\left(\frac{x_{t}^{s}}{k_{t}^{s}}\right), s \in\{c, x\} \\
\lambda_{t}=\beta\left(1+i_{t}\right) E_{t}\left[\lambda_{t+1}\right], \\
\lambda_{t} \gamma_{t}^{s}=\beta E_{t}\left[\lambda_{t+1} r_{k, t+1}^{s}+\lambda_{t+1} \gamma_{t+1}^{s}\left((1-\delta)+\vartheta\left(\frac{x_{t+1}^{s}}{k_{t+1}^{s}}\right)-\vartheta^{\prime}\left(\frac{x_{t+1}^{s}}{k_{t+1}^{s}}\right) \frac{x_{t+1}^{s}}{k_{t+1}^{s}}\right)\right], s \in\{c, x\} .
\end{gathered}
$$

Firms Both sectors have a competitive aggregating firm and a unit continuum of differentiated firms which compete monopolistically. The aggregating firm in sector $s \in\{c, x\}$ assembles the varieties into the sector's output using a CES aggregator with elasticity $\varepsilon, s_{t}=\left[\int_{0}^{1}\left(s_{j, t}\right)^{\frac{\varepsilon-1}{\varepsilon}} d j\right]^{\frac{\varepsilon}{\varepsilon-1}}$. Optimal behavior yields the demand curves

$$
s_{j, t}=s_{t}\left(\frac{p_{j, t}^{s}}{p_{t}^{s}}\right)^{-\varepsilon}, \text { for all } j
$$

and the price index $p_{t}^{s}=\left(\int_{0}^{1}\left(p_{j, t}^{s}\right)^{1-\varepsilon} d j\right)^{\frac{1}{1-\varepsilon}}$.

Monopolistic competitors operate Cobb-Douglas production functions

$$
s_{j, t}=\left(k_{t}^{g}\right)^{\alpha_{g}}\left(k_{j, t}^{s}\right)^{\alpha}\left(n_{j, t}^{s}\right)^{1-\alpha}, \quad s \in\{c, x\},
$$

and minimize costs, taking the sector-specific factor prices $r_{k, t}^{s}$ and $w_{t}^{s}$ as given. Following earlier work by Baxter and King (1993) and Leeper, Walker, and Yang (2010), the government capital stock $k_{t}^{g}$ is productive and affects output with elasticity $\alpha_{g}{ }^{7}$ Nominal marginal costs in sector $s \in\{c, x\}$ are

$$
m c_{t}^{s}=\frac{1}{\left(k_{t}^{g}\right)^{\alpha_{g}}}\left(\frac{r_{k, t}^{s}}{\alpha}\right)^{\alpha}\left(\frac{w_{t}^{s}}{1-\alpha}\right)^{1-\alpha},
$$

\footnotetext{
${ }^{7}$ Note that this assumption differs from those in e.g. Linnemann and Schabert (2006) and Albertini, Poirier, and Roulleau-Pasdeloup (2014) who assume that current government expenditures - and not the stock of public capital-provide productive services.
} 
and factor demands conditional on marginal costs satisfy

$$
\begin{aligned}
\frac{w_{t}^{s}}{p_{t}^{s}} & =\frac{m c_{t}^{s}}{p_{t}^{s}}(1-\alpha)\left(k_{t}^{g}\right)^{\alpha_{g}}\left(k_{j, t}^{s}\right)^{\alpha}\left(n_{j, t}^{s}\right)^{-\alpha} \\
\frac{r_{k, t}^{s}}{p_{t}^{s}} & =\frac{m c_{t}^{s}}{p_{t}^{s}} \alpha\left(k_{t}^{g}\right)^{\alpha_{g}}\left(k_{j, t}^{s}\right)^{\alpha-1}\left(n_{j, t}^{s}\right)^{1-\alpha} .
\end{aligned}
$$

Price setting Let $m_{t, t+\tau}$ be the stochastic discount factor for nominal cash flows. Firms set prices as in Calvo (1983), choosing $p_{j, t}^{s}$ to maximize

$$
E_{t}\left[\sum_{\tau=0}^{\infty}\left(\theta_{s}\right)^{\tau} m_{t, t+\tau}\left[p_{j, t}^{s} s_{j, t+\tau}-m c_{t+\tau}^{s} s_{j, t+\tau}\right]\right]
$$

subject to the sequence of demand curves (10). $\theta_{s}$ parameterizes price stickiness in sector $s$. The optimal reset price is

$$
p_{t}^{s *}=\frac{\varepsilon}{\varepsilon-1} \frac{E_{t} \sum_{\tau=0}^{\infty}\left(\theta_{s}\right)^{\tau} m_{t, t+\tau} s_{t+\tau}\left(p_{t+\tau}^{s}\right)^{\varepsilon} m c_{t+\tau}^{s}}{E_{t} \sum_{\tau=0}^{\infty}\left(\theta_{s}\right)^{\tau} m_{t, t+\tau} s_{t+\tau}\left(p_{t+\tau}^{s}\right)^{\varepsilon}} .
$$

Closing the model Markets in both sectors clear

$$
\begin{aligned}
& x_{t}=x_{t}^{x}+x_{t}^{c}+x_{t}^{g}, \\
& c_{t}=c_{t}^{h}+c_{t}^{g},
\end{aligned}
$$

and government spending in each sector follows $\mathrm{AR}(1)$ processes

$$
s_{t}^{g}=\left(1-\varrho_{s}^{g}\right) s^{g}+\varrho_{s}^{g} s_{t-1}^{g}+\varepsilon_{s, t}^{g}, \quad s \in\{c, x\} .
$$

The government capital stock $k_{t}^{g}$ follows the same law of motion as the private capital stocks (equation (4) for $s=g$ ), and the government finances spending with a contemporaneous lumpsum tax $\tau_{t}^{l}=p_{t}^{x} x_{t}^{g}+p_{t}^{c} c_{t}^{g}$. Letting $p^{x}$ and $p^{c}$ denote steady state prices, real GDP is $y_{t}=p^{x} x_{t}+p^{c} c_{t}$ and the deflator $p_{t}=\left(p_{t}^{x} x_{t}+p_{t}^{c} c_{t}\right) / y_{t}$. The central bank follows a Taylor rule of the form

$$
i_{t}=\beta^{-1}-1+\phi_{\pi} \pi_{t}
$$

where $\pi_{t}$ is inflation of the GDP deflator. The government consumption and investment multipliers are defined as $m_{c}:=\frac{\mathrm{d} y_{t}}{\mathrm{~d} p^{c} c_{t}^{g}}$ and $m_{x}:=\frac{\mathrm{d} y_{t}}{\mathrm{~d} p^{x} x_{t}^{g}}$. 


\section{$2.2 \quad$ A numerical example}

I begin with a numerical example which illustrates the main claim and subsequently discuss the mechanism. For the numerical example, I choose parameters symmetrically for the consumption and investment goods sector to highlight that the results are driven by the long service life of capital goods and not other forces. The time period is a quarter and households discount the future with a discount factor $\beta$ of 0.995 . Labor is immobile across sectors so that $\mu=1$. Consistent with recent estimates, I set the intertemporal elasticity of substitution $\sigma$ to 0.25 (e.g. Cashin and Unayama, 2016), and the Frisch labor supply elasticity $\eta$ to 0.75 (Chetty et al., 2011). I further set $\alpha=1 / 3$ and choose a depreciation rate $\delta$ of 0.025. Following Basu and Leo (2016) who calibrate a similar model to match investment volatility in the data, I set the adjustment cost parameter $\zeta$ to 2. To match the estimates in Section 3, I choose the persistence of government spending so that fiscal shocks decay to about one third after 2 years. This requires $\varrho_{x}^{g}=\varrho_{c}^{g}=0.86$. Based on the 2005 U.S. national accounts, the government's share of purchases in the two sectors is set to $s_{c}^{g}=s_{x}^{g}=0.175$. I follow Leeper, Walker, and Yang (2010) and choose an elasticity of output with respect to public capital, $\alpha_{g}$, of 0.05 . As the literature lacks consensus on this parameter, I also consider alternate values below. Finally, I select Calvo parameters $\theta_{x}$ and $\theta_{c}$ of 0.7, implying an approximate half-life of 6 months. Although most central banks target consumer price inflation, I prefer a benchmark parameterization which treats both sectors symmetrically and assume that the central bank responds to GDP deflator inflation with a coefficient of $\phi_{\pi}$ of 1.5. Below, I discuss an alternative calibration which takes this and other asymmetries between the consumption and investment goods sector into account. Appendix A Table A1 summarizes this benchmark calibration.

Figure 1 shows the impulse response functions to an increase in government spending by one quantity unit. In the figure, circles indicate responses to a government consumption shock and crosses indicate responses to a government investment shock. Panel B shows purchases of the household. In response to the increase in government consumption, household consumption $c_{t}^{h}$ drops mildly, in the order of 0.1 to 0.35 quantity units, depending on whether prices are sticky. In stark contrast, private investment $x_{t}^{c}+x_{t}^{x}$ drops by approximately 0.8 to 0.9 quantity units when the government purchases the investment good. Put differently, private sector spending is crowded out to a much larger degree when spending occurs in the x-sector.

Because private investment contracts more than consumption after government spending 
Figure 1: Impulse response functions
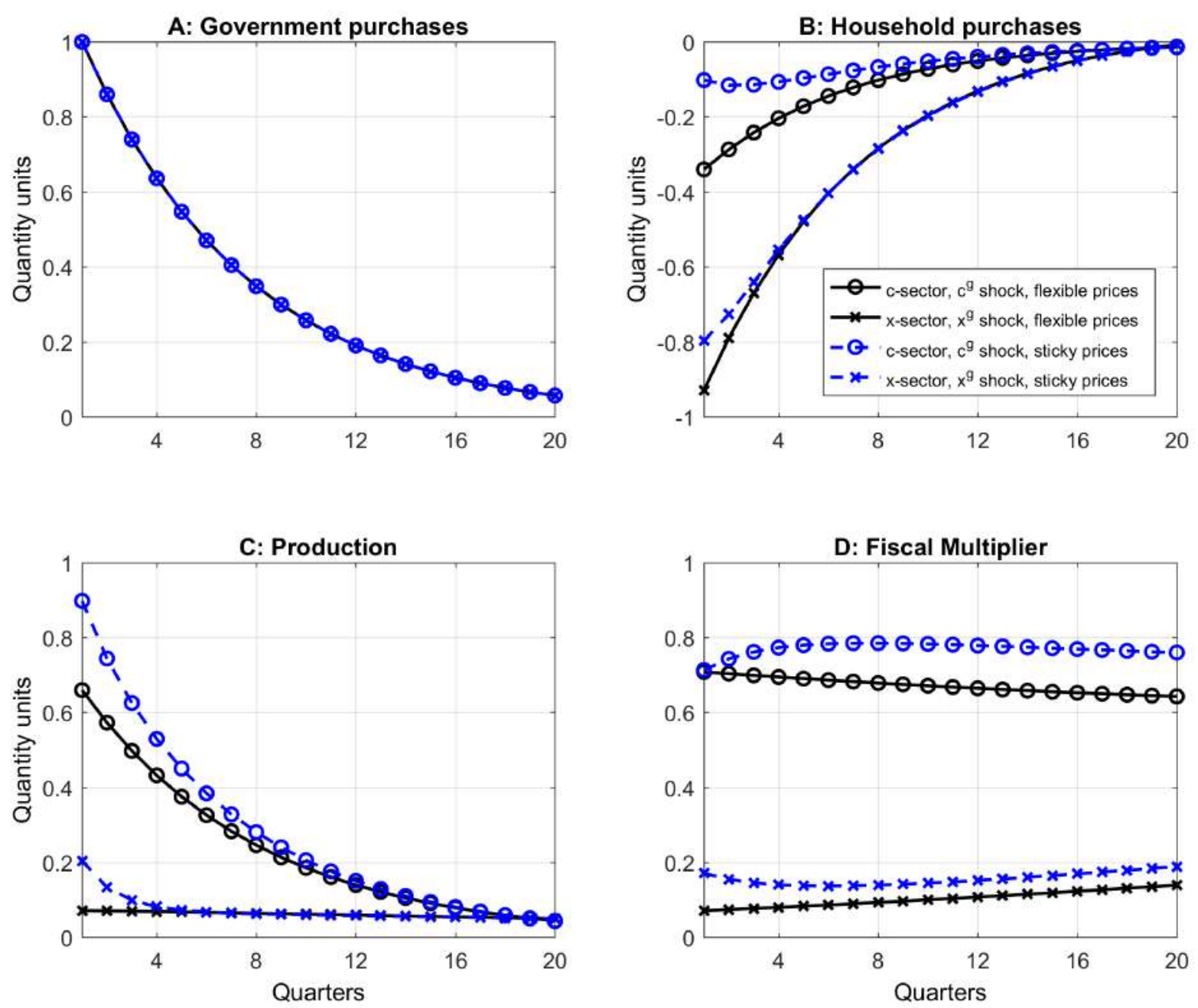

Notes: The figure plots the impulse response functions for a one unit increase in government spending based on the baseline calibration. Circles indicate responses to a government consumption shock and crosses indicate responses to a government investment shock.

shocks, production expands less in the investment sector. This is shown in Panel C. Panel D plots the multipliers associated with government consumption and government investment. The key conclusion is that the investment multiplier is small relative to the consumption multiplier. Price stickiness has quantitatively small effects in this example.

The role of productive government capital Before turning to the mechanism, it is useful to note that the productivity of government capital plays a very limited role for transitory govern- 
ment investment shocks. The reason is that temporary changes in investment have small effects on the capital stock. For instance, with an annual depreciation rate of $\delta_{\mathrm{ann}}=0.1$, a one percent increase in government investment for one year raises the capital stock by 0.1 percent. This, in turn, and holding all else equal, raises output and the marginal products of capital and labor in both sectors by $\alpha_{g} \cdot \delta_{\mathrm{ann}}=0.05 \cdot 0.1=0.005$ percent (i.e. 0.5 basis points). The implications for fiscal policy are quantitatively small in the short run: For values of $\alpha_{g}$ equal to 0, 0.05, and 0.1, the four-quarter GDP multipliers for government investment are 0.12, 0.14, and 0.16. Baxter and King (1993) and Leeper, Walker, and Yang (2010) show that productive government investment is more important for more persistent shocks and for longer-run fiscal multipliers.

\subsection{The mechanism}

The large difference between the consumption multiplier and the investment multiplier ultimately follows from the long service life of capital goods. While nondurable goods are consumed within the same quarter, capital goods deliver service flows until fully depreciated. In what follows, I link the small government investment multiplier to two closely related properties of capital goods which are well understood in the literature (Barsky, House, and Kimball, 2007). First, the shadow value of capital responds very little to temporary shocks and second investment is highly intertemporally substitutable.

\subsubsection{The nearly constant shadow value of capital}

Assume for simplicity that there are no adjustment costs ( $\vartheta$ is the identity), and that labor is immobile across sectors $(\mu=1)$. In the absence of adjustment costs, equation (9) can be solved forward to obtain

$$
\lambda_{t} \gamma_{t}^{x}=\beta E_{t}\left[\sum_{\tau=0}^{\infty}[\beta(1-\delta)]^{\tau} \lambda_{t+\tau+1} r_{k, t+\tau+1}^{x}\right]
$$

Since $\lambda_{t} \gamma_{t}^{x}$ depends on service flows far in the future, it responds very little to temporary shocks. Such shocks only affect the first few terms in the infinite sum. As $\delta$ approaches zero and $\beta$ tends to 1 , the household places sufficient weight on future flows that approximating $\lambda_{t} \gamma_{t}^{x}$ with the steady state value becomes arbitrarily precise (Barsky, House, and Kimball, 2007, House and Shapiro, 2008).

To see how this matters for the government investment multiplier, combine equations $(5-7)$ 
to obtain the labor supply conditions

$$
\begin{aligned}
& \phi\left(n_{t}^{c}\right)^{\frac{1}{\eta}}=\left(c_{t}^{h}\right)^{-\frac{1}{\sigma}} \frac{w_{t}^{c}}{p_{t}^{c}} \\
& \phi\left(n_{t}^{x}\right)^{\frac{1}{\eta}}=\lambda_{t} \gamma_{t}^{x} \frac{w_{t}^{x}}{p_{t}^{x}} .
\end{aligned}
$$

For the consumption goods sector, the wealth effect is $\left(c_{t}^{h}\right)^{-\frac{1}{\sigma}}$. If public consumption crowds out private consumption, households increase their labor supply. This "impoverishment" effect has been highlighted in, for instance, Aiyagari, Christiano, and Eichenbaum (1992) and Baxter and King (1993). However, the model predicts that the wealth effect is extremely weak in the investment goods sector. After a government investment shock, even if private investment is crowded out, the shadow value of capital remains approximately unchanged. With $\lambda_{t} \gamma_{t}^{x}$ approximately constant, the household does not find it worthwhile to increase the supply of labor. I conclude that the near-constancy of the shadow value of capital essentially eliminates the wealth effect after government investment shocks.

Suppose we approximate $\lambda_{t} \gamma_{t}^{x}, k_{t}^{x}, k_{t}^{c}$, and $k_{t}^{g}$ with their steady state values. Then, combining (17) with (12) gives

$$
\phi\left(n_{t}^{x}\right)^{\frac{1}{\eta}} \approx \lambda \gamma^{x} \frac{m c_{t}^{x}}{p_{t}^{x}}(1-\alpha)\left(k^{g}\right)^{\alpha_{g}}\left(k^{x}\right)^{\alpha}\left(n_{t}^{x}\right)^{-\alpha}
$$

In words, labor in the investment goods sector is only a function of the markup in the investment goods sector. Employment only rises if the markup falls in this approximation. A particularly striking case arises when prices are flexible. Since the markup is constant, labor and production in the investment goods sector remain approximately constant after a shock to government investment. As Proposition 2.1 shows under a somewhat more general set of assumptions, the government investment multiplier is zero in this environment. This contrasts to the government consumption multiplier, which is positive but smaller than one.

Proposition 2.1. Consider the model in Section 2.1 and suppose prices are flexible. Suppose further that $\delta$ is arbitrarily close to zero. Then, for a short-lived increase in spending $\left(\varrho_{x}^{g}=\varrho_{c}^{g}=\right.$ $0)$,

$$
\begin{aligned}
& m_{x} \approx 0, \\
& m_{c} \approx \frac{(1-\alpha)\left(\frac{\mu}{\eta}+\alpha\right)}{(1-\alpha)\left(\frac{1-\mu}{\eta} s_{y}^{x}+\frac{\mu}{\eta}+\alpha\right)+\left(1-s_{c}^{g}\right) \sigma\left(\frac{\mu}{\eta}+\alpha\right)\left(\alpha+\frac{1}{\eta}\right)} .
\end{aligned}
$$


Proof. See Appendix A.2.1

As is intuitive, the government consumption multiplier is increasing in the labor supply elasticity $\eta$, decreasing in the capital share $\alpha$, and increasing in $s_{c}^{g}{ }^{8}$ The consumption multiplier is also decreasing in the intertemporal elasticity of substitution $\sigma$. As $\sigma \rightarrow \infty$, the multiplier approaches zero. Note that the multiplier's dependence on the intertemporal elasticity of substitution follows from the fact that $\sigma$ parameterizes the strength of the wealth effect (see equation 16). For large $\sigma$ the labor supply becomes independent of the household's consumption. Since the intertemporal elasticity of substitution is extremely high for investment goods, the multiplier must be small. I next discuss an alternative interpretation which more directly highlights the role of the intertemporal elasticity of substitution.

\subsubsection{The intertemporal elasticity of substitution of investment}

Unlike consumption of nondurable goods, investment into durable goods and capital is highly interest-elastic. Because the service flow of capital depends on the stock and new investment constitutes a small fraction of next period's capital stock, households are much more willing to change the timing of investment in response to price changes than to change their consumption. One way to make this statement precise is to consider the partial elasticities of consumption and investment with respect to their own real interest rates (defined as $1+r_{t}^{s}=\left(1+i_{t}\right) / E_{t}\left[1+\pi_{t+1}^{s}\right]$, $s \in\{c, x\})$.

Combining equations $\left(4,5,7,8,9\right.$, and 13), and assuming that next period's labor $n_{t+1}^{s}$, investment $x_{t+1}^{s}, s \in\{c, x\}$, government capital $k_{t+1}^{g}$, consumption $c_{t+1}^{h}$, and the relative price $\frac{p_{t+1}^{x}}{p_{t+1}^{c}}$ are held constant, these partial elasticities are

$$
\begin{aligned}
& \frac{\partial \ln c_{t}^{h}}{\partial r_{t}^{c}}=-\sigma \beta, \\
& \frac{\partial \ln x_{t}^{s}}{\partial r_{t}^{x}}=-\frac{1}{(1-\alpha)\left(\beta^{-1}-1+\delta\right) \delta+\zeta \delta\left(\beta^{-1}+\delta\right)}, \quad s \in\{c, x\} .
\end{aligned}
$$

\footnotetext{
${ }^{8}$ The consumption multiplier is also decreasing in factor mobility (smaller $\mu$ ). The intuition is that government consumption crowds out private investment when factors are mobile. In the benchmark case with labor immobility $(\mu=1)$, the consumption multiplier becomes, as in Hall (2009),

$$
m_{c} \approx \frac{(1-\alpha)}{(1-\alpha)+\left(1-s_{c}^{g}\right) \sigma\left(\alpha+\eta^{-1}\right)} .
$$
}


Figure 2: Crowding out of private sector spending
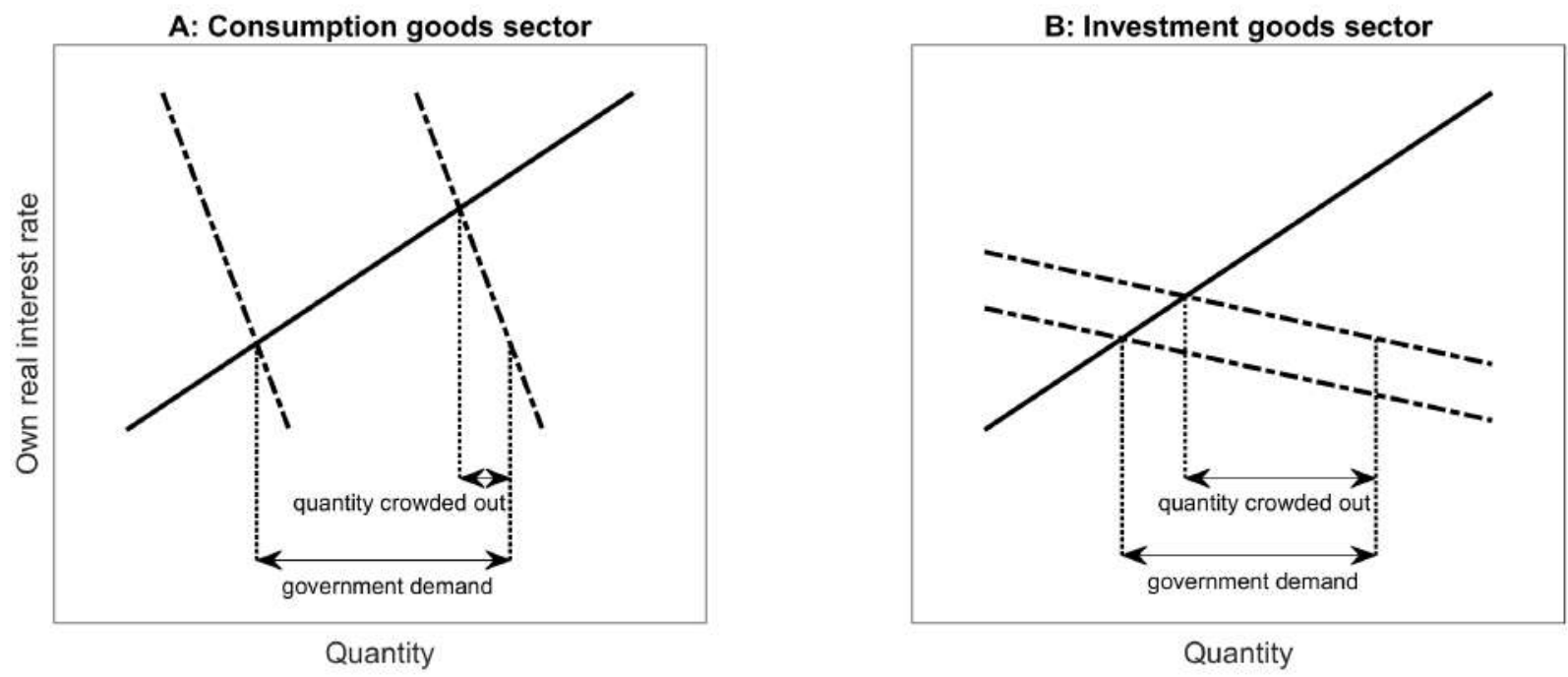

In the benchmark calibration $\frac{\partial \ln c_{t}^{h}}{\partial r_{t}^{c}}=-0.25$ and $\frac{\partial \ln x_{t}^{s}}{\partial r_{t}^{x}}=-19.23$. The difference by a factor of approximately 80 stems from the fact that the depreciation rate $\delta$ and the rate of time preference $\beta^{-1}-1$ in the denominator of (21) are small. Further, the dependence on these two parameters highlights that it is precisely the long service life that drives both the high elasticity and ultimately the small multiplier.

Figure 2 illustrates how this elasticity effects the equilibrium after an increase in government spending. Notice that the figure assumes that both sectors have the same supply elasticities. ${ }^{9}$ Because demand is so elastic, identical increases in the own real interest rates lead to much larger contractions of private investment. This makes the government investment multiplier small.

This mechanism also provides useful intuition for Proposition 2.1: As higher demand in the investment goods sector threatens to raise the own real interest rate, the private sector postpones purchases to the future. In the limiting approximation, private investment demand is infinitely elastic so that the demand curve is horizontal $(\delta \rightarrow 0$ in equation 21). As a result investment falls one for one with increased government spending and the real interest rate remains the same. Instead of buying the investment good the household hands the resources to the government (which then buys the investment good). Total output in the investment goods sector remains unchanged, and, in fact, no other variable changes in equilibrium. ${ }^{10}$

\footnotetext{
${ }^{9}$ Equal elasticities follow from the symmetric setup, in particular, the production functions and labor supply: $\frac{\partial \ln s_{t}}{\partial r_{t}^{s}}=\frac{1-\alpha}{\alpha+\frac{\mu}{\eta}}$, for $s \in\{c, x\}$. See Appendix A.4 for details.

${ }^{10} \mathrm{I}$ discuss the mathematical details in Appendix A.5
} 
Figure 2 highlights the role of prices for crowding out private sector spending. It is the increase in the own real interest rate that leads to the contraction of private spending. In Section 3 I will test the prediction that real interest rates rise after a government spending shock. To have a benchmark, Appendix A.6 reports the impulse response functions after government spending shocks.

\subsubsection{Long-lived spending shocks}

All results I have presented this far rely on the shock being transitory. Long-lived shocks have a larger effect on household wealth and leave less room for intertemporal substitution. Further, the public and private capital stocks adjusts more to persistent changes in investment. This implies that the multiplier for government investment will be greater after long-lived shocks.

Proposition 2.2 reports the long-run government consumption and investment multipliers for permanent shocks. Because this proposition focuses on the long run (this is a steady state comparison), I assume that labor moves freely across sectors.

Proposition 2.2. Consider the model Section 2.1 and assume that labor is mobile across sectors $(\mu=0)$. Then the multipliers for a permanent change in purchases are

$$
\begin{aligned}
m_{c}^{\infty} & =\frac{\eta}{\eta\left(1-s_{y}^{x}\left(1-s_{x}^{g}\right)\right)+\sigma\left(1-s_{c}^{g}\right)\left(1-s_{y}^{x}\right)}, \\
m_{x}^{\infty} & =m_{c}^{\infty}+\frac{(1+\eta) \sigma}{\eta\left(1-s_{y}^{x}\left(1-s_{x}^{g}\right)\right)+\sigma\left(1-s_{c}^{g}\right)\left(1-s_{y}^{x}\right)} \cdot \frac{\left(1-s_{c}^{g}\right)\left(1-s_{y}^{x}\right)}{s_{y}^{x} s_{x}^{g}} \cdot \frac{\alpha_{g}}{1-\alpha},
\end{aligned}
$$

where $s_{y}^{x}$ denotes the steady state share of the investment goods sector in GDP, and $s_{c}^{g}$ and $s_{x}^{g}$ are the steady state shares of government purchases in the respective sector.

Proof. See Appendix A.2.2

Note that long-run multipliers can be greater than one. In the baseline calibration, but with perfectly mobile labor and permanent shocks, $m_{c}^{\infty}=1.11$ and $m_{x}^{\infty}=1.55$. The government investment multiplier is weakly greater than the government consumption multiplier and equal to it if government capital is not productive $\left(\alpha_{g}=0\right)$.

Returning to the case with immobile labor $(\mu=1)$, I next illustrate how the short-run multipliers depend on shock persistence. Figure 3 plots 4-quarter multipliers for alternate half-lives of the government spending shock. The figure is based on the benchmark calibration except that 
Figure 3: Short-run multipliers and shock persistence

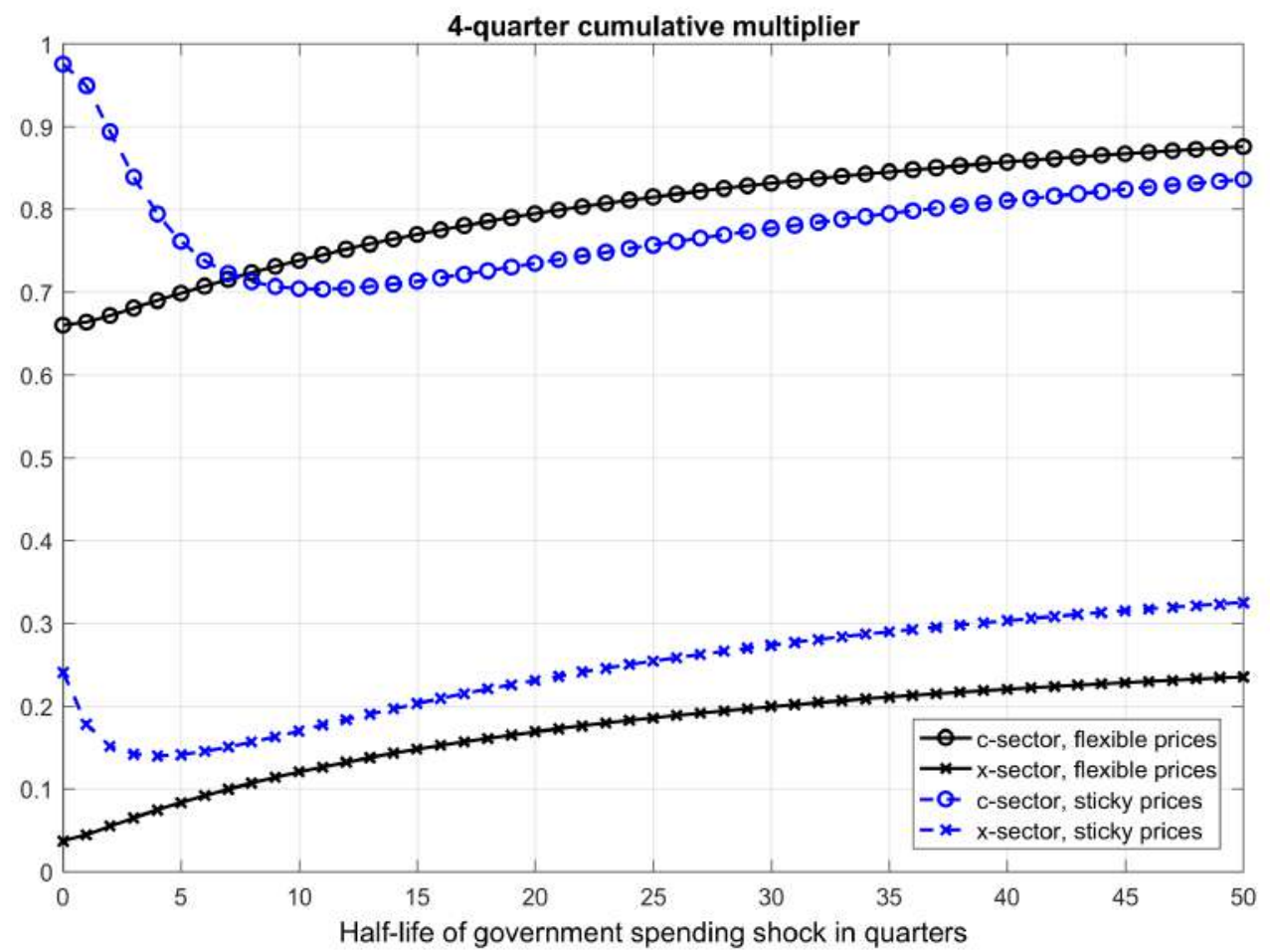

Notes: The figure plots the 4-quarter cumulative multipliers using the benchmark calibration except for the shock persistence which is chosen to generate the half-lives as indicated on the horizontal axis.

$\varrho_{x}^{g}$ and $\varrho_{c}^{g}$ are chosen to generate the half-lives as indicated on the horizontal axis. While the investment multiplier is always smaller than the consumption multiplier, the difference depends on the persistence of the shock. For entirely transient government spending shocks, the difference is about 0.75 in the sticky-price model. For long-lived shocks, it is closer to 0.5 . I conclude that the difference between the government consumption and investment multiplier should be harder to identify in the data when shocks are long-lived.

\subsection{Robustness and discussion}

It is clear that the model is too stylized to be taken literally. I present it here because it makes a relevant prediction for fiscal policy which should be tested in the data. I briefly discuss the robustness of this prediction.

Adjustment costs The easiest way to break the result is to introduce extremely high investment adjustment costs. If the adjustment cost parameter $\zeta$ is infinite, then investment is constant, 
Table 1: Multipliers with and without high adjustment costs

\begin{tabular}{lcccc}
\hline \hline & \multicolumn{2}{c}{ 4-quarter multipliers } \\
& $\begin{array}{c}\text { Baseline calibration } \\
\zeta=2\end{array}$ & $\begin{array}{c}\text { High adjustment costs } \\
\zeta=156.1\end{array}$ \\
& flexible prices & sticky prices & flexible prices & sticky prices \\
\hline Government consumption multiplier & 0.69 & 0.77 & 0.68 & 0.90 \\
Government investment multiplier & 0.08 & 0.14 & 0.66 & 0.84 \\
\hline
\end{tabular}

Notes: The table reports the cumulative multipliers at a 4 quarter horizon. The multipliers are based on the benchmark calibration except that $\zeta$ is set to 156.1 in the high adjustment costs case.

and the investment multiplier close to one. However, high adjustment costs also produce low investment volatility and potentially counterfactually low investment volatility. In the data, fixed investment is approximately 3 times as volatile as GDP, which naturally puts an upper bound on how high adjustment costs can be.

One can ask how high $\zeta$ must be to generate an investment multiplier that is similar to the government consumption multiplier. One simple way to do this is to choose $\zeta$ so as to equate the partial elasticities of consumption and investment with respect to their own real interest rate (equations 20 and 21). Using the benchmark calibration, $\zeta$ must be set to 156.1 to generate the same partial elasticity. The multipliers for this case are indeed close together and reported in Table 1. While a value of $\zeta=156.1$ is presumably too high to be realistic, it is clear that moderate values of $\zeta$ above 2 can shrink the difference between the government consumption and investment multiplier.

Although I have relied on the standard convex adjustment cost framework for tractability, a number of papers have demonstrated that these models exhibit very similar aggregate dynamics as models that are more consistent with evidence on plant-level investment behavior, once analyzed in general equilibrium (Thomas, 2002, Veracierto, 2002). House (2014) shows that models with fixed costs of investment also exhibit the high interest elasticity of neoclassical investment models. This fact implies that the small government investment multiplier is more general than the specific framework adopted here. 
Distortionary taxes and non-Ricardian consumers I have this far assumed that the government finances spending with contemporaneous non-distortionary taxes - a canonical starting point. Relaxing this assumption can have large effects on the fiscal multiplier. For instance, Baxter and King (1993) and Leeper, Walker, and Yang (2010) show that financing spending with a distortionary tax on output reduces the size of the multiplier (potentially below zero). Further, with distortionary taxes or hand-to-mouth consumers Ricardian equivalence ceases to hold, and it begins to matter whether spending is financed by issuing debt or raising current revenues (e.g. Galí, López-Salido, and Vallés, 2007).

Since in theory the financing decision of government expenditures is orthogonal to whether the government purchases consumption or investment goods, I do not present an exhaustive discussion of the effects on the two multipliers here. I do, however, note two caveats. First, contemporaneous tax changes which affect the intertemporal price of investment goods have large effects in these frameworks. The reason is that investment responds to such tax changes with the same high intertemporal elasticity of substitution that is responsible for the small government investment multiplier (House and Shapiro, 2008). Second, it is possible that, in practice, investment is more frequently financed with borrowed funds than government consumption. To the extent that taxes are distortionary or households non-Ricardian, this could affect estimates of fiscal multipliers. In the empirical section below I will discuss this concern extensively.

Private and public purchases One assumption of the model in Section 2.1 is that the government and the private sector purchase identical goods from the two sectors. This assumption can be relaxed. One may alternatively assume that the consumption (investment) goods purchased by the private sector require at least some of the same factors of production as the consumption (investment) good purchased by the government. For instance, it would be sufficient to assume that workers that build roads and office buildings for the government can also build houses, factories, or parking lots for the private sector. If this was not the case, then government investment would not crowd out private investment - a prediction I will test below.

A non-symmetric calibration While I preferred a symmetric benchmark calibration which highlights that the different multipliers arise from the long service life of capital goods, there exist other differences between consumption and investment goods in the data. In Appendix A.3 I replicate Figures 1 and 3 for a calibration which takes into account that 1 ) government 
consumption shocks as identified in Section 3 are more persistent, 2) the government purchases a slightly larger share from the consumption goods sector, 3) durable goods have less sticky prices, and 4) the Federal Reserve targets personal consumption expenditure inflation rather than GDP deflator inflation. The model's predictions for the two multipliers change very little.

\section{Summary of model predictions}

Before turning to the empirical analysis, I summarize the model's main predictions. First, the government investment multiplier after a temporary shock is smaller than the government consumption multiplier. Second, the reason for this difference is that private investment falls more after a government investment shock than private consumption falls after a government consumption shock. Third, it is the increase in the own real interest rate of investment which crowds out private investment. Testing the second and third prediction is critical, because the government investment multiplier could differ from the government consumption multiplier for a variety of reasons, many of which are not captured by the model. In Section 3.4.2 below, I will empirically assess whether additional or alternative mechanisms can explain the difference between the multipliers.

\section{$3 \quad$ Empirical evidence}

The main objective of this section is to test whether the data support the hypothesis that the investment multiplier is smaller than the consumption multiplier. The answer is broadly positive. As in the model, the reason is that private investment falls significantly after government investment shocks.

\subsection{Data}

My primary source of data are various editions of the OECD Economic Outlook's Statistics and Projections Database. This dataset covers the member countries and a handful of large developing economies. From 2003 onwards the data are available at a quarterly frequency. Editions published prior to 2003 only contain semiannual data. Since the identification assumption will require that the government does not respond to changing economic conditions within the same period, I construct a quarterly panel from 2003 to 2016. 
For most countries the dataset contains separate series for government consumption and government investment. Further, for a subset of countries and periods, the OECD constructs forecasts of government consumption and government investment. These forecasts are published biannually and include information up until the 6th month of the semester. The OECD describes its forecasts as combining "expert judgement with a variety of existing and new information relevant to current and prospective developments". ${ }^{11}$ Lenain (2002) and Vogel (2007) find that the OECD's forecasts broadly perform similar to private sector forecasts. I will use these forecasts to address the concern that shocks constructed from the Blanchard-Perotti identification scheme could be anticipated (Ramey, 2011b). Since not accounting for such anticipation effects can lead to downward-biased estimates (Ramey, 2009), I drop observations for which these forecasts are not available.

As in the model, I define the consumption goods sector as including household consumption and government consumption, and the investment goods sector as including private and public investment. Table 2 lists the countries in the sample, together with their 2005 shares of government purchases in the two sectors. The government's share in the consumption goods sector averages 27.2 percent and varies moderately across countries. The government's share in the investment goods sector is lower and averages 13.6 percent in the sample. It also varies more across countries with 8 percent in Germany and 20.4 percent in Japan.

\subsection{Empirical methodology}

My empirical methodology builds on Blanchard and Perotti (2002) and numerous studies thereafter. The key identifying assumption is that the government does not respond to new information about the state of the business cycle within the same quarter. To address Ramey's (2011b) critique that shocks from this scheme could be anticipated, I follow Auerbach and Gorodnichenko (2012, 2013), and Miyamoto, Nguyen, and Sergeyev (2017) and purify changes in government purchases of their predicted components. I will discuss and address identification challenges in Section 3.4.1 below.

The government investment shocks from this expectations-augmented Blanchard-Perotti iden-

\footnotetext{
${ }^{11}$ See also http://www.oecd.org/eco/outlook/forecastingmethodsandanalyticaltools.htm Last accessed $02 / 26 / 2018$.
} 
Table 2: Government consumption and investment shares

\begin{tabular}{lccc}
\hline \hline Country & Observations & $\begin{array}{c}\text { Government share in } \\
\text { consumption goods sector } \\
\text { (percent) }\end{array}$ & $\begin{array}{c}\text { Government share in } \\
\text { investment goods sector } \\
\text { (percent) }\end{array}$ \\
\hline Australia & 52 & 24.1 & 8.3 \\
Belgium & 50 & 30.1 & 8.3 \\
Canada & 52 & 25.7 & 12.0 \\
Germany & 52 & 24.1 & 8.0 \\
Denmark & 40 & 34.7 & 8.4 \\
Finland & 52 & 30.1 & 12.9 \\
France & 52 & 29.5 & 16.4 \\
United Kingdom & 52 & 25.3 & 11.4 \\
Ireland & 28 & 25.7 & 13.1 \\
Japan & 52 & 24.0 & 20.4 \\
Korea & 52 & 21.2 & 18.2 \\
Netherlands & 52 & 32.8 & 17.4 \\
Norway & 52 & 32.2 & 12.5 \\
New Zealand & 52 & 23.4 & 19.1 \\
Portugal & 18 & 24.6 & 13.2 \\
Sweden & 52 & 36.0 & 16.0 \\
United States $\dagger$ & 52 & 18.4 & 13.1 \\
& & & 13.6 \\
mean & & 27.2 & \\
\hline
\end{tabular}

Notes: Data are from the OECD Economic Outlook: Statistics and Projections Database. The countries are those included in the baseline sample.

$\dagger$ : The fraction of government investment in total investment in the OECD data differs slightly from the U.S. National Income and Product Accounts, Tables 1.1.5 and 3.9.5, which is 16.9.

tification scheme are the residuals from the regression

$$
\begin{aligned}
\frac{x_{i, t}^{g}-x_{i, t-1}^{g}}{y_{i, t-1}}= & \alpha_{c}^{x} \frac{c_{i, t}^{g}-c_{i, t-1}^{g}}{y_{i, t-1}}+\beta_{c}^{x} F_{t-1} \frac{c_{i, t}^{g}-c_{i, t-1}^{g}}{y_{i, t-1}}+\beta_{x}^{x} F_{t-1} \frac{x_{i, t}^{g}-x_{i, t-1}^{g}}{y_{i, t-1}} \\
& + \text { controls }+\gamma_{i}^{x}+\delta_{t}^{x}+\tau_{i}^{x} t+u_{i, t}^{x} .
\end{aligned}
$$

The left hand side variable is the change in per capita government purchases in country $i$ and sector $x$, divided by real per capita GDP in $t-1 . F_{t-1}$ denotes the forecast. ${ }^{12}$ The change in government investment is regressed on the change in government consumption, the forecasts of government purchases in both sectors, a number of control variables, as well as country fixed effects, time fixed effects, and a linear country-specific time trend. Note that the division by

\footnotetext{
${ }^{12}$ Because the OECD publishes new editions of the dataset only biannually, I have the $t-1$ forecast only for the first and third quarter of each year. Forecasts for the second and fourth quarter are based on information available in $t-2$.
} 
lagged GDP which I will use throughout avoids the potentially problematic ex-post conversion from elasticities to currency units (Ramey and Zubairy, 2017). The government consumption shocks are constructed analogously.

The baseline control variables include four lags of the changes in real per capita private consumption, public consumption, private investment, public investment, and GDP, all divided by real per capita GDP in $t-1$. They further include four lags of the unemployment rate, the growth rate of the GDP deflator, and the changes in per capita government revenues as well as transfers relative to per capita GDP. Finally, because the countries in the sample are heterogeneous in their openness to trade, I control for lagged openness defined as imports plus exports divided by GDP. All real variables use the corresponding deflator. I construct private investment from total investment and government investment using the method in Whelan (2000). ${ }^{13}$ Details are available in Appendix B.

The government purchases shocks $\hat{u}_{i, t}^{c}$ and $\hat{u}_{i, t}^{x}$ are neither contemporaneously correlated with one another $\left(\rho\left(\hat{u}_{i, t}^{c}, \hat{u}_{i, t}^{x}\right)=-0.029\right)$, nor are they autocorrelated $\left(\rho\left(\hat{u}_{i, t}^{c}, \hat{u}_{i, t-1}^{c}\right)=-0.039\right.$, $\left.\rho\left(\hat{u}_{i, t}^{x}, \hat{u}_{i, t-1}^{x}\right)=0.012\right)$. None of these correlations is significant at the 20 percent level. I note, however, that the non-purified changes in purchases $\frac{c_{i, t}^{g}-c_{i, t-1}^{g}}{y_{i, t-1}}$ and $\frac{x_{i, t}^{g}-x_{i, t-1}^{g}}{y_{i, t-1}}$ are correlated ( $\rho=0.059$ ) over the period from 1980 to 2016. Further, their forecasts in the actual sample are correlated $(\rho=0.156)$. Both correlations are significant at the 1 percent level. This suggests that it is, in general, more prudent to analyze government consumption and investment jointly. I present histograms of the shocks $\hat{u}_{i, t}^{c}$ and $\hat{u}_{i, t}^{x}$ in Figure C1 of Appendix C.

I estimate impulse response functions using Jordà's (2005) method. In particular, and letting $v$ denote a generic variable of interest, I estimate

$$
\begin{aligned}
\frac{v_{i, t+h}-v_{i, t-1}}{y_{i, t-1}}= & \alpha_{c}^{h} \frac{c_{i, t}^{g}-c_{i, t-1}^{g}}{y_{i, t-1}}+\alpha_{x}^{h} \frac{x_{i, t}^{g}-x_{i, t-1}^{g}}{y_{i, t-1}} \\
& +\beta_{c}^{h} F_{t-1} \frac{c_{i, t}^{g}-c_{i, t-1}^{g}}{y_{i, t-1}}+\beta_{x}^{h} F_{t-1} \frac{x_{i, t}^{g}-x_{i, t-1}^{g}}{y_{i, t-1}} \\
& + \text { controls }+\gamma_{i}^{h}+\delta_{t}^{h}+\tau_{i}^{h} t+\varepsilon_{i, t+h}^{v}
\end{aligned}
$$

for $h=0, \ldots, H$. The control variables in this equation are the same as the right hand side of equation (22). Importantly, the forecasted changes in purchases purify the actual changes of

\footnotetext{
${ }^{13}$ It would be interesting to study which components of investment (e.g. structures, equipment, inventories) are affected in the data. Unfortunately, the data from the OECD for these components are highly incomplete and cannot be used for this purpose.
} 
their anticipated components. The parameters $\left\{\alpha_{c}^{h}\right\}_{h=0}^{h}$ and $\left\{\alpha_{x}^{h}\right\}_{h=0}^{h}$ are the impulse response coefficients for government consumption and investment shocks.

Further, and following Ramey and Zubairy (2017), I estimate

$$
\begin{aligned}
\sum_{j=0}^{h} \frac{v_{i, t+j}-v_{i, t-1}}{y_{i, t-1}}= & m_{c}^{h} \sum_{j=0}^{h} \frac{c_{i, t+j}^{g}-c_{i, t-1}^{g}}{y_{i, t-1}}+m_{x}^{h} \sum_{j=0}^{h} \frac{x_{i, t+j}^{g}-x_{i, t-1}^{g}}{y_{i, t-1}} \\
& +\beta_{c}^{h} F_{t-1} \frac{c_{i, t}^{g}-c_{i, t-1}^{g}}{y_{i, t-1}}+\beta_{x}^{h} F_{t-1} \frac{x_{i, t}^{g}-x_{i, t-1}^{g}}{y_{i, t-1}} \\
& + \text { controls }+\gamma_{i}^{h}+\delta_{t}^{h}+\tau_{i}^{h} t+\varepsilon_{i, t+h}^{v}, \quad h=0, \ldots, H .
\end{aligned}
$$

where $m_{c}^{h}$ and $m_{x}^{h}$ are the multipliers for government consumption and investment, respectively. Note that these multipliers are cumulative, which contrasts to alternative definitions occasionally used in the literature. The definition used here is both consistent with the model and favored by

recent work. When I estimate this specification, I use $\frac{c_{i, t}^{g}-c_{i, t-1}^{g}}{y_{i, t-1}}$ and $\frac{x_{i, t}^{g}-x_{i, t-1}^{g}}{y_{i, t-1}}$ as instruments for the cumulative government spending variables. Conditional on the controls, these are identical to the shocks $\hat{u}_{i, t}^{c}$ and $\hat{u}_{i, t}^{x}$. Note that in specifications (23) and (24) all coefficients are specific to the left hand side variable $v$. I omit this dependence for notational clarity.

Throughout the analysis, I use Driscoll and Kraay (1998) standard errors which allow for arbitrary autocorrelation and cross-sectional correlation of the regression error. Because the sample is relatively short, I calculate impulse response functions and multipliers up to a time horizon of two years $(H=7)$.

\subsection{Baseline results}

I begin with estimates for the full sample which includes episodes at and away from the zero lower bound on nominal interest rates. I will present separate estimates below.

Government purchases Figure 4 shows the impulse response functions of government consumption and investment. The government consumption shock leads to persistently elevated levels of government consumption for all 8 quarters. Government investment responds largely insignificantly to a government consumption shock. The government investment shock raises government investment which then decays gradually to about one third after 8 quarters. This corresponds to a half-life of 4 to 5 quarters. As Figure 3 illustrated, the model predicts that this configuration of shock persistence should lead to large differences between the government consumption 
Figure 4: Impulse response functions of government purchases
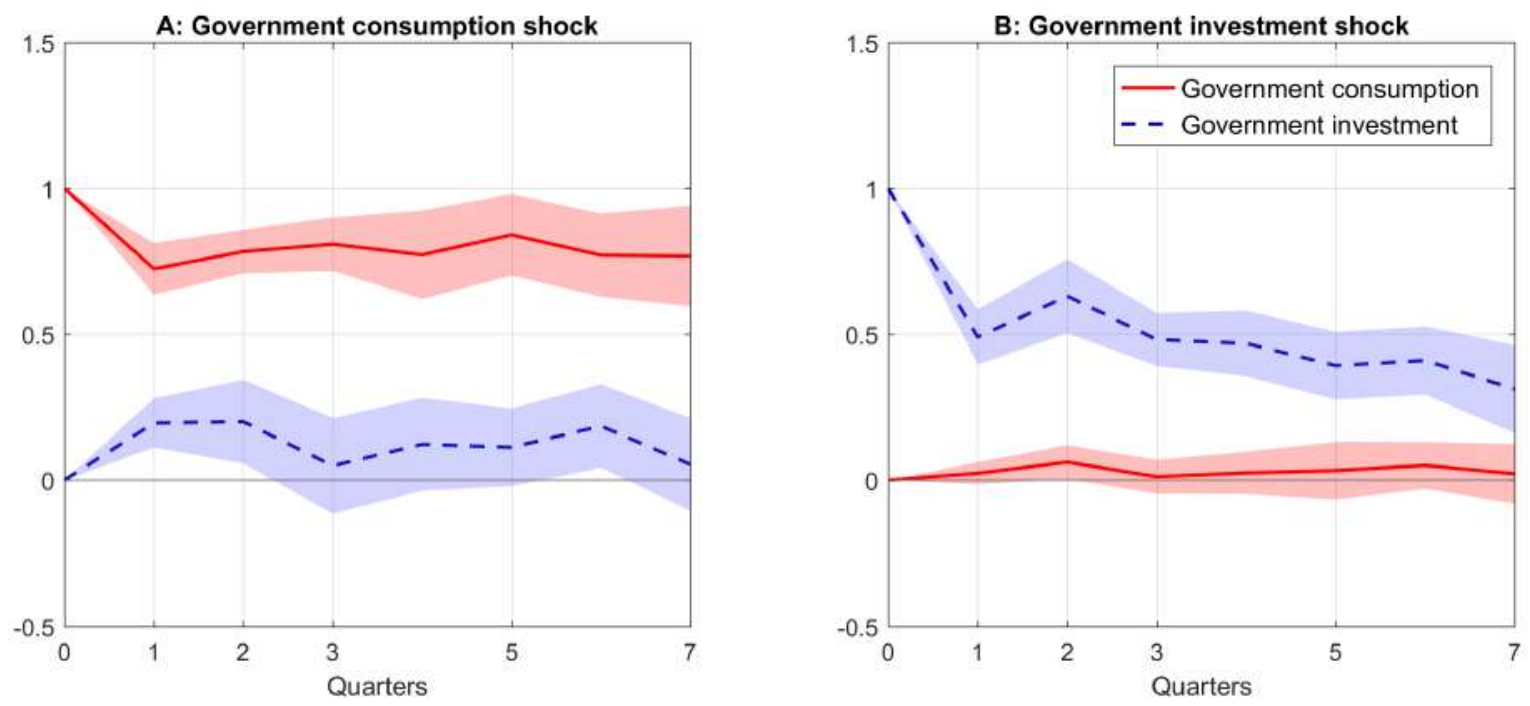

Notes: These estimates are based on specification (23). The shaded areas are 90 percent confidence bands based on Driscoll-Kraay standard errors.

and investment multiplier. Government consumption virtually remains unchanged after a government investment shock. ${ }^{14}$ The fact that government consumption responds strongly to its own shock, but not to the government investment shock (and analogously for government investment), foreshadows that the "partial" F-statistics in the first stages of the multiplier estimation will be high.

GDP, private consumption, and private investment Figure 5 shows the impulse response functions of GDP, private consumption, and private investment. In response to a government consumption shock, GDP rises above zero and becomes statistically significant in the second quarter (Panel A). In contrast, GDP remains indistinguishable from zero at all horizons after a government investment shock (Panel B). Panel C demonstrates that private consumption remains roughly unchanged after a government consumption shock. At no horizon is the response significantly different from zero at the 10 percent level. Finally, Panel D shows the response of private investment. After a government investment shock, private investment falls significantly below zero-without a lag. The estimates become insignificant in the sixth quarter, but remain more than one standard error below zero until the eighth quarter. Note that the shape of the impulse

\footnotetext{
${ }^{14}$ Perotti (2004) uses an alternative identification scheme which leads to significant responses of government consumption to government investment shocks for some countries.
} 
Figure 5: Impulse response functions of GDP, consumption, and investment
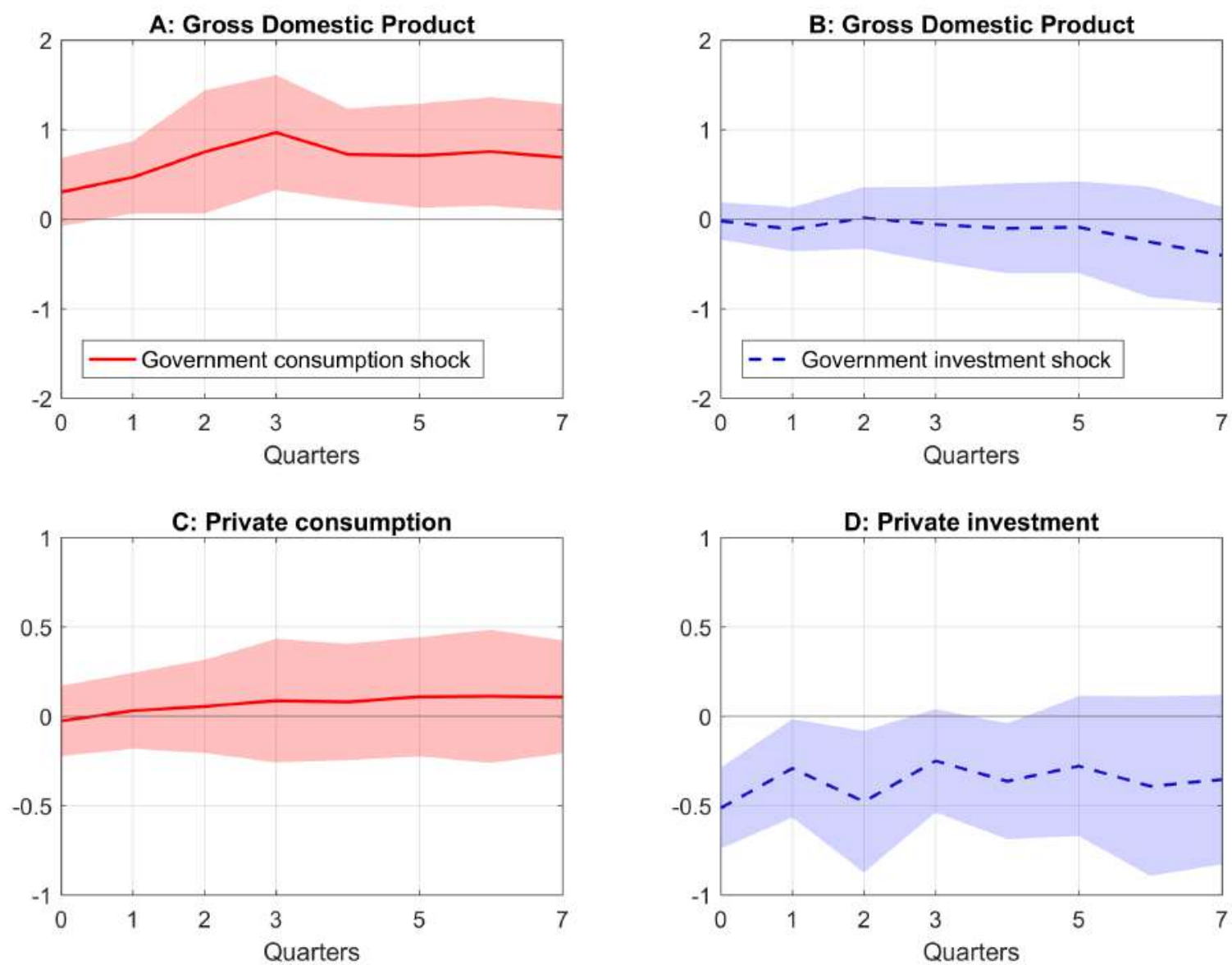

Notes: These estimates are based on specification (23). The shaded areas are 90 percent confidence bands based on Driscoll-Kraay standard errors.

response function strongly resembles the model's prediction in Figure 1 Panel B (although the horizontal axis is scaled differently). ${ }^{15}$

Table 3 presents the associated multipliers. GDP rises by approximately 80 cents per dollar spent on government consumption goods. There is no measurable effect of government investment on GDP. The data rejects the hypothesis of equal GDP multipliers at a 4 quarter horizon with a p-value of 0.061 and at a 8 quarter horizon with a p-value of 0.057 . Private consumption is neither crowded in nor out after either of the two shocks. However, private investment falls by 57 cents per dollar spent on investment goods after 4 quarters and by 75 cents after 8 quarters. The

\footnotetext{
${ }^{15}$ Leeper, Walker, and Yang (2010) study the role of implementation delays in government investment. Under a gradual increase in government investment, the crowding out of private investment is similarly delayed. Since private investment drops without a lag (Figure 5, Panel D), implementation lags do not appear to be a salient feature of my sample.
} 
Table 3: Estimated government consumption and investment multipliers

\begin{tabular}{|c|c|c|c|c|c|c|}
\hline \multirow[b]{2}{*}{$\begin{array}{l}\text { Horizon (quarters) } \\
\text { LHS variable }\end{array}$} & \multicolumn{2}{|c|}{$\begin{array}{l}\text { Government } \\
\text { consumption }\end{array}$} & \multicolumn{2}{|c|}{$\begin{array}{c}\text { Government } \\
\text { investment }\end{array}$} & \multicolumn{2}{|c|}{$\begin{array}{l}\mathrm{p} \text {-value of } \\
\text { differencet }\end{array}$} \\
\hline & 4 & 8 & 4 & 8 & 4 & 8 \\
\hline Gross domestic product & $\begin{array}{l}0.76^{* *} \\
(0.36)\end{array}$ & $\begin{array}{r}0.85^{* *} \\
(0.35)\end{array}$ & $\begin{array}{l}-0.08 \\
(0.22)\end{array}$ & $\begin{array}{l}-0.06 \\
(0.35)\end{array}$ & 0.061 & 0.057 \\
\hline Private consumption & $\begin{array}{c}0.05 \\
(0.18)\end{array}$ & $\begin{array}{c}0.14 \\
(0.23)\end{array}$ & $\begin{array}{c}0.06 \\
(0.13)\end{array}$ & $\begin{array}{l}-0.15 \\
(0.23)\end{array}$ & 0.991 & 0.472 \\
\hline Private investment & $\begin{array}{l}-0.12 \\
(0.22)\end{array}$ & $\begin{array}{c}0.18 \\
(0.30)\end{array}$ & $\begin{array}{c}-0.57^{* * *} \\
(0.22)\end{array}$ & $\begin{array}{c}-0.75^{* *} \\
(0.33)\end{array}$ & 0.123 & 0.072 \\
\hline First stage Angrist-Pischke F & 371.0 & 131.4 & 213.6 & 115.3 & & \\
\hline Observations & 762 & 697 & 762 & 697 & & \\
\hline
\end{tabular}

Notes: The estimates are based on specification (24). Driscoll-Kraay standard errors are reported in parentheses. $* * *, * *$ and $*$ denote significance at the 1,5 and 10 percent level.

$\dagger$ : The null hypothesis is that the government consumption and investment multipliers are equal.

estimates are significantly different from zero at the 1 and 5 percent level, respectively. The fact that private investment falls, rules out that the difference between the government consumption and investment multiplier is driven by greater measurement error of government investment. Note that the first stage F-statistics, calculated as suggested by Angrist and Pischke (2009, pp. 217-18) are far above $10 .^{16}$

Real interest rates The model predicts that real interest rates increase in response to government spending shocks (see Appendix A.6). In particular, it is the rise in own real interest rates which crowd out private sector spending. To test this prediction in the data, I estimate impulse response functions analogous to equation (23) but replace the left hand side with the absolute change in the real interest rate $r_{i, t+h}^{s}-r_{i, t-1}^{s}, s \in\{c, x\}$. The controls include the baseline controls as well as four lags of the change in the real interest rates, respectively.

I construct the real interest rates in the two sectors from the Fisher relationship using a measure for the short-term nominal interest rate and the OECD's real-time forecasts for prices

\footnotetext{
${ }^{16}$ In the presence of heteroskedasticity, autocorrelation, and clustering the conventional threshold of 10 does not generally apply. Olea and Pflueger (2013) develop a correction of the critical value which can be as high as 23.1 to bound the bias, still far below the F-statistics here. Further, the alternative test by Sanderson and Windmeijer (2016) rejects the null hypothesis of underidentification with p-values below 0.0001 for both endogenous regressors.
} 
Figure 6: Impulse response functions of real interest rates
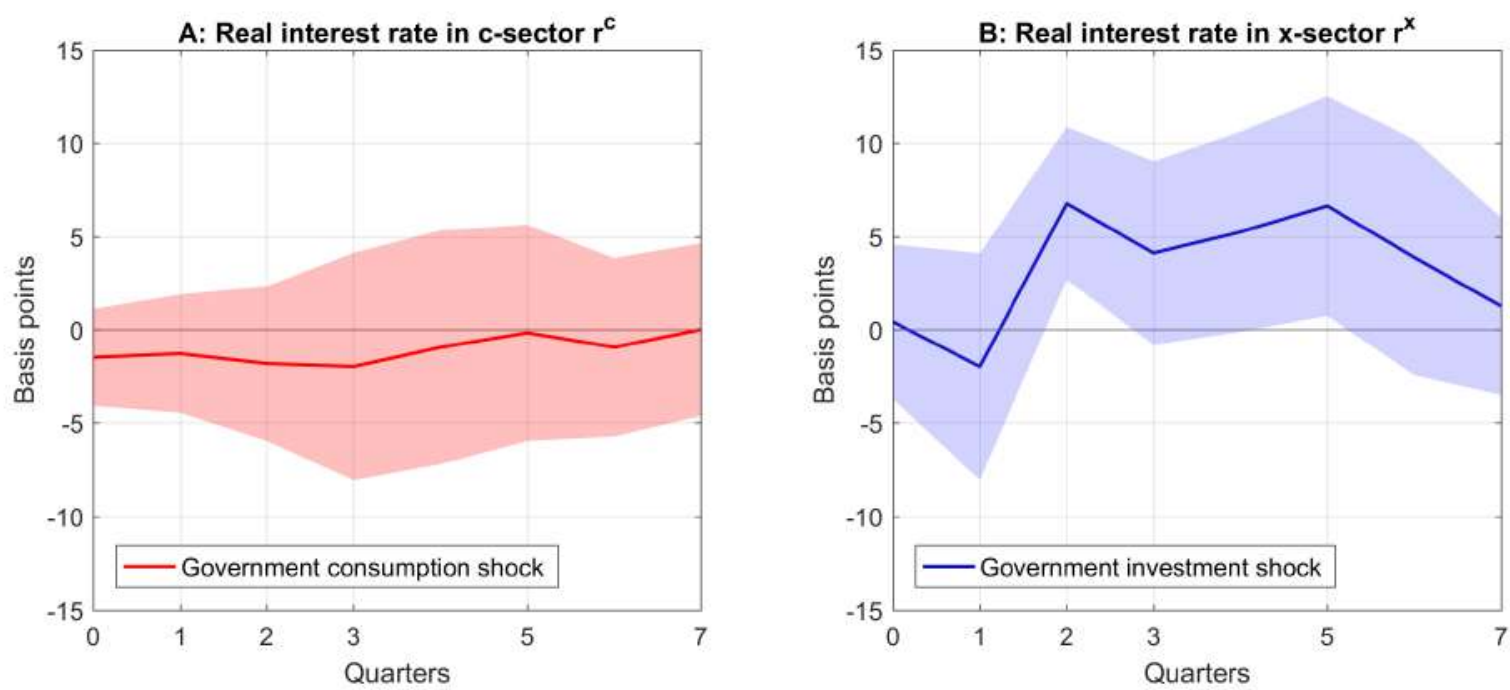

Notes: The impulse response functions are estimated based on equation (23) after replacing the left hand side with the absolute change in the real interest rate $r_{i, t+h}^{s}-r_{i, t-1}^{s}, s \in\{c, x\}$. The controls include the baseline controls as well as four lags of the change in $r$, respectively. The impulse response functions are scaled to reflect a one standard deviation change in the respective measure of spending. Shaded areas are 90 percent confidence bands based on Driscoll-Kraay standard errors.

in the two sectors. While these real interest rates are direct empirical analogues for the model, it is clear that they will imperfectly measure the actual (or opportunity) cost of funds of investing firms. As a result, the estimates should be interpreted with caution.

Figure 6 shows the estimated impulse response functions. The responses are scaled to reflect a one standard deviation shock to the two measures of spending in the data. While the model predicts that the own real interest rate in the consumption goods sector should increase after a government consumption shock, there is little evidence for this prediction - the real interest rate in the consumption goods sector remains roughly unchanged after the shock (Panel A). However, the real interest rate in the investment goods sector rises after a government investment shock. This evidence is consistent with the prediction that an elevated real interest rate crowds out private investment (Panel B).

Summary I conclude from the empirical analysis this far that the data broadly support the model's predictions. First, the government investment multiplier is smaller than the government consumption multiplier. Second, the difference between these two multipliers is driven by a drop in private investment. Third, the own real interest rate of the investment goods sector rises after a shock to government investment. 


\subsection{Discussion, extensions, and robustness}

I next extend the analysis, beginning with a discussion and examination of possible violations of the identification assumption. Subsequently, I explore whether alternative mechanisms can explain the difference between the two multipliers. Finally, I present results from additional robustness exercises, including multiplier estimates at and away from the zero lower bound.

\subsubsection{Discussion of the identification assumption}

The Blanchard-Perotti identification assumption maintains that the government does not respond to new information about the state of the business cycle within the same time period. Under this assumption, a change in government spending, conditional on the controls, including the forecasts of government purchases, constitutes a shock. It has been argued that the Blanchard-Perotti identification assumption is reasonable for quarterly data since governments typically require more time than a quarter to plan, pass, and implement fiscal stimulus packages. There are, however, two concerns in the context of my analysis. First, it is possible that governments have private information which is not captured by the OECDs' forecasts. If this was the case, then the "minimum delay" of one quarter would not apply and the identification assumption could be violated even if the government required more time than a quarter for the fiscal intervention. Second, the arrival of new information may prompt the government to adjust the size of a stimulus program which it is currently planning. To the extent that this adjustment occurs within a quarter, the identification assumption is again violated. In both cases the multiplier estimates would be biased downwards.

One way to assess the importance of these concerns is to estimate the government consumption and investment multipliers after dropping the Great Recession years 2008 to 2010 from the sample. Since a number of countries passed fiscal stimulus packages at the time, and in some cases fairly quickly, these years have the highest risk of being subject to the above identification concerns in my sample from 2003 to 2016. If the identification assumption was indeed violated, one would expect the estimates to be greater when the Great Recession years 2008 to 2010 are dropped from the sample. Table 4 shows the results.

Without the Great Recession years, the GDP multiplier for government consumption is indeed slightly larger and around unity. However, the GDP multiplier for government investment is now smaller than before and significantly negative. Investment falls by 60 cents on the dollar after 
Table 4: Robustness: Drop Great Recession

\begin{tabular}{lccccccc}
\hline \hline & \multicolumn{2}{c}{ Government } & \multicolumn{2}{c}{ Government } & \multicolumn{2}{c}{ p-value of } \\
investment & \multicolumn{2}{c}{ difference } \\
Horizon (quarters) & 4 & 8 & 4 & 8 & 4 & 8 \\
LHS variable & & & & & & & \\
\hline & & & & & & & \\
Gross domestic product & $1.06^{* * *}$ & $1.20^{* * *}$ & $-0.61^{* * *}$ & $-1.22^{* * *}$ & 0.000 & 0.000 \\
Private consumption & $(0.30)$ & $(0.35)$ & $(0.24)$ & $(0.39)$ & & \\
& 0.17 & 0.27 & -0.10 & $-0.56^{* *}$ & 0.300 & 0.030 \\
Private investment & $(0.20)$ & $(0.25)$ & $(0.12)$ & $(0.22)$ & & \\
& 0.08 & 0.27 & $-0.60^{* * *}$ & $-1.39^{* * *}$ & 0.053 & 0.009 \\
First stage Angrist-Pischke F & $(0.27)$ & $(0.34)$ & $(0.19)$ & $(0.41)$ & & \\
Observations & 411.9 & 61.4 & 181.4 & 53.0 & & \\
\hline
\end{tabular}

Notes: The estimates are based on specification (24). The sample excludes the years 2008 to 2010. DriscollKraay standard errors are reported in parentheses. ${ }^{* * *},{ }^{* *}$ and ${ }^{*}$ denote significance at the 1,5 and 10 percent level.

$\dagger$ : The null hypothesis is that the government consumption and investment multipliers are equal.

4 quarters and by more than one for one after 8 quarters. Further, private consumption falls significantly 8 quarters after an increase in government investment. While the baseline results are more consistent with the model's predictions, it is does not appear that violations of the minimum delay assumption drive the difference in the government consumption and investment multipliers.

\subsubsection{Additional/alternative mechanisms}

I next turn to the question whether the data supports additional or alternative mechanism of why the government consumption and investment multipliers differ.

Is government capital productive? Since the longitudinal dimension of my panel is too short to estimate precise multipliers at longer horizons, I use the standard Blanchard-Perotti identification scheme without including forecasts to purify the spending shocks. The advantage of not requiring forecasts is that the sample size more than doubles. On the other hand, the estimates are potentially biased downwards (Ramey, 2009) and thus should be interpreted with caution. The results, reported in Table 5, are similar to the benchmark estimates. The government consumption multiplier is around 0.8 for the first 8 quarters and the investment multiplier indistinguishable from zero. Further, the government investment multiplier remains very close to zero for horizons 
up to 20 quarters while the point estimates of the government consumption multiplier rise above unity. Consistent with earlier estimates by Perotti (2004) and Voss (2002) there is little evidence that government capital is productive under this identification scheme. 
Table 5: Estimated multipliers for standard Blanchard-Perotti identification, extended sample

\begin{tabular}{|c|c|c|c|c|c|c|c|c|c|c|c|c|c|c|c|}
\hline \multirow[b]{2}{*}{$\begin{array}{l}\text { Horizon (quarters) } \\
\text { LHS variable }\end{array}$} & \multicolumn{5}{|c|}{ Government consumption } & \multicolumn{5}{|c|}{ Government investment } & \multicolumn{5}{|c|}{ p-value of difference (percent) $\dagger$} \\
\hline & 4 & 8 & 12 & 16 & 20 & 4 & 8 & 12 & 16 & 20 & 4 & 8 & 12 & 16 & 20 \\
\hline GDP & $\begin{array}{c}0.72^{* * *} \\
(0.16)\end{array}$ & $\begin{array}{c}0.88^{* * *} \\
(0.21)\end{array}$ & $\begin{array}{c}0.93^{* * *} \\
(0.24)\end{array}$ & $\begin{array}{c}1.00 * * * \\
(0.26)\end{array}$ & $\begin{array}{c}1.15^{* * * *} \\
(0.29)\end{array}$ & $\begin{array}{c}0.20 \\
(0.16)\end{array}$ & $\begin{array}{c}0.10 \\
(0.26)\end{array}$ & $\begin{array}{c}0.04 \\
(0.33)\end{array}$ & $\begin{array}{c}0.05 \\
(0.38)\end{array}$ & $\begin{array}{l}-0.01 \\
(0.44)\end{array}$ & 4.9 & 4.0 & 5.8 & 6.5 & 5.0 \\
\hline Priv. consumption & $\begin{array}{l}0.14^{*} \\
(0.09)\end{array}$ & $\begin{array}{l}0.27^{* *} \\
(0.12)\end{array}$ & $\begin{array}{l}0.32^{* *} \\
(0.15)\end{array}$ & $\begin{array}{l}0.37^{* *} \\
(0.17)\end{array}$ & $\begin{array}{l}0.43^{* *} \\
(0.19)\end{array}$ & $\begin{array}{c}0.08 \\
(0.09)\end{array}$ & $\begin{array}{c}0.01 \\
(0.14)\end{array}$ & $\begin{array}{l}-0.05 \\
(0.18)\end{array}$ & $\begin{array}{l}-0.08 \\
(0.22)\end{array}$ & $\begin{array}{l}-0.13 \\
(0.27)\end{array}$ & 62.0 & 20.0 & 14.4 & 13.3 & 12.5 \\
\hline Priv. investment & $\begin{array}{c}0.09 \\
(0.15)\end{array}$ & $\begin{array}{c}0.27 \\
(0.19)\end{array}$ & $\begin{array}{c}0.29 \\
(0.21)\end{array}$ & $\begin{array}{c}0.36 \\
(0.24)\end{array}$ & $\begin{array}{l}0.46^{*} \\
(0.26)\end{array}$ & $\begin{array}{l}-0.31^{*} \\
(0.17)\end{array}$ & $\begin{array}{r}-0.47^{*} \\
(0.25)\end{array}$ & $\begin{array}{l}-0.46 \\
(0.30)\end{array}$ & $\begin{array}{l}-0.45 \\
(0.32)\end{array}$ & $\begin{array}{l}-0.51 \\
(0.36)\end{array}$ & 10.0 & 4.1 & 7.1 & 6.5 & 5.4 \\
\hline $\begin{array}{l}\text { First stage AP F } \\
\text { Observations }\end{array}$ & $\begin{array}{l}868.2 \\
2116\end{array}$ & $\begin{array}{l}459.1 \\
2048\end{array}$ & $\begin{array}{l}341.5 \\
1980\end{array}$ & $\begin{array}{c}266.5 \\
1912\end{array}$ & $\begin{array}{l}217.3 \\
1844\end{array}$ & $\begin{array}{l}295.6 \\
2116\end{array}$ & $\begin{array}{l}178.0 \\
2048\end{array}$ & $\begin{array}{l}146.9 \\
1980\end{array}$ & $\begin{array}{l}110.7 \\
1912\end{array}$ & $\begin{array}{l}91.2 \\
1844\end{array}$ & & & & & \\
\hline
\end{tabular}

Notes: The estimates are based on specification (24), but do not include the forecasts of changes in purchases as controls. The sample includes the same countries as those listed in Table 2, but spans the years 1980 to 2016. AP abbreviates Angrist-Pischke. Driscoll-Kraay standard errors are reported in parentheses. ${ }^{* * *}, * *$, and ${ }^{*}$ denote significance at the 1,5 , and 10 percent level.

$\dagger$ : The null hypothesis is that the government consumption and investment multipliers are equal. 
Government net revenues One concern with the empirical analysis this far is that the effectiveness of government consumption and investment could differ because their financing differs. For instance, it possible is that debt-financing would be more likely for government investment than for government consumption. In the presence of distortionary taxes and/or non-Ricardian consumers, this could explain the differently sized multipliers. To explore this possibility, I estimate the impulse response function for government revenues net of transfers. The estimates, reported in Figure $\mathrm{C} 2$ of Appendix $\mathrm{C}$, show that net revenues respond insignificantly to a government consumption shock. In contrast, net revenues fall gradually after a government investment shock. Since higher revenues should be associated with contractionary effects on output, the behavior of net revenues cannot explain the relatively large government consumption and the relatively small government investment multipliers. Standard models would predict that the difference should be larger under identical financing schemes.

Monetary policy A second concern is that the difference between the two multipliers could be driven by central banks "leaning more against the wind" after government investment shocks. Figure C3 in Appendix C shows the impulse response functions of the nominal short rate after shocks to government consumption and investment. At no time horizon is this interest rate different from zero after either shock. This suggests that the difference between the government consumption and investment multipliers is not driven by differential monetary responses. ${ }^{17}$

Exchange rates A further possibility is that the difference between the multipliers is attributable to differential exchange rate responses. I thus estimate impulse response functions for nominal and real effective exchange rates after government consumption and investment shocks. I do so separately for the entire sample and when I restrict the sample to observations with floating exchange rates. ${ }^{18}$ Figure $\mathrm{C} 4$ in Appendix $\mathrm{C}$ shows the results. There is no evidence that the nominal or real effective exchange rates respond to either government purchases shocks.

Net exports I next estimate the multiplier for net exports after government consumption shocks. As shown in Table 6, and consistent with standard models, net exports fall after both

\footnotetext{
${ }^{17}$ If the central bank responded to changes in output, one would expect the increase in the policy rate after a government consumption shock because output rises. Relative to this benchmark, the interest rate response to government consumption shocks is accommodative. A similar argument applies to inflation. However, the inflation response after both government consumption and investment shocks is quantitatively small (results not shown).

${ }^{18}$ Floaters are classified according to the coarse classification in Ilzetzki, Reinhart, and Rogoff (2017): Categories 1 and 2 are defined as fixed and 3,4 , and 5 as floating.
} 
Table 6: Multipliers for net exports

\begin{tabular}{|c|c|c|c|c|c|c|}
\hline \multirow[b]{2}{*}{$\begin{array}{l}\text { Horizon (quarters) } \\
\text { LHS variable }\end{array}$} & \multicolumn{2}{|c|}{$\begin{array}{l}\text { Government } \\
\text { consumption }\end{array}$} & \multicolumn{2}{|c|}{$\begin{array}{l}\text { Government } \\
\text { investment }\end{array}$} & \multicolumn{2}{|c|}{$\begin{array}{l}\mathrm{p} \text {-value of } \\
\text { difference } \dagger\end{array}$} \\
\hline & 4 & 8 & 4 & 8 & 4 & 8 \\
\hline Net exports & $\begin{array}{l}-0.52^{*} \\
(0.30)\end{array}$ & $\begin{array}{c}-0.73^{* *} \\
(0.29)\end{array}$ & $\begin{array}{c}-0.57^{* *} \\
(0.29)\end{array}$ & $\begin{array}{l}-0.29 \\
(0.46)\end{array}$ & 0.863 & 0.362 \\
\hline First stage Angrist-Pischke F & $\begin{array}{c}397.6 \\
76 ?\end{array}$ & 134.8 & 210.4 & 114.5 & & \\
\hline
\end{tabular}

Notes: The estimates are based on specification (24). The control variables include the baseline controls and four lags of the change in net exports divided by GDP. Driscoll-Kraay standard errors are reported in parentheses. ${ }^{* *}$ and ${ }^{*}$ denote significance at the 5 and 10 percent level.

$\dagger$ : The null hypothesis is that the government consumption and investment multipliers are equal.

shocks. Since the multipliers are not statistically different from one another, there is no evidence that the response of net exports is an additional reason why the GDP multiplier for government consumption and investment shocks should differ. Note that due to statistical discrepancy (Whelan, 2000), the multipliers of the components of GDP do not sum to the GDP multiplier.

The supply of consumption and investment goods Finally, it is possible that sectoral differences in the supply of goods explain the difference in multipliers. As I discussed in Section 2.3.2, the short-run multipliers can (approximately) be interpreted as the change in the equilibrium quantity after an outward shift in demand (Figure 2). Since the multipliers are decreasing in the own interest elasticity of demand and the demand for investment goods is highly interest elastic, the multiplier for investment goods is small. However, the multipliers are also increasing in the elasticity of supply. While this elasticity was identical across sectors in the model (see Appendix A.4) it is possible that, in practice, the government investment multiplier is smaller than the government consumption multiplier in part because of a lower supply elasticity in the investment goods sector.

Although I cannot rule out that part of the difference in multipliers is explained by sectoral differences in the supply elasticities, they are unlikely to be a major factor. First, if the supply elasticity in the investment goods sector was small, and investment demand interest inelastic, one would have expected a large increase in the own real interest rate of investment after a government investment shock. As Figure 6 Panel D showed, there is only a modest increase in the 
data. Second, empirical work consistently finds greater intertemporal substitutability for durable and investment goods than for nondurable goods. Further, the available evidence on the supply elasticity suggests that it is quite large (e.g. House and Shapiro, 2008). Finally, simple calculations based on equation (19) suggest that differences in the supply elasticity can generate meaningful differences in multipliers only under implausible assumptions on parameters. For instance, with $\mu=1, \eta=0.75$, and a government spending share in the sector of 0.175 (as in the benchmark calibration), raising $\alpha$ from $1 / 3$ to $1 / 2$ reduces the multiplier from 0.66 to 0.57 . This difference is too small to explain the empirical findings.

\subsubsection{The zero lower bound}

New Keynesian models typically behave discontinuously at a nominal interest rate of zero (Christiano, Eichenbaum, and Rebelo, 2011, Woodford, 2011, and others). Further, under certain assumptions these models predict that government purchases are far more effective when monetary policy is constrained by the zero lower bound (ZLB). The reason is that at the ZLB, inflation generated by government purchases lowers the real rate and crowds in private sector spending, leading to a multiplier greater than one. Bouakez, Guillard, and Roulleau-Pasdeloup (2017) find in a calibrated DSGE model that the multiplier for government investment is above 2. Given these predictions, it is potentially incorrect to estimate a single multiplier for the entire sample period which includes episodes at and away from the ZLB. Table 7 reports separate estimates. When constructing the samples I assume that an economy is at the ZLB when the short-term nominal interest rate is below 0.75 , see Appendix B for details.

When I restrict the sample to episodes away from the ZLB (Panel A), the estimated multipliers are very similar to those in the baseline (Table 3). The GDP multiplier remains much larger when the government consumes than when it invests. Further, government investment crowds out private investment, and significantly so at a 4 quarter horizon. Private consumption responds very little.

At the ZLB, however, the estimates are different (Panel B). GDP rises by approximately one dollar per dollar spent on the government consumption good. The rise in GDP is attributable in part to consumption, which rises insignificantly, and to investment, which rises significantly after 8 quarters. The GDP multiplier for government investment is 1.21 after 4 quarters and 0.95 after 8 quarters. Somewhat surprisingly, the 4-quarter multiplier reflects a significant rise in 
Table 7: Robustness: The Zero Lower Bound

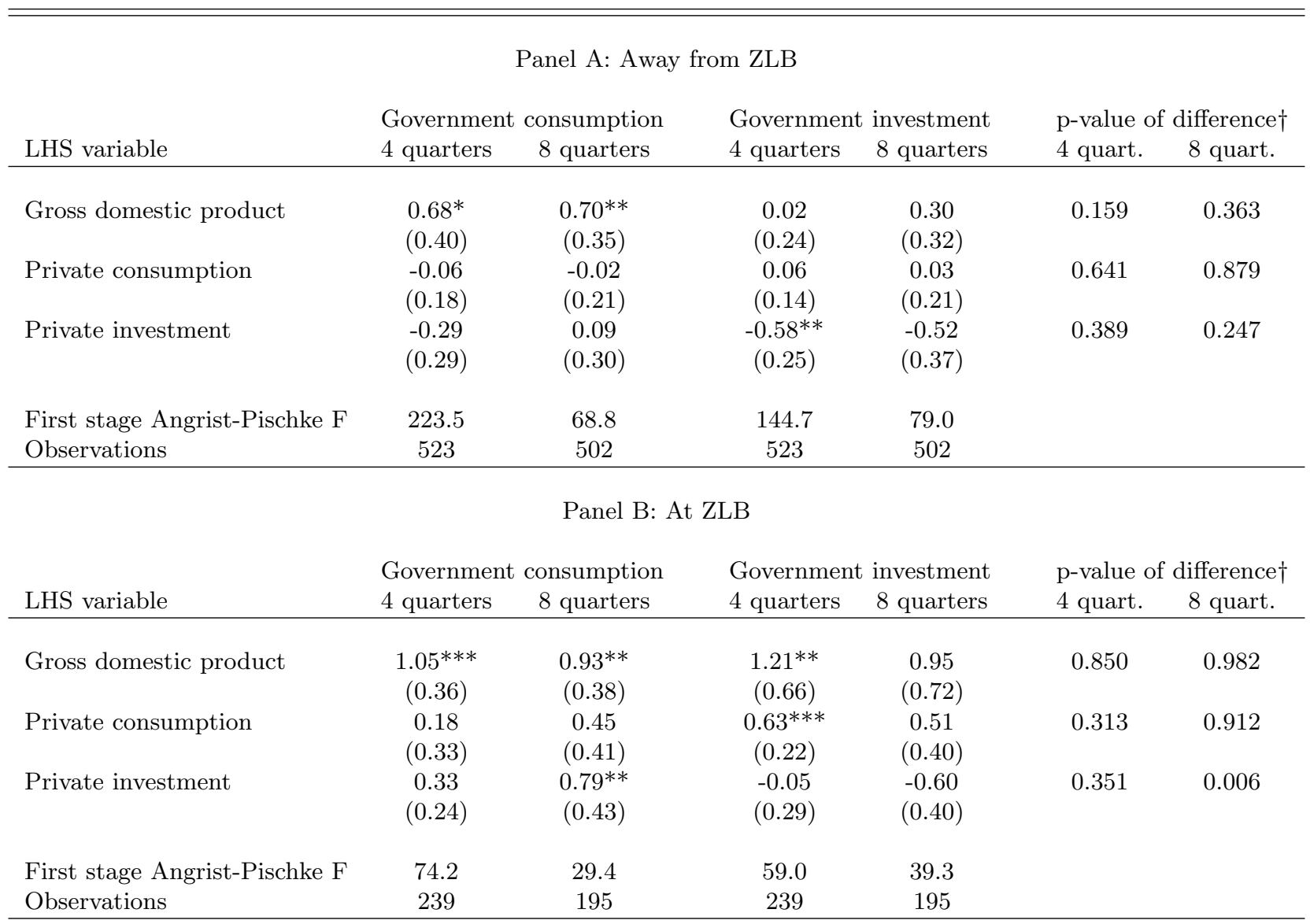

Panel C: p-values (H0: Multipliers at and away from the ZLB are equal)

\begin{tabular}{|c|c|c|c|c|}
\hline & \multicolumn{2}{|c|}{ Government consumption } & \multicolumn{2}{|c|}{ Government investment } \\
\hline & 4 quarters & 8 quarters & 4 quarters & 8 quarters \\
\hline Gross domestic product & 0.536 & 0.637 & 0.095 & 0.425 \\
\hline Private consumption & 0.546 & 0.327 & 0.025 & 0.322 \\
\hline Private investment & 0.091 & 0.099 & 0.226 & 0.871 \\
\hline
\end{tabular}

Notes: The estimates are based on specification (24) with a restricted sample. Away from ZLB uses observations with short-term interest rates above 0.75, and At the ZLB uses observations with short-term interest rates below 0.75. DriscollKraay standard errors are reported in parentheses. ${ }^{* *},{ }^{* *}$, and ${ }^{*}$ denote significance at the 1,5 , and 10 percent level.

$\dagger$ : The null hypothesis is that the government consumption and investment multipliers are equal. 
consumption. Private investment falls insignificantly — which is inconsistent with the view that a rise in inflation drives down the real rate and crowds in private investment. Although the point estimates of the government investment multiplier at and away from the ZLB are quite different, the standard errors are large and the equality of the multipliers can only be rejected in relatively few instances (Panel C).

Broadly, these findings are in line with Miyamoto, Nguyen, and Sergeyev (2017), although the difference in multipliers at and away from the ZLB are not as large in my sample. My estimates also suggest that the large multiplier at the ZLB is potentially driven by government investment. There is some evidence that prices increase in the consumption goods sector after a government consumption shock when the economy is at the ZLB. Investment prices show no clear pattern after government investment shocks (see Figure C6 in Appendix C).

\subsubsection{Robustness of the estimates}

I next verify that the results are not driven by outliers. In Figure C5 of Appendix C, I present leave-one-out estimates of the multipliers. I summarize the main findings of this robustness exercise: First, GDP always increases significantly after a government consumption shock and never after a government investment shock. Second, private consumption never responds significantly after either shock, and third, private investment always drops significantly after government investment shocks, but never after government consumption shocks. Thus the results do not depend on the inclusion of individual countries.

\subsubsection{The state of the business cycle}

In Appendix C.2, I explore the possibility that fiscal multipliers depend on the state of the business cycle (Auerbach and Gorodnichenko, 2012, 2013, Ramey and Zubairy, 2017). Reflecting the disagreement in the literature, the results strongly depend on how I measure the state of the business cycle. Since alternative measures of slack yield different results, no clear picture emerges as to whether multipliers are greater or smaller in times of slack.

\section{External validity of multipliers for total purchases}

In this section I discuss the implications of my findings for estimated multipliers for total government purchases. I show that this multiplier can suffer from external validity problems. 


\subsection{A decomposition}

Building on Kraay (2012), I present an identity which relates the multiplier for total purchases to the government consumption and investment multipliers. In what follows variables without subscripts are vectors or matrices of stacked variables with subscripts. For instance, $y$ is the vector of stacked $y_{i, t}, Q$ is the matrix of stacked $q_{i, t}^{\prime}$, and so forth.

Proposition 4.1. Consider the three models

$$
\begin{aligned}
& y_{i, t}=m_{g} g_{i, t}+q_{i, t}^{\prime} \beta_{g}+\varepsilon_{i, t}^{g}, \\
& y_{i, t}=m_{x} x_{i, t}^{g}+q_{i, t}^{\prime} \beta_{x}+\varepsilon_{i, t}^{x}, \\
& y_{i, t}=m_{c} c_{i, t}^{g}+q_{i, t}^{\prime} \beta_{c}+\varepsilon_{i, t}^{c},
\end{aligned}
$$

where $y_{i, t}$ is a common left hand side variable, $q_{i, t}$ a common vector of control variables, and

$$
g_{i, t}=x_{i, t}^{g}+c_{i, t}^{g}
$$

There are instruments $z_{i, t}^{g}$ for $g_{i, t}, z_{i, t}^{x}$ for $x_{i, t}^{g}$, and $z_{i, t}^{c}$ for $c_{i, t}^{g}$, such that

$$
z_{i, t}^{g}=z_{i, t}^{x}+z_{i, t}^{c}
$$

Then the exactly identified instrumental variable (IV) estimators satisfy

$$
\hat{m}_{g}=\omega_{x} \hat{m}_{x}+\omega_{c} \hat{m}_{c}
$$

where

$$
\omega_{x}=\frac{\left(M_{Q} z^{x}\right)^{\prime} M_{Q} x^{g}}{\left(M_{Q} z^{g}\right)^{\prime} M_{Q} g}, \quad \omega_{c}=\frac{\left(M_{Q} z^{c}\right)^{\prime} M_{Q} c^{g}}{\left(M_{Q} z^{g}\right)^{\prime} M_{Q} g},
$$

and $M_{Q}=I-Q\left(Q^{\prime} Q\right)^{-1} Q^{\prime}$.

Proof. See Appendix D.

When applied to the question at hand, the proposition states that multiplier estimates for total purchases are weighted averages of the estimates for government consumption and investment (equation 30). 
The weights $\omega_{x}$ and $\omega_{c}$ capture the fraction of the identifying variation due to government investment and consumption. More precisely, the weight $\omega_{x}$ is the covariance between the instrument $z_{i, t}^{x}$ and the spending variable $x_{i, t}^{g}$ divided by the covariance between the instrument for total purchases $z_{i, t}^{g}$ with total purchases $g_{i, t}$. Both covariances are calculated after residualizing with respect to the control variables. This is what the matrix $M_{Q}$ does.

I add two remarks. First, the proposition requires no assumption on the true underlying model but relates the estimates of the three different multipliers under any data generating process. This implies that if the conditions of the proposition were satisfied, then equation (30) would hold exactly in the data. Second, the weights $\omega_{x}$ and $\omega_{c}$ do not in general sum to one. If the instrument for government investment $\left(z^{x}\right)$ is correlated with government consumption $\left(c^{g}\right)$ (and vice versa), after controlling for other factors, then $\omega_{x}+\omega_{c} \neq 1$. I discuss details in Appendix D.

In practice, the assumptions of Proposition 4.1 do not hold exactly. First, chained indexes are not additive, so that equation (28) does not hold due to statistical discrepancy (see Whelan, 2000). Second, I prefer to estimate the government consumption multiplier while controlling for government investment shocks and the government investment multiplier while controlling for government consumption shocks. In other words, I add an additional control to equations (26) and (27). As I established in Section 3, these controls have only small effects on the estimates, but break the identity in equation (30).

\subsection{Multiplier estimates for total purchases}

Panel A of Table 8 shows the estimate of the multiplier for total purchases and compares them to the estimates for government consumption and investment which are restated here for convenience. I estimate the multiplier for total purchases based on equation (24), using $z^{g}=\left(c_{i, t}^{g}-c_{i, t-1}^{g}\right) / y_{i, t-1}+\left(x_{i, t}^{g}-x_{i, t-1}^{g}\right) / y_{i, t-1}$ as the instrument. The estimate is surprisingly small with a value of 0.25 after 4 quarters and 0.34 after 8 quarters. At neither horizon is the estimate significantly different from zero.

The fact that the multiplier estimate for total purchases is small and closer to the estimate for government investment can be understood using the decomposition introduced above (equation 30). Although government investment constitutes a much smaller fraction of GDP than government consumption (on average, 3 versus 19 percent), it is more volatile. In my sample, the standard deviation of $\left(x_{i, t}^{g}-x_{i, t-1}^{g}\right) / y_{i, t-1}$ is 0.0025 while the standard deviation of $\left(c_{i, t}^{g}-c_{i, t-1}^{g}\right) / y_{i, t-1}$ 
Table 8: Comparison of multiplier estimates

\begin{tabular}{|c|c|c|c|c|c|c|}
\hline \multicolumn{7}{|c|}{ Panel A: Multiplier estimates } \\
\hline \multirow[b]{2}{*}{ Horizon (quarters) } & \multicolumn{2}{|c|}{$\begin{array}{l}\text { Government } \\
\text { consumption }\end{array}$} & \multicolumn{2}{|c|}{$\begin{array}{c}\text { Government } \\
\text { investment }\end{array}$} & \multicolumn{2}{|c|}{$\begin{array}{c}\text { Total } \\
\text { purchases }\end{array}$} \\
\hline & 4 & 8 & 4 & 8 & 4 & 8 \\
\hline Gross Domestic Product & $\begin{array}{c}0.76^{* *} \\
(0.36)\end{array}$ & $\begin{array}{c}0.85^{* *} \\
(0.35)\end{array}$ & $\begin{array}{l}-0.08 \\
(0.22)\end{array}$ & $\begin{array}{l}-0.06 \\
(0.35)\end{array}$ & $\begin{array}{c}0.25 \\
(0.19)\end{array}$ & $\begin{array}{c}0.34 \\
(0.28)\end{array}$ \\
\hline First stage F-statistic & 371.0 & 131.4 & 213.6 & 115.3 & 134.9 & 93.5 \\
\hline Observations & 762 & 697 & 762 & 697 & 762 & 697 \\
\hline
\end{tabular}

Panel B: Multipliers constructed from approximation (30)

\begin{tabular}{|c|c|c|c|c|c|c|}
\hline \multirow[b]{2}{*}{ Horizon (quarters) } & \multicolumn{2}{|c|}{$\omega_{c}$} & \multicolumn{2}{|c|}{$\omega_{x}$} & \multicolumn{2}{|c|}{$\begin{array}{c}\text { Total } \\
\text { purchases }\end{array}$} \\
\hline & 4 & 8 & 4 & 8 & 4 & 8 \\
\hline Weights & 0.317 & 0.360 & 0.591 & 0.544 & & \\
\hline Gross Domestic Product & & & & & 0.20 & 0.27 \\
\hline
\end{tabular}

Notes: The estimates in Panel A are based on specification (24) as described in the text. Panel B reports the weights as stated in (31) and constructs the multiplier for total purchases from the government consumption and investment multipliers as reported in Panel A, using approximation (30). Driscoll-Kraay standard errors are reported in parentheses. ${ }^{* *}$ denotes significance at the 5 percent level.

is 0.0016. This implies that a larger share of the identifying variation comes from government investment shocks so that $\omega_{x}$ is greater than $\omega_{c}$. Panel B of Table 8 reports these weights (constructed from 31). At a 4 quarter horizon $\omega_{x}$ is 0.591 while $\omega_{c}$ is 0.317 . At an 8 quarter horizon $\omega_{x}=0.544$ and $\omega_{c}=0.360$. Hence, the majority of the variation of total purchases is driven by government investment. This renders the associated multiplier estimate small.

When I compute the multiplier for total purchases from equation (30), using the estimates and weights as reported in Table 8, I obtain a multiplier of 0.20 after 4 quarters and a multiplier of 0.27 after 8 quarters. As noted before, these values differ slightly from the estimates in Panel A since relationship (30) holds only approximately (see Appendix Table D1 for details).

Since the estimated multipliers for total purchases in Table 8 are small in comparison to the literature, I also report results from a standard Blanchard-Perotti identification scheme (i.e. without purifying changes in purchases of their anticipated components) in Appendix C Table 
C1. The multiplier for total purchases is now 0.51 (0.58) after 4 (8) quarters and the weights $\omega_{x}$ and $\omega_{c}$ are roughly equal in this sample. This case illustrates that estimates of the total purchases multiplier vary with the composition of the identifying variation and explains why the estimate of the total purchases multiplier in the baseline sample is so small.

\subsection{External validity}

If government consumption and government investment are associated with different multipliers, the econometric model for total purchases is misspecified. This misspecification has the potentially important implication that a change in the composition of government purchases affects the multiplier - even if the underlying multipliers for government consumption and investment remain the same. As a result, such compositional changes lead to an external validity problem for multipliers which are estimated from variation in total purchases.

In practice, this external validity problem appears in various forms. First and most importantly, if actual stimulus programs have a different composition of purchases than the variation underlying the estimation, then the estimated multiplier for total purchases will not provide accurate guidance for policy. Second, it is likely that alternate samples and identification schemes rely on different compositions of variation in government consumption and investment. To the extent that this is the case, one would not expect to find the same multiplier across samples or identification schemes. Third, even for a given sample and a given identification scheme, the estimated multipliers at different time horizons are not generally comparable. Since government consumption shocks are more persistent than government investment shocks in my sample, the identifying variation at short time horizons is different from the identifying variation at longer horizons. As Panel B of Table 8 shows, the weight shifts towards government consumption at the 8 quarter horizon (by approximately 5 percentage points). It follows that the point estimate at 8 quarters is greater than that at 4 quarters in part due to the relatively greater importance of the government consumption shock.

To provide one concrete example for the relevance of this external validity problem for the estimation of fiscal multipliers, I perform the following exercise. I first draw 10,000 bootstrap samples from the main sample and then calculate the estimates of the 4-quarter multipliers of total purchases $m_{g}$ as well as the corresponding weights $\omega_{c}$ and $\omega_{x}$ in each bootstrap sample. I then approximate the conditional mean $E\left[m_{g} \mid \omega_{c}, \omega_{x}\right]$ as a second order polynomial in $\omega_{c}$ and $\omega_{x}$. 
Figure 7: Total purchases multiplier conditional on weights

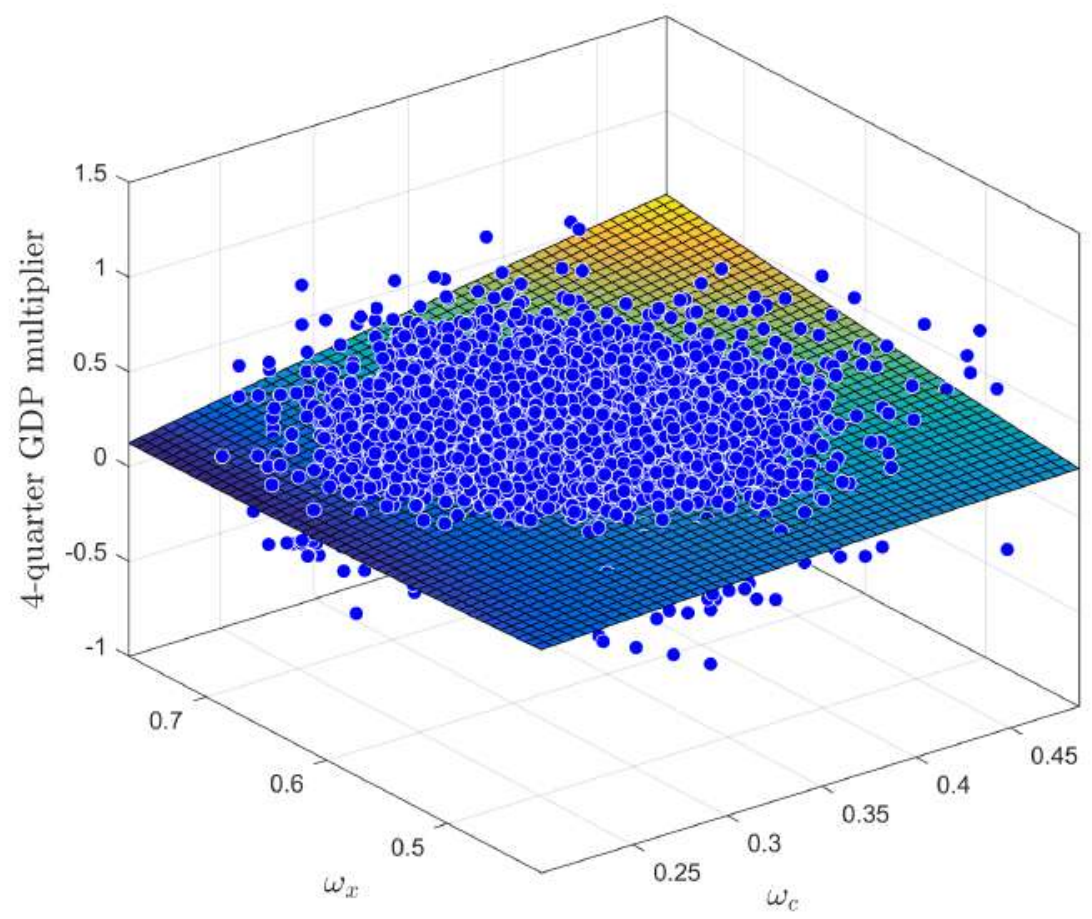

Notes: The figure is based on 10,000 bootstrap subsamples for each of which I computed the 4-quarter total purchases multiplier and the corresponding weights $\omega_{c}$ and $\omega_{x}$. I then fit a second order polynomial of the multiplier in the weights $\omega_{c}$ and $\omega_{x}$.

This surface is plotted in Figure 7. In the figure, each dot represents the multiplier estimate in one bootstrap subsample. As expected, the conditional mean is increasing in $\omega_{c}{ }^{19}$

It turns out that the standard deviations of the weights $\omega_{c}$ and $\omega_{x}$ are small (0.035 and 0.044) relative to the standard deviations of the multiplier estimates (around 0.3). As a result, changing weights across subsamples explain a small share of the variance of the multiplier of total purchases: the $R^{2}$ of the second order polynomial is 1.6 percent. However, as shown in Table 9 , this low $R^{2}$ disguises the fact that the weights $\omega_{c}$ and $\omega_{x}$ vary substantially across countries. When I use these weights to predict the country-specific multipliers based on the estimated conditional mean, the multipliers also differ substantially. For instance, the multiplier for total purchases is 0.63 for Denmark while it is negative 0.13 for Korea. Although this example is extreme, it highlights that

\footnotetext{
${ }^{19}$ Note that equation (30) cannot generally used to predict the multiplier for total purchases from the weights. The reason is that the multiplier for total purchases and the weights $\omega_{c}$ and $\omega_{x}$ are based on the same data and thus jointly distributed. Hence, it is not generally possible to change the weights without changing the multiplier as well. The bootstrapping exercise resolves this issue by considering the conditional mean $E\left[m_{g} \mid \omega_{c}, \omega_{x}\right]$.
} 
Table 9: Predicted 4-quarter multiplier for total purchases

\begin{tabular}{lccc}
\hline \hline Country & \multicolumn{2}{c}{ Weights } & Predicted multiplier \\
& $\omega_{c}$ & $\omega_{x}$ & for total purchases \\
& & & \\
\hline Australia & 0.33 & 0.60 & 0.27 \\
Belgium & 0.44 & 0.51 & 0.30 \\
Canada & 0.30 & 0.61 & 0.24 \\
Germany & 0.40 & 0.53 & 0.29 \\
Denmark & 0.61 & 0.70 & 0.63 \\
Finland & 0.57 & 0.48 & 0.32 \\
France & 0.30 & 0.37 & 0.21 \\
United Kingdom & 0.62 & 0.34 & 0.17 \\
Ireland & 0.20 & 0.61 & 0.14 \\
Japan & 0.32 & 0.62 & 0.26 \\
Korea & 0.08 & 0.88 & -0.13 \\
Netherlands & 0.67 & 0.26 & 0.04 \\
Norway & 0.33 & 0.66 & 0.28 \\
New Zealand & 0.15 & 0.77 & 0.03 \\
Portugal & 0.18 & 0.34 & 0.20 \\
Sweden & 0.35 & 0.44 & 0.23 \\
United States & 0.44 & 0.25 & 0.16 \\
\hline
\end{tabular}

Notes: The weights $\omega_{c}$ and $\omega_{x}$ are calculated by country using equations (31) and from the actual sample. The last column reports the predicted multiplier based on a fitted second order polynomial of the multiplier in the weights $\omega_{c}$ and $\omega_{x}$ in 10,000 bootstrap samples. See text for details.

comparing multipliers for total purchases across countries is potentially problematic. ${ }^{20}$

\section{Conclusion}

A standard two sector model predicts that the government investment multiplier is smaller than the government consumption multiplier. I offer two equivalent explanations for this result. The first explanation highlights that government investment has essentially no wealth effect on household's labor supply. The second explanation emphasizes that due to greater intertemporal substitutability, private investment contracts more after government investment shocks than private consumption after government consumption shocks. Given that prior work has placed significant

\footnotetext{
${ }^{20}$ While the "portability" of the government consumption and investment multipliers is likely better than that of the multiplier for total purchases, this external validity comes at a cost. Since total purchases exhibits greater variation than the two components alone, the multiplier for total purchases is estimated with greater precision (see Panel A of Table 8).
} 
emphasis on both the wealth effect and the crowding out of private investment these findings suggest that researchers should - if the data permit - separate total government purchases into government consumption and government investment. If the composition of purchases matters, multiplier estimates for total purchases suffer from an external validity problem. Once the composition of purchases changes, the multiplier changes as well.

I test the model's predictions in a panel of OECD countries and obtain results broadly consistent with the model's predictions. First, the output multiplier for government consumption shocks exceeds the multiplier for government investment shocks. Second, this difference is driven in large part by the contraction in private investment after public investment shocks. Third, there is evidence of an increase in the own real interest rate in the investment goods sector. This evidence is based on a Blanchard-Perotti identification scheme with quarterly data and uses forecasts to purge spending shocks of their anticipated components.

These results raise concerns about the effectiveness of fiscal stimulus that is targeted towards infrastructure. As many other stimulus programs, the American Recovery and Reinvestment Act contained provisions to raise spending on highly durable goods such as highway infrastructure, high-speed rail corridors, railroads, airports, and broadband. Further, it has been suggested to assemble a pool of "shovel-ready" investment projects - to be implemented when the economy next plunges into recession. This initiative could potentially overcome the main hurdle for using government investment as a tool for stabilization policy. The findings in this paper suggest that it may be desirable to focus on government consumption instead since such stimulus is likely more effective. 


\section{References}

Aiyagari, S. Rao, Lawrence J. Christiano, and Martin Eichenbaum. 1992. "The output, employment, and interest rate effects of government consumption." Journal of Monetary Economics 30 (1):73-86.

Albertini, Julien, Arthur Poirier, and Jordan Roulleau-Pasdeloup. 2014. "The composition of government spending and the multiplier at the zero lower bound." Economics Letters $122(1): 31-35$.

Angrist, Joshua David and Jörn-Steffen Pischke. 2009. Princeton, NJ: Princeton Univ. Press.

Aschauer, David Alan. 1989a. "Does public capital crowd out private capital?" Journal of Monetary Economics 24 (2):171-188.

. 1989b. "Is public expenditure productive?" Journal of Monetary Economics $23(2): 177-200$.

Auerbach, Alan J. and Yuriy Gorodnichenko. 2012. "Measuring the Output Responses to Fiscal Policy." American Economic Journal: Economic Policy 4 (2):1-27.

— 2013. "Fiscal Multipliers in Recession and Expansion." In Fiscal Policy after the Financial Crisis, edited by Alberto Alesina and Francesco Giavazzi, NBER Chapters. Chicago, IL: National Bureau of Economic Research, Inc, 63-98.

Barro, Robert J. 1981. "Output Effects of Government Purchases." Journal of Political Economy 89 (6):1086-1121.

Barro, Robert J. and Charles J. Redlick. 2011. "Macroeconomic Effects From Government Purchases and Taxes." The Quarterly Journal of Economics 126 (1):51-102.

Barsky, Robert B., Christoph E. Boehm, Christopher L. House, and Miles S. Kimball. 2015. "Monetary Policy and Durable Goods." Tech. rep.

Barsky, Robert B., Christopher L. House, and Miles S. Kimball. 2007. "Sticky-Price Models and Durable Goods." American Economic Review 97 (3):984-998.

Basu, Susanto and Pierre De Leo. 2016. "Should Central Banks Target Investment Prices?" Boston college working papers in economics, Boston College Department of Economics.

Baxter, Marianne and Robert G King. 1993. "Fiscal Policy in General Equilibrium." American Economic Review 83 (3):315-34.

Berger, David and Joseph Vavra. 2014. "Measuring How Fiscal Shocks Affect Durable Spending in Recessions and Expansions." American Economic Review 104 (5):112-15.

Blanchard, Olivier and Roberto Perotti. 2002. "An Empirical Characterization of the Dynamic Effects of Changes in Government Spending and Taxes on Output." The Quarterly Journal of Economics 117 (4):1329-1368.

Boehm, Christoph E. 2016. "Government Spending and Durable Goods." Tech. rep. 
Boehm, Christoph E. and Nitya Pandalai-Nayar. 2018. "Are supply curves convex? Implications for state-dependent responses to shocks." Tech. rep.

Bouakez, Hafedh, Michel Guillard, and Jordan Roulleau-Pasdeloup. 2017. "Public Investment, Time to Build, and the Zero Lower Bound." Review of Economic Dynamics 23:60-79.

Calvo, Guillermo A. 1983. "Staggered prices in a utility-maximizing framework." Journal of Monetary Economics 12 (3):383-398.

Cashin, David and Takashi Unayama. 2016. "Measuring Intertemporal Substitution in Consumption: Evidence from a VAT Increase in Japan." The Review of Economics and Statistics 98 (2):285-297.

Chetty, Raj, Adam Guren, Day Manoli, and Andrea Weber. 2011. "Are Micro and Macro Labor Supply Elasticities Consistent? A Review of Evidence on the Intensive and Extensive Margins." American Economic Review 101 (3):471-75.

Chodorow-Reich, Gabriel. 2017. "Geographic Cross-Sectional Fiscal Spending Multipliers: What Have We Learned?" Nber working papers, National Bureau of Economic Research, Inc.

Christiano, Lawrence, Martin Eichenbaum, and Sergio Rebelo. 2011. "When Is the Government Spending Multiplier Large?" Journal of Political Economy 119 (1):78 - 121.

Cogan, John F., Tobias Cwik, John B. Taylor, and Volker Wieland. 2010. "New Keynesian versus old Keynesian government spending multipliers." Journal of Economic Dynamics and Control 34 (3):281-295.

Cohen, Lauren, Joshua Coval, and Christopher Malloy. 2011. "Do Powerful Politicians Cause Corporate Downsizing?" Journal of Political Economy 119 (6):1015-1060.

Driscoll, John C. and Aart C. Kraay. 1998. "Consistent Covariance Matrix Estimation With Spatially Dependent Panel Data." The Review of Economics and Statistics 80 (4):549560 .

Edelberg, Wendy, Martin Eichenbaum, and Jonas D.M. Fisher. 1999. "Understanding the Effects of a Shock to Government Purchases." Review of Economic Dynamics 2 (1):166206.

Eden, Maya and Aart Kraay. 2014. "\&quot;Crowding in\&quot;and the returns to government investment in low-income countries." Policy research working paper series, The World Bank.

Erceg, Christopher and Andrew Levin. 2006. "Optimal monetary policy with durable consumption goods." Journal of Monetary Economics 53 (7):1341-1359.

Fisher, Walter H and Stephen J Turnovsky. 1998. "Public Investment, Congestion, and Private Capital Accumulation." Economic Journal 108 (447):399-413. 
Galí, Jordi, J. David López-Salido, and Javier Vallés. 2007. "Understanding the Effects of Government Spending on Consumption." Journal of the European Economic Association $5(1): 227-270$.

Hall, Robert E. 1988. "Intertemporal Substitution in Consumption." Journal of Political Economy 96 (2):339-57.

Hall, Robert E. 2009. "By How Much Does GDP Rise If the Government Buys More Output?" Brookings Papers on Economic Activity 40 (2 (Fall)):183-249.

House, Christopher L. 2009. "Comment on: By How Much Does GDP Rise If the Government Buys More Output?" Brookings Papers on Economic Activity 40 (2 (Fall)):236-244.

. 2014. "Fixed costs and long-lived investments." Journal of Monetary Economics $68: 86-100$.

House, Christopher L. and Matthew D. Shapiro. 2008. "Temporary Investment Tax Incentives: Theory with Evidence from Bonus Depreciation." American Economic Review 98 (3):737-68.

Ilzetzki, Ethan, Enrique G. Mendoza, and Carlos A. Végh. 2013. "How big (small?) are fiscal multipliers?" Journal of Monetary Economics 60 (2):239-254.

Ilzetzki, Ethan, Carmen M. Reinhart, and Kenneth S. Rogoff. 2017. "The Country Chronologies to Exchange Rate Arrangements into the 21st Century: Will the Anchor Currency Hold?" NBER Working Papers, National Bureau of Economic Research, Inc.

International Labour Organization. 2011. "A review of global fiscal stimulus." International Institute for Labour Studies, International Labour Organization. URL http://www.ilo.org/inst/research/addressing-crisis-challenges/ discussion-paper-series/WCMS_194175/lang--en/index.htm.

Jordà, Òscar. 2005. "Estimation and Inference of Impulse Responses by Local Projections." American Economic Review 95 (1):161-182.

Kamps, Christophe. 2005. "The Dynamic Effects of Public Capital: VAR Evidence for 22 OECD Countries." International Tax and Public Finance 12 (4):533-558.

Klenow, Peter J. and Benjamin A. Malin. 2010. "Microeconomic Evidence on PriceSetting." In Handbook of Monetary Economics. Elsevier, 231-284.

Kraay, Aart. 2012. "How large is the Government Spending Multiplier? Evidence from World Bank Lending." The Quarterly Journal of Economics 127 (2):829-887.

Krugman, Paul. 2016. "A Pause That Distresses." The New York Times URL https: //www.nytimes.com/2016/06/06/opinion/a-pause-that-distresses.html.

Leduc, Sylvain and Daniel Wilson. 2012. "Roads to Prosperity or Bridges to Nowhere? Theory and Evidence on the Impact of Public Infrastructure Investment." NBER Macroeconomics Annual 27 (1):89 - 142. 
Leeper, Eric M., Nora Traum, and Todd B. Walker. 2017. "Clearing Up the Fiscal Multiplier Morass." American Economic Review 107 (8):2409-2454.

Leeper, Eric M., Todd B. Walker, and Shu-Chun S. Yang. 2010. "Government investment and fiscal stimulus." Journal of Monetary Economics 57 (8):1000-1012.

Lenain, Patrick. 2002. "What is the track record of OECD Economic Projections?" OECD.

Linnemann, Ludger and Andreas Schabert. 2006. "Productive Government Expenditure In Monetary Business Cycle Models." Scottish Journal of Political Economy 53 (1):28-46.

Mankiw, N Gregory. 1985. "Consumer Durables and the Real Interest Rate." The Review of Economics and Statistics 67 (3):353-62.

Michaillat, Pascal. 2014. "A Theory of Countercyclical Government Multiplier." American Economic Journal: Macroeconomics 6 (1):190-217.

Miyamoto, Wataru, Thuy Lan Nguyen, and Dmitriy Sergeyev. 2017. "Government Spending Multipliers Under the Zero Lower Bound: Evidence from Japan." Tech. rep.

Mountford, Andrew and Harald Uhlig. 2009. "What are the effects of fiscal policy shocks?" Journal of Applied Econometrics 24 (6):960-992.

Nakamura, Emi and Jon Steinsson. 2014. "Fiscal Stimulus in a Monetary Union: Evidence from US Regions." American Economic Review 104 (3):753-92.

Olea, José Luis Montiel and Carolin Pflueger. 2013. "A Robust Test for Weak Instruments." Journal of Business $\&$ Economic Statistics 31 (3):358-369.

Pappa, Evi. 2010. "The effects of fiscal expansions: an international comparison." Working Paper, Barcelona Graduate School of Economics.

Pereira, Alfredo M. 2000. "Is All Public Capital Created Equal?" The Review of Economics and Statistics $82(3): 513-518$.

Perotti, Roberto. 2004. "Public investment: another (different) look." Working Paper, Bocconi University.

- 2008. "In Search of the Transmission Mechanism of Fiscal Policy." NBER Macroeconomics Annual 2007 22:169-226.

Ramey, Valerie A. 2009. "Identifying Government Spending Shocks: It's All in the Timing." NBER Working Papers, National Bureau of Economic Research, Inc.

—. 2011a. "Can Government Purchases Stimulate the Economy?" Journal of Economic Literature 49 (3):673-685.

- 2011b. "Identifying Government Spending Shocks: It's all in the Timing." The Quarterly Journal of Economics 126 (1):1-50.

Ramey, Valerie A. and Matthew D. Shapiro. 1998. "Costly capital reallocation and the effects of government spending." Carnegie-Rochester Conference Series on Public Policy 48 (1):145-194. 
Ramey, Valerie A. and Sarah Zubairy. 2017. "Government Spending Multipliers in Good Times and in Bad: Evidence from U.S. Historical Data." Working Paper, .

Sanderson, Eleanor and Frank Windmeijer. 2016. "A weak instrument F-test in linear IV models with multiple endogenous variables." Journal of Econometrics 190 (2):212-221.

Snyder, Jason Alan and Ivo Welch. 2017. "Do Powerful Politicians Really Cause Corporate Downsizing?" Journal of Political Economy 125 (6):2225-2231.

Thomas, Julia K. 2002. "Is Lumpy Investment Relevant for the Business Cycle?" Journal of Political Economy 110 (3):508-534.

Veracierto, Marcelo L. 2002. "Plant-Level Irreversible Investment and Equilibrium Business Cycles." American Economic Review 92 (1):181-197.

Vogel, Lukas. 2007. "How do the OECD Growth Projections for the G7 Economies Perform?: A Post-Mortem." OECD Economics Department Working Papers, OECD.

Voss, Graham M. 2002. "Public and private investment in the United States and Canada." Economic Modelling 19 (4):641-664.

Whelan, Karl. 2000. "A guide to the use of chain aggregated NIPA data." Tech. rep.

Woodford, Michael. 2011. "Simple Analytics of the Government Expenditure Multiplier." American Economic Journal: Macroeconomics 3 (1):1-35. 
For Online Publication 


\section{A Model appendix}

For this Appendix, I define the following constants

$$
\begin{aligned}
s_{y}^{x} & :=\frac{p^{x} x}{p^{x} x+p^{c} c}=\left(\frac{n^{x}}{n}\right)^{\frac{\eta+\mu}{\eta}}=\frac{\alpha \delta}{\left(1-s_{x}^{g}\right)\left(\beta^{-1}-1+\delta\right)} \\
s_{x}^{x} & :=\frac{x^{x}}{x}=\frac{\alpha \delta}{\beta^{-1}-1+\delta} \\
s_{x}^{c} & :=\frac{x^{c}}{x}=1-s_{x}^{g}-\frac{\alpha \delta}{\beta^{-1}-1+\delta}
\end{aligned}
$$

\section{A.1 Summary of model equations}

Labor supply decisions

$$
\begin{aligned}
& \phi\left(n_{t}\right)^{\frac{1}{\eta}-\frac{\mu}{\eta}}\left(n_{t}^{x}\right)^{\frac{\mu}{\eta}}=\left(c_{t}^{h}\right)^{-\frac{1}{\sigma}} \frac{p_{t}^{x}}{p_{t}^{c}} \frac{w_{t}^{x}}{p_{t}^{x}} \\
& \phi\left(n_{t}\right)^{\frac{1}{\eta}-\frac{\mu}{\eta}}\left(n_{t}^{c}\right)^{\frac{\mu}{\eta}}=\left(c_{t}^{h}\right)^{-\frac{1}{\sigma}} \frac{w_{t}^{c}}{p_{t}^{c}}
\end{aligned}
$$

Euler equation for nominal bond

$$
\left(c_{t}^{h}\right)^{-\frac{1}{\sigma}}=\beta\left(1+i_{t}\right) E_{t}\left[\frac{1}{1+\pi_{t+1}^{c}}\left(c_{t+1}^{h}\right)^{-\frac{1}{\sigma}}\right]
$$

Labor aggregator

$$
n_{t}=\left[\left(n_{t}^{c}\right)^{\frac{\eta+\mu}{\eta}}+\left(n_{t}^{x}\right)^{\frac{\eta+\mu}{\eta}}\right]^{\frac{\eta}{\eta+\mu}}
$$

Investment choice

$$
\begin{aligned}
1 & =\frac{\gamma_{t}^{c}}{p_{t}^{x}} \vartheta^{\prime}\left(\frac{x_{t}^{c}}{k_{t}^{c}}\right) \\
1 & =\frac{\gamma_{t}^{x}}{p_{t}^{x}} \vartheta^{\prime}\left(\frac{x_{t}^{x}}{k_{t}^{x}}\right)
\end{aligned}
$$

Euler equations for capital

$$
\begin{aligned}
& \frac{\gamma_{t}^{c}}{p_{t}^{x}}=E_{t}\left[\frac{1}{1+i_{t}} \frac{p_{t+1}^{x}}{p_{t}^{x}}\left(\frac{r_{k, t+1}^{c}}{p_{t+1}^{x}}+\frac{\gamma_{t+1}^{c}}{p_{t+1}^{x}}\left((1-\delta)+\vartheta\left(\frac{x_{t+1}^{c}}{k_{t+1}^{c}}\right)-\vartheta^{\prime}\left(\frac{x_{t+1}^{c}}{k_{t+1}^{c}}\right) \frac{x_{t+1}^{c}}{k_{t+1}^{c}}\right)\right)\right] \\
& \frac{\gamma_{t}^{x}}{p_{t}^{x}}=E_{t}\left[\frac{1}{1+i_{t}} \frac{p_{t+1}^{x}}{p_{t}^{x}}\left(\frac{r_{k, t+1}^{x}}{p_{t+1}^{x}}+\frac{\gamma_{t+1}^{x}}{p_{t+1}^{x}}\left((1-\delta)+\vartheta\left(\frac{x_{t+1}^{x}}{k_{t+1}^{x}}\right)-\vartheta^{\prime}\left(\frac{x_{t+1}^{x}}{k_{t+1}^{x}}\right) \frac{x_{t+1}^{x}}{k_{t+1}^{x}}\right)\right)\right]
\end{aligned}
$$

Capital accumulation equations

$$
\begin{aligned}
& k_{t+1}^{x}=k_{t}^{x}(1-\delta)+\vartheta\left(\frac{x_{t}^{x}}{k_{t}^{x}}\right) k_{t}^{x} \\
& k_{t+1}^{c}=k_{t}^{c}(1-\delta)+\vartheta\left(\frac{x_{t}^{c}}{k_{t}^{c}}\right) k_{t}^{c} \\
& k_{t+1}^{g}=k_{t}^{g}(1-\delta)+\vartheta\left(\frac{x_{t}^{g}}{k_{t}^{g}}\right) k_{t}^{g}
\end{aligned}
$$


Phillips curves (tildes denote percent deviations from steady state, linear approximations)

$$
\begin{aligned}
\pi_{t}^{x} & =\frac{\left(1-\theta_{x}\right)\left(1-\theta_{x} \beta\right)}{\theta_{x}} \frac{\widetilde{m c_{t}^{x}}}{p_{t}^{x}}+\beta E_{t}\left[\pi_{t+1}^{x}\right] \\
\pi_{t}^{c} & =\frac{\left(1-\theta_{c}\right)\left(1-\theta_{c} \beta\right)}{\theta_{c}} \frac{\frac{m c_{t}^{c}}{p_{t}^{c}}}{p_{t}} \beta E_{t}\left[\pi_{t+1}^{c}\right]
\end{aligned}
$$

Factor demands

$$
\begin{aligned}
\frac{w_{t}^{c}}{p_{t}^{c}} & =\frac{m c_{t}^{c}}{p_{t}^{c}}(1-\alpha)\left(k_{t}^{g}\right)^{\alpha_{g}}\left(k_{t}^{c}\right)^{\alpha}\left(n_{t}^{c}\right)^{-\alpha} \\
\frac{r_{k, t}^{c}}{p_{t}^{c}} & =\frac{m c_{t}^{c}}{p_{t}^{c}} \alpha\left(k_{t}^{g}\right)^{\alpha_{g}}\left(k_{t}^{c}\right)^{\alpha-1}\left(n_{t}^{c}\right)^{1-\alpha} \\
\frac{w_{t}^{x}}{p_{t}^{x}} & =\frac{m c_{t}^{x}}{p_{t}^{x}}(1-\alpha)\left(k_{t}^{g}\right)^{\alpha_{g}}\left(k_{t}^{x}\right)^{\alpha}\left(n_{t}^{x}\right)^{-\alpha} \\
\frac{r_{k, t}^{x}}{p_{t}^{x}} & =\frac{m c_{t}^{x}}{p_{t}^{x}} \alpha\left(k_{t}^{g}\right)^{\alpha_{g}}\left(k_{t}^{x}\right)^{\alpha-1}\left(n_{t}^{x}\right)^{1-\alpha}
\end{aligned}
$$

Production functions

$$
\begin{aligned}
x_{t} & =\left(k_{t}^{g}\right)^{\alpha_{g}}\left(k_{t}^{x}\right)^{\alpha}\left(n_{t}^{x}\right)^{1-\alpha} \\
c_{t} & =\left(k_{t}^{g}\right)^{\alpha_{g}}\left(k_{t}^{c}\right)^{\alpha}\left(n_{t}^{c}\right)^{1-\alpha}
\end{aligned}
$$

Market clearing conditions

$$
\begin{aligned}
x_{t} & =x_{t}^{x}+x_{t}^{c}+x_{t}^{g} \\
c_{t} & =c_{t}^{h}+c_{t}^{g}
\end{aligned}
$$

Fisher equations

$$
\begin{aligned}
& 1+i_{t}=\left(1+r_{t}^{x}\right) E_{t}\left[1+\pi_{t+1}^{x}\right] \\
& 1+i_{t}=\left(1+r_{t}^{c}\right) E_{t}\left[1+\pi_{t+1}^{c}\right]
\end{aligned}
$$

Evolution of relative prices

$$
\frac{\frac{p_{t}^{x}}{p_{t-1}^{x}}}{\frac{p_{t}^{c}}{p_{t-1}^{c}}}=\frac{\pi_{t}^{x}}{\pi_{t}^{c}}
$$

Taylor rule (d denotes absolute deviations from steady state)

$$
\begin{aligned}
& \mathrm{d} i_{t}=\phi_{\pi} \pi_{t} \quad \text { in baseline calibration } \\
& \mathrm{d} i_{t}=\phi_{\pi} \pi_{t}^{c} \quad \text { in non-symmetric calibration }
\end{aligned}
$$

Real GDP

$$
y_{t}=p^{x} x_{t}+p^{c} c_{t}
$$

Deflator inflation

$$
\pi_{t}=s_{y}^{x} \pi_{t}^{x}+\left(1-s_{y}^{x}\right) \pi_{t}^{c}
$$


Shock processes

$$
\begin{aligned}
x_{t}^{g} & =\left(1-\varrho_{x}^{g}\right) x^{g}+\varrho_{x}^{g} x_{t-1}^{g}+\varepsilon_{x, t}^{g} \\
c_{t}^{g} & =\left(1-\varrho_{c}^{g}\right) c^{g}+\varrho_{c}^{g} c_{t-1}^{g}+\varepsilon_{c, t}^{g}
\end{aligned}
$$

This is a total of 29 equations. To solve the model, I linearize around the non-stochastic steady state and solve the model with a version of the Anderson-Moore algorithm.

\section{A.2 Proofs}

\section{A.2.1 Proof of Proposition 2.1}

Proposition. Consider the model in Section 2.1 and suppose prices are flexible $\left(\theta_{c}=\theta_{x}=0\right)$. Suppose further that $\delta$ is arbitrarily close to zero. Then, for a short-lived increase in spending $\left(\varrho_{x}^{g}=\varrho_{c}^{g}=0\right)$,

$$
\begin{aligned}
& m_{x} \approx 0, \\
& m_{c} \approx \frac{(1-\alpha)\left(\frac{\mu}{\eta}+\alpha\right)}{(1-\alpha)\left(\frac{1-\mu}{\eta} s_{y}^{x}+\frac{\mu}{\eta}+\alpha\right)+\left(1-s_{c}^{g}\right) \sigma\left(\frac{\mu}{\eta}+\alpha\right)\left(\alpha+\frac{1}{\eta}\right)} .
\end{aligned}
$$

Proof. Letting tildes denote percent deviations from steady state, and d absolute deviations, the linearized equations for the flexible price model are:

Labor supply decisions

$$
\begin{aligned}
\frac{1-\mu}{\eta} \tilde{n}_{t}+\frac{\mu}{\eta} \tilde{n}_{t}^{x} & =-\frac{1}{\sigma} \tilde{c}_{t}^{h}+\frac{\widetilde{p_{t}^{x}}}{p_{t}^{c}}+\frac{\widetilde{w_{t}^{x}}}{p_{t}^{x}} \\
\frac{1-\mu}{\eta} \tilde{n}_{t}+\frac{\mu}{\eta} \tilde{n}_{t}^{c} & =-\frac{1}{\sigma} \tilde{c}_{t}^{h}+\frac{\widetilde{w_{t}^{c}}}{p_{t}^{c}}
\end{aligned}
$$

Euler equation for nominal bond

$$
-\frac{1}{\sigma} \tilde{c}_{t}^{h}=\beta \mathrm{d} r_{t}^{c}-\frac{1}{\sigma} E_{t}\left[\tilde{c}_{t+1}^{h}\right]
$$

Labor aggregator

$$
\tilde{n}_{t}=\left(1-s_{y}^{x}\right) \tilde{n}_{t}^{c}+s_{y}^{x} \tilde{n}_{t}^{x}
$$

Investment choice

$$
\begin{aligned}
& \frac{\widetilde{\gamma_{t}^{x}}}{p_{t}^{x}}=\zeta \delta \tilde{x}_{t}^{x}-\zeta \delta \tilde{k}_{t}^{x} \\
& \frac{\widetilde{\gamma_{t}^{c}}}{p_{t}^{x}}=\zeta \delta \tilde{x}_{t}^{c}-\zeta \delta \tilde{k}_{t}^{c}
\end{aligned}
$$

Euler equations for capital

$$
\begin{aligned}
& \frac{\widetilde{\gamma_{t}^{x}}}{p_{t}^{x}}+\beta \mathrm{d} r_{t}^{x}=E_{t}\left[(1-\beta(1-\delta)) \frac{\widetilde{r_{k, t+1}^{x}}}{p_{t+1}^{x}}+\beta(1-\delta) \frac{\widetilde{\gamma_{t+1}^{x}}}{p_{t+1}^{x}}+\beta \zeta \delta^{2}\left(\tilde{x}_{t+1}^{x}-\tilde{k}_{t+1}^{x}\right)\right] \\
& \frac{\widetilde{\gamma_{t}^{c}}}{p_{t}^{x}}+\beta \mathrm{d} r_{t}^{x}=E_{t}\left[(1-\beta(1-\delta))\left[\widetilde{\frac{r_{k, t+1}^{c}}{p_{t+1}^{c}}}-\widetilde{p_{t+1}^{x}}\right]+\beta(1-\delta) \widetilde{\frac{\gamma_{t+1}^{c}}{p_{t+1}^{c}}}+\beta \zeta \delta^{2}\left(\tilde{x}_{t+1}^{c}-\tilde{k}_{t+1}^{c}\right)\right]
\end{aligned}
$$


Capital accumulation equations

$$
\begin{aligned}
& \tilde{k}_{t+1}^{x}=(1-\delta) \tilde{k}_{t}^{x}+\delta \tilde{x}_{t}^{x} \\
& \tilde{k}_{t+1}^{c}=(1-\delta) \tilde{k}_{t}^{c}+\delta \tilde{x}_{t}^{c} \\
& \tilde{k}_{t+1}^{g}=(1-\delta) \tilde{k}_{t}^{g}+\delta \tilde{x}_{t}^{g}
\end{aligned}
$$

Factor demands

$$
\begin{aligned}
\frac{\widetilde{w_{t}^{c}}}{p_{t}^{c}} & =\alpha_{g} \tilde{k}_{t}^{g}+\alpha \tilde{k}_{t}^{c}-\alpha \tilde{n}_{t}^{c} \\
\frac{\widetilde{r_{k, t}^{c}}}{p_{t}^{c}} & =\alpha_{g} \tilde{k}_{t}^{g}-(1-\alpha) \tilde{k}_{t}^{c}+(1-\alpha) \tilde{n}_{t}^{c} \\
\frac{\frac{w_{t}^{x}}{p_{t}^{x}}}{\frac{r_{k, t}^{x}}{p_{t}^{x}}}=\alpha_{g} \tilde{k}_{t}^{g}+\alpha \tilde{k}_{t}^{x}-\alpha \tilde{n}_{t}^{x} & \alpha_{g} \tilde{k}_{t}^{g}-(1-\alpha) \tilde{k}_{t}^{x}+(1-\alpha) \tilde{n}_{t}^{x}
\end{aligned}
$$

Production functions

$$
\begin{aligned}
\tilde{x}_{t} & =\alpha_{g} \tilde{k}_{t}^{g}+\alpha \tilde{k}_{t}^{x}+(1-\alpha) \tilde{n}_{t}^{x} \\
\tilde{c}_{t} & =\alpha_{g} \tilde{k}_{t}^{g}+\alpha \tilde{k}_{t}^{c}+(1-\alpha) \tilde{n}_{t}^{c}
\end{aligned}
$$

Market clearing conditions

$$
\begin{aligned}
\tilde{x}_{t} & =s_{x}^{x} \tilde{x}_{t}^{x}+s_{x}^{c} \tilde{x}_{t}^{c}+s_{x}^{g} \tilde{x}_{t}^{g} \\
\tilde{c}_{t} & =\left(1-s_{c}^{g}\right) \tilde{c}_{t}^{h}+s_{c}^{g} \tilde{c}_{t}^{g}
\end{aligned}
$$

Fisher equations

$$
\beta \mathrm{d} r_{t}^{x}=\beta \mathrm{d} r_{t}^{c}-E_{t}\left[\widetilde{\frac{p_{t+1}^{x}}{p_{t+1}^{c}}}\right]+\frac{\widetilde{p_{t}^{x}}}{p_{t}^{c}}
$$

Real GDP

$$
\tilde{y}_{t}=s_{y}^{x} \tilde{x}_{t}+\left(1-s_{y}^{x}\right) \tilde{c}_{t}
$$

Shock processes

$$
\begin{aligned}
\tilde{x}_{t}^{g} & =\varrho_{x}^{g} \tilde{x}_{t-1}^{g}+\varepsilon_{x, t}^{g} \\
\tilde{c}_{t}^{g} & =\varrho_{c}^{g} \tilde{c}_{t-1}^{g}+\varepsilon_{c, t}^{g}
\end{aligned}
$$

Now assume $\varrho_{x}^{g}=\varrho_{c}^{g}=0$. Further note that the only other state variables are the capital stocks. If $\delta$ is close to zero, then the accumulation equations (A5, A6), and A7) imply that

$$
\begin{aligned}
& \tilde{k}_{t+1}^{x} \approx \tilde{k}_{t}^{x} \approx 0 \\
& \tilde{k}_{t+1}^{c} \approx \tilde{k}_{t}^{c} \approx 0 \\
& \tilde{k}_{t+1}^{g} \approx \tilde{k}_{t}^{g} \approx 0
\end{aligned}
$$

where I assumed that the economy begins in steady state. Hence, in period $t+1$, all state variables are zero and as a result, all variables dated $t+1$ must be zero. Further note that equations (A1, A2) imply that for fixed $\zeta$ and arbitrarily small $\delta, \frac{\widetilde{\gamma_{t}^{x}}}{p_{t}^{x}} \approx \frac{\widetilde{\gamma_{t}^{c}}}{p_{t}^{x}} \approx 0$. The Euler equations for capital (A3, A4) then yield 
$\mathrm{d} r_{t}^{x} \approx 0$.

Now the above system simplifies to:

Labor supply decisions

$$
\begin{aligned}
\frac{1-\mu}{\eta} \tilde{n}_{t}+\frac{\mu}{\eta} \tilde{n}_{t}^{x} & \approx-\frac{1}{\sigma} \tilde{c}_{t}^{h}+\frac{\widetilde{p_{t}^{x}}}{p_{t}^{c}}+\frac{\widetilde{w_{t}^{x}}}{p_{t}^{x}} \\
\frac{1-\mu}{\eta} \tilde{n}_{t}+\frac{\mu}{\eta} \tilde{n}_{t}^{c} & \approx-\frac{1}{\sigma} \tilde{c}_{t}^{h}+\frac{\widetilde{w_{t}^{c}}}{p_{t}^{c}}
\end{aligned}
$$

Euler equation for nominal bond

$$
-\frac{1}{\sigma} \tilde{c}_{t}^{h} \approx \beta \mathrm{d} r_{t}^{c}
$$

Labor aggregator

$$
\tilde{n}_{t} \approx\left(1-s_{y}^{x}\right) \tilde{n}_{t}^{c}+s_{y}^{x} \tilde{n}_{t}^{x}
$$

Factor demands

$$
\begin{aligned}
\frac{\widetilde{w_{t}^{c}}}{p_{t}^{c}} & \approx-a \tilde{n}_{t}^{c} \\
\frac{\widetilde{w_{t}^{x}}}{p_{t}^{x}} & \approx-\alpha \tilde{n}_{t}^{x}
\end{aligned}
$$

Production functions

$$
\begin{aligned}
& \tilde{x}_{t} \approx(1-\alpha) \tilde{n}_{t}^{x} \\
& \tilde{c}_{t} \approx(1-\alpha) \tilde{n}_{t}^{c}
\end{aligned}
$$

Market clearing conditions

$$
\begin{aligned}
& \tilde{x}_{t} \approx s_{x}^{x} \tilde{x}_{t}^{x}+s_{x}^{c} \tilde{x}_{t}^{c}+s_{x}^{g} \tilde{x}_{t}^{g} \\
& \tilde{c}_{t} \approx\left(1-s_{c}^{g}\right) \tilde{c}_{t}^{h}+s_{c}^{g} \tilde{c}_{t}^{g}
\end{aligned}
$$

Fisher equations

$$
0 \approx \beta \mathrm{d} r_{t}^{c}+\frac{\widetilde{p_{t}^{x}}}{p_{t}^{c}}
$$

Real GDP

$$
\tilde{y}_{t} \approx s_{y}^{x} \tilde{x}_{t}+\left(1-s_{y}^{x}\right) \tilde{c}_{t}
$$

The endogenous variables are $\tilde{n}_{t}, \tilde{n}_{t}^{x}, \tilde{n}_{t}^{c}, \tilde{c}_{t}^{h}, \widetilde{p_{t}^{x}}, \widetilde{p_{t}^{c}}, \widetilde{\frac{w_{t}^{c}}{p_{t}^{x}}}, \frac{w_{t}^{c}}{p_{t}^{c}}, \mathrm{~d} r_{t}^{c}, \tilde{x}_{t}, \tilde{c}_{t}, s_{x}^{x} \tilde{x}_{t}^{x}+s_{x}^{c} \tilde{x}_{t}^{c}, \tilde{y}_{t}$, a total of 12 . Note that in the limiting approximation $\tilde{x}_{t}^{x}$ and $\tilde{x}_{t}^{c}$ are not separately determined. The variables $\widetilde{\frac{r_{k, t}^{c}}{p_{t}^{c}}}$ and $\widetilde{\frac{r_{k, t}^{x}}{p_{t}^{x}}}$ and the equations

$$
\begin{aligned}
& \frac{\widetilde{r_{k, t}^{c}}}{p_{t}^{c}} \approx(1-\alpha) \tilde{n}_{t}^{c} \\
& \frac{\widetilde{r_{k, t}^{x}}}{p_{t}^{x}} \approx(1-\alpha) \tilde{n}_{t}^{x}
\end{aligned}
$$

are redundant. The multipliers now follow from basic algebra. 


\section{A.2.2 Proof of Proposition 2.2}

Proposition. Consider the model Section 2.1 and assume that labor is mobile across sectors $(\mu=0)$. Then the multipliers for a permanent change in purchases are

$$
\begin{aligned}
m_{c}^{\infty} & =\frac{\eta}{\eta\left(1-s_{y}^{x}\left(1-s_{x}^{g}\right)\right)+\sigma\left(1-s_{c}^{g}\right)\left(1-s_{y}^{x}\right)}, \\
m_{x}^{\infty} & =m_{c}^{\infty}+\frac{(1+\eta) \sigma}{\eta\left(1-s_{y}^{x}\left(1-s_{x}^{g}\right)\right)+\sigma\left(1-s_{c}^{g}\right)\left(1-s_{y}^{x}\right)} \cdot \frac{\left(1-s_{c}^{g}\right)\left(1-s_{y}^{x}\right)}{s_{y}^{x} s_{x}^{g}} \cdot \frac{\alpha_{g}}{1-\alpha},
\end{aligned}
$$

where $s_{y}^{x}$ denotes the steady state share of the investment goods sector in GDP, and $s_{c}^{g}$ and $s_{x}^{g}$ are the steady state shares of government purchases in the respective sector.

Proof. Without loss of generality, I proof the proposition for the case without monopoly distortion. I consider permanent changes in $x^{g}$ and $c^{g}$ relative to their initial level and compare steady states. Begin with the system of equations as summarized in Appendix A.1, set $\mu=0$, notice that $r^{c}, r^{x}, \frac{\gamma^{x}}{p^{x}}, \frac{\gamma^{c}}{p^{x}}$, and $\frac{r_{k}^{x}}{p^{x}}$ are independent of the level of government spending. Then the system of equation reduces to:

Labor supply conditions

$$
\begin{aligned}
\phi(n)^{\frac{1}{\eta}} & =\left(c^{h}\right)^{-\frac{1}{\sigma}} \frac{w^{c}}{p_{c}} \\
\phi(n)^{\frac{1}{\eta}} & =\left(c^{h}\right)^{-\frac{1}{\sigma}} \frac{p_{x}}{p_{c}} \frac{w^{x}}{p_{x}}
\end{aligned}
$$

Labor aggregator

$$
n=n^{c}+n^{x}
$$

Capital accumulation equations

$$
\begin{aligned}
\delta k^{x} & =x^{x} \\
\delta k^{c} & =x^{c} \\
\delta k^{g} & =x^{g}
\end{aligned}
$$

Factor demand functions

$$
\begin{aligned}
\frac{w^{x}}{p^{x}} & =(1-\alpha)\left(k^{g}\right)^{\alpha_{g}}\left(k^{x}\right)^{\alpha}\left(n^{x}\right)^{-\alpha} \\
r^{x}+\delta & =\alpha\left(k^{g}\right)^{\alpha_{g}}\left(k^{x}\right)^{\alpha-1}\left(n^{x}\right)^{1-\alpha} \\
\frac{w^{c}}{p^{c}} & =(1-\alpha)\left(k^{g}\right)^{\alpha_{g}}\left(k^{c}\right)^{\alpha}\left(n^{c}\right)^{-\alpha} \\
\left(r^{x}+\delta\right) \frac{p^{x}}{p^{c}} & =\alpha\left(k^{g}\right)^{\alpha_{g}}\left(k^{c}\right)^{\alpha-1}\left(n^{c}\right)^{1-\alpha}
\end{aligned}
$$

Production functions

$$
\begin{aligned}
x & =\left(k^{g}\right)^{\alpha_{g}}\left(k^{x}\right)^{\alpha}\left(n^{x}\right)^{1-\alpha} \\
c & =\left(k^{g}\right)^{\alpha_{g}}\left(k^{c}\right)^{\alpha}\left(n^{c}\right)^{1-\alpha}
\end{aligned}
$$

Market clearing conditions

$$
\begin{aligned}
x & =x^{x}+x^{c}+x^{g} \\
c & =c^{h}+c^{g}
\end{aligned}
$$


Table A1: Symmetric and non-symmetric calibrations

\begin{tabular}{cccl}
\hline \hline & & & \\
Parameter & Symmetric & Non-symmetric & \\
& & & \\
& & & \\
$\sigma$ & 0.25 & 0.25 & Cashin and Unayama (2016), Hall (1988) \\
$\eta$ & 0.75 & 0.75 & Chetty et al. (2011) \\
$\mu$ & 1 & 1 & 0 for perfect labor mobility, 1 for immobile labor \\
$\beta$ & 0.995 & 0.995 & \\
$\alpha$ & $1 / 3$ & $1 / 3$ & \\
$\delta$ & 0.025 & 0.025 & \\
$\zeta$ & 2 & 2 & Basu and Leo (2016) \\
$\varrho_{g x}$ & 0.86 & 0.86 & Estimate in Section 3 \\
$\varrho_{g c}$ & 0.86 & 0.96 & Estimate in Section 3 \\
$s_{x}^{g}$ & 0.175 & 0.17 & U.S. NIPA 2005, Tables 1.1.5 and 3.9.5 \\
$s_{c}^{g}$ & 0.175 & 0.185 & U.S. NIPA 2005, Tables 1.1.5 and 3.9.5 \\
$\alpha_{g}$ & 0.05 & 0.05 & Baxter and King (1993), Leeper, Walker, and Yang (2010) \\
$\theta_{x}$ & 0.7 & 0.6 & Klenow and Malin (2010) \\
$\theta_{c}$ & 0.7 & 0.75 & Galí, López-Salido, and Vallés (2007) \\
$\phi_{\pi}$ & 1.5 & n.a. & \\
$\phi_{\pi_{c}}$ & n.a. & 1.5 & Replace Taylor rule (14) with dit $i_{t}=\phi_{\pi^{c}} \pi_{t}^{c}$ \\
\hline
\end{tabular}

Real GDP (holding prices $p^{x}, p^{c}$ fixed)

$$
y=p^{x} x+p^{c} c
$$

The endogenous variables are $n^{c}, n^{x}, n, c^{h}, \frac{w^{c}}{p^{c}}, \frac{r_{k}^{c}}{p^{c}}, \frac{p_{x}}{p_{c}}, x^{x}, x^{c}, k^{x}, k^{c}, k^{g}, x, c, y$, a total of 15 . Now approximate linearly around the old steady state and solve the system of 15 equations in 15 unknowns.

\section{A.3 A non-symmetric calibration}

In this Appendix I discuss a calibration which takes differences between the consumption and investment goods sector into account. Relative to the symmetric benchmark calibration, I take into account that 1) government consumption shocks as identified in Section 3 are more persistent than government investment shocks, 2) the government purchases a slightly larger share from the consumption goods sector (18.5 percent vs. 17 percent), 3) durable goods have slightly less sticky prices (Klenow and Malin, 2010), and 4) the Federal Reserve targets personal consumption expenditure inflation rather than GDP deflator inflation. Table A1 summarizes both calibrations.

Figure A1 shows the impulse response functions for this non-symmetric calibration. The differences to the benchmark results as shown in Figure 1 are small. Figure A2 shows how the 4-quarter multipliers vary with the half-life of the shock. Again, there are only minor differences to the benchmark calibration as shown in Figure 3 
Figure A1: Impulse response functions for non-symmetric calibration
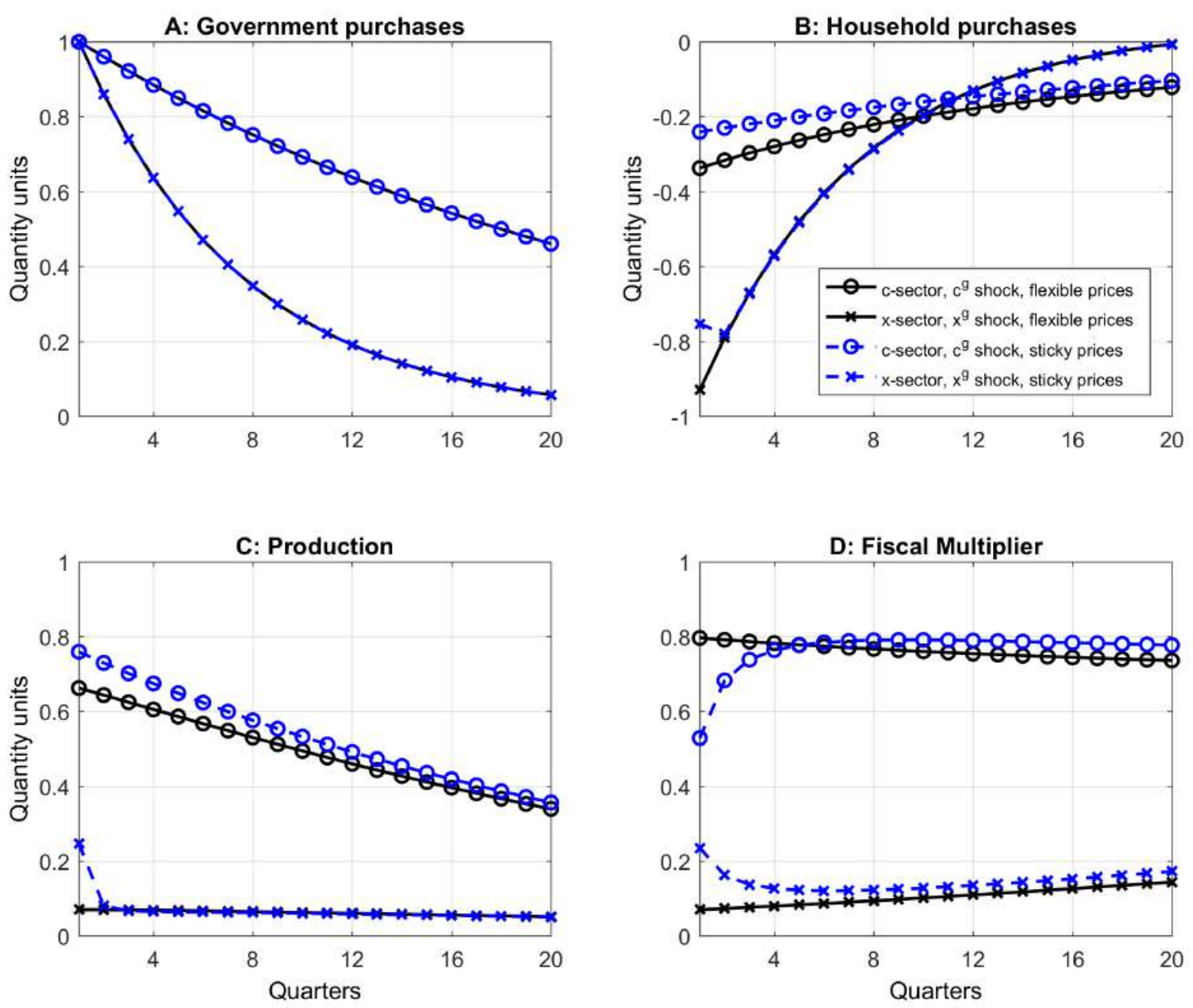

Notes: The figure plots the impulse response functions for a one unit increase in government spending based on the non-symmetric calibration (Table A1). Circles indicate responses to a government consumption shock and crosses indicate responses to a government investment shock.

\section{A.4 Supply elasticities}

In Figure 2 I assumed that the consumption and investment goods sectors have equal supply elasticities. This follows from the production functions and the assumptions of labor supply.

Combining the Fisher equations for the consumption and investment goods sectors gives

$$
\left(1+r_{t}^{x}\right) E_{t}\left[\frac{p_{t+1}^{x}}{p_{t}^{x}}\right]=\left(1+r_{t}^{c}\right) E_{t}\left[\frac{p_{t+1}^{c}}{p_{t}^{c}}\right]
$$

Next, combine this relationship with the labor supply conditions (5) and (6), the labor demands (12) and 
Figure A2: Short-run multipliers and shock persistence

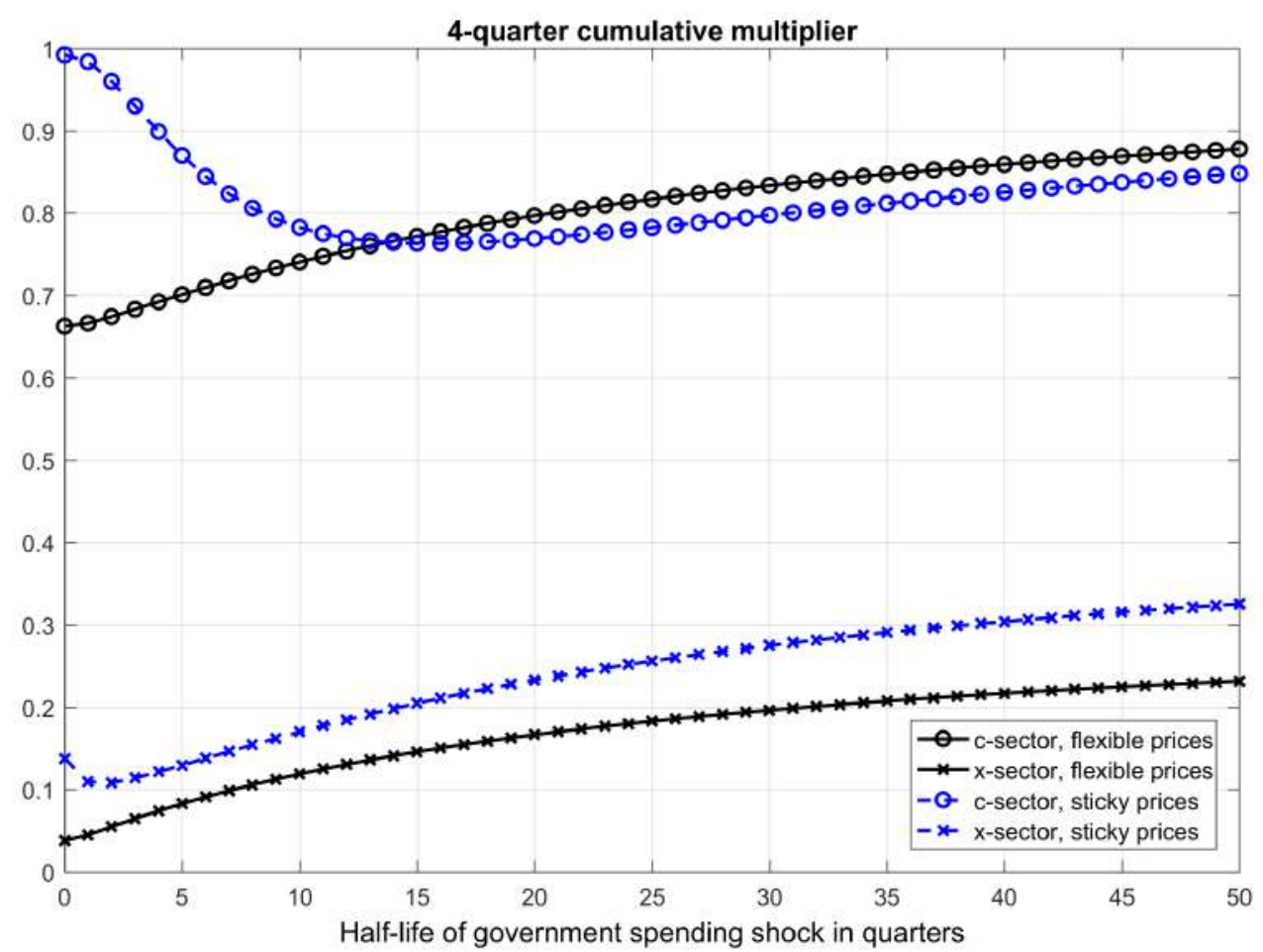

Notes: The figure plots the 4-quarter cumulative multipliers using the non-symmetric calibration (Table A1), except for the shock persistence which is chosen to generate the half-lives as indicated on the horizontal axis.

the production functions (11) to obtain

$$
\left(c_{t}\right)^{\frac{\alpha+\frac{\mu}{\eta}}{1-\alpha}}\left(1+r_{t}^{x}\right)=\frac{\frac{m c_{t}^{c}}{p_{t}^{c}}\left(\left(k_{t}^{g}\right)^{\alpha_{g}}\left(k_{t}^{c}\right)^{\alpha}\right)^{\frac{1+\frac{\mu}{\eta}}{1-\alpha}}}{E_{t}\left[\frac{p_{t+1}^{x}}{p_{t+1}^{c}}\right] \frac{m c_{t}^{x}}{p_{t}^{x}}\left(\left(k_{t}^{g}\right)^{\alpha_{g}}\left(k_{t}^{x}\right)^{\alpha}\right)^{\frac{1+\frac{\mu}{\eta}}{1-\alpha}}}\left(1+r_{t}^{c}\right)\left(x_{t}\right)^{\frac{\alpha+\frac{\mu}{\eta}}{1-\alpha}}
$$

This equation is simultaneously the supply curve for both sectors with (common and partial) supply elasticities $\frac{\partial \ln s_{t}}{\partial r_{t}^{s}}=\frac{1-\alpha}{\alpha+\frac{\mu}{\eta}}$, for $s \in\{c, x\}$. Note that in the approximation with flexible prices and purely transitory shocks, the fraction on the right hand side remains constant.

\section{A.5 Supplement for Section 2.3.2}

Consider here, for simplicity, the case with immobile labor so that $\mu=1$. Then, and using the approximation as discussed in Appendix A.2.1, equation A8 becomes up to a first order

$$
\beta d r_{t}^{c}+\frac{\alpha+\frac{1}{\eta}}{1-\alpha} \tilde{x}_{t} \approx \beta d r_{t}^{x}+\frac{\alpha+\frac{1}{\eta}}{1-\alpha} \tilde{c}_{t}
$$


Figure A3: Real interest rates in the model
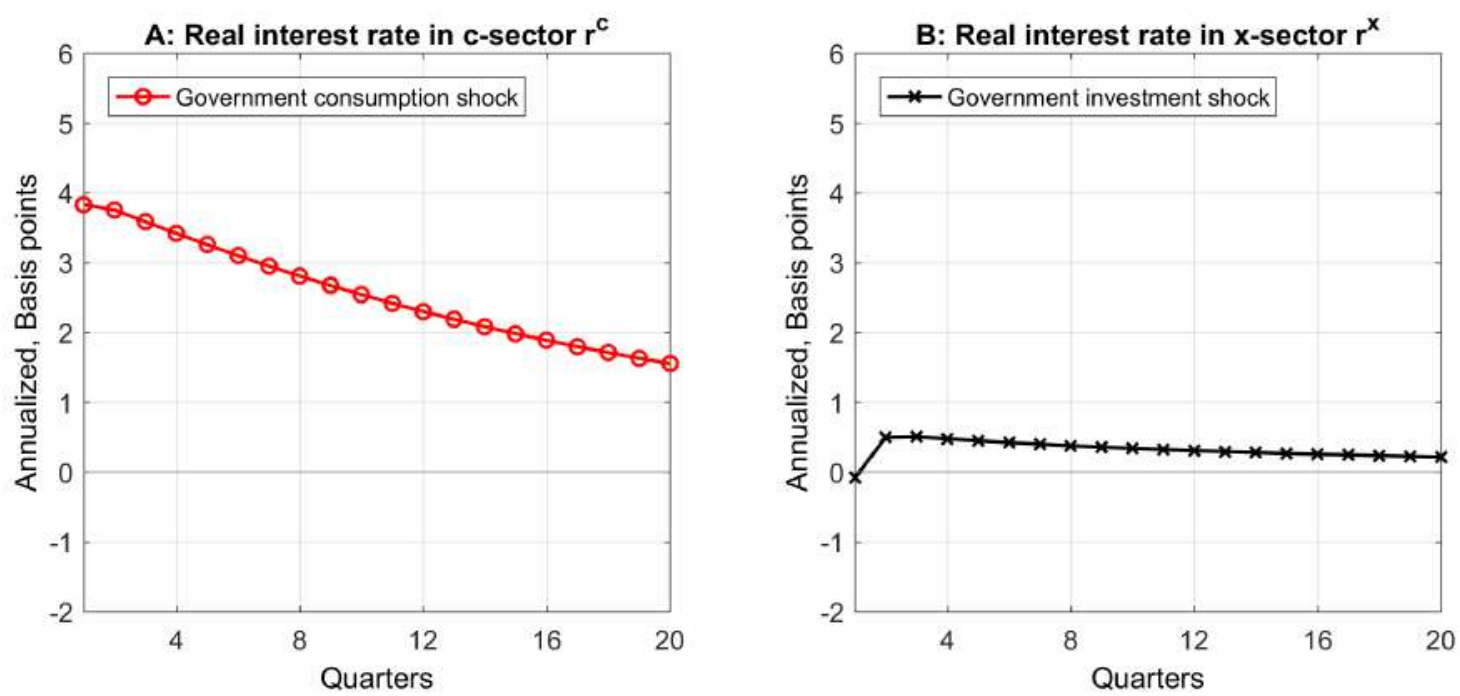

Notes: The figure presents the impulse response functions of own real interest rates to a one standard deviation government spending shock. The figure is based on the non-symmetric calibration as summarized in Table A1.

Further, the demand functions in the two sectors are given by

$$
\begin{aligned}
\beta \mathrm{d} r_{t}^{c} & \approx-\frac{1}{\sigma} \tilde{c}_{t}^{h}, \\
\beta d r_{t}^{x} & \approx 0 .
\end{aligned}
$$

It is easily shown that if $\mu=1$ then $\tilde{x}_{t} \approx 0$ in this approximation (see Appendix A.2.1). Now imposing market clearing and using the definition of real GDP yields the multipliers as given in equations (18 and 19).

\section{A.6 Predictions for real interest rates}

In this appendix I discuss the model's predictions for the behavior of real interest rates after government spending shocks.

Figure A3 presents the impulse response functions after a one percent increase in government spending over the steady state level. Panel A shows the impulse response function of the consumption goods real rate $r^{c}$ after a shock to government consumption. Panel B shows the impulse response functions of the own real interest rate $r^{x}$ after a shock to government investment. Both rise after a government spending shock in their own sector and the increase is larger in the consumption goods sector. The reason is, that investment demand is too price-elastic to support large changes in the real rate. All impulse response functions are based on the non-symmetric calibration as summarized in Table A1 


\section{B Data appendix}

\section{B.1 Main data}

The data come from editions 74 to 102 of the OECD Economic Outlook: Statistics and Projections Database. Editions 74 to 100 were downloaded on 01/27/2017. Editions 101 and 102 were downloaded on 01/10/2018. The variables are summarized in Table B1.

Different editions Forecasts of government spending and inflation expectations are constructed in real time and therefore use the edition of the database available up to that date. All other variables are constructed from the latest available edition. That is, if available, I use edition 102. If a particular variable is not available in edition 102, I use the same variable from edition 101, and so forth. Because the base years of all real variables and deflators vary by country within edition of the database and also across editions of the database, I convert all time series into variables which are independent of the base year. For instance, to use real GDP from an earlier edition, I do not use the level but convert it into a growth rate.

Manual fixes I apply a number of manual fixes when the data is unambiguously incorrect. For instance, the United Kingdom has a negative level of investment in the second quarter of 2005. I average the value of the first and third quarter to replace the negative value in quarter 2 .

\section{B.2 Notes on variable construction}

Openness Openness is defined as imports plus exports divided by GDP.

Real Private Investment Real private investment is constructed from total and government investment (ITISKV, IGV, ITISK, and IG) using the Törnqvist approximation of the Fisher ideal index (see Whelan, 2000), whenever possible. (For some countries and years the OECD's measure of real private investment (IPV) exists and is essentially identical to my measure of real private investment.) Sometimes the nominal variables are not available. If this is the case, I construct the simple difference. I checked that the deflators are not trending relative to one another whenever I performed this operation, so that the simple subtraction does not introduce significant error.

Real total government purchases Real total government purchases are constructed from IGV, IG, CGV, and CG. As for real private investment I use the Törnqvist approximation of the Fisher ideal index to construct total government purchases whenever possible and used the simple addition of IGV and CGV as an alternative. I again checked that the deflators were not trending relative to one another. 
Real interest rates I construct expected inflation as $\left(p_{t+4 \mid t}^{s}-p_{t \mid t}^{s}\right) / p_{t \mid t}^{s}, s \in\{c, x\}$. For $p^{x}$ I use PITISK and for $p^{c}$ PCP. When the investment deflator PITISK is missing, I use the deflator for total fixed investment PIT, which is highly correlated. I then construct the real interest rates for the consumption and investment goods sector based on the Fisher equation, using IRS as the measure for the nominal interest rate.

\section{B.3 The zero lower bound}

To define whether a country is at the zero lower bound, I use the variables IRSTCI (Immediate interest rates, Call Money, Interbank Rate, Per cent per annum) and IR3TIB (Short-term interest rates, Per cent per annum) from the OECD Main Economic Indicators: Finance database, downloaded 1/30/2018. An observation is defined to be at the zero lower bound if IRSTCI $\leq 0.75$. If IRSTCI is missing, I use IR3TIB instead. 
Table B1: Data from the OECD Economic Outlook: Statistics and Projections database

\begin{tabular}{|c|c|c|c|}
\hline Variable & Variable code & OECD variable name & Download date \\
\hline Real Gross Domestic Product & GDPV & Gross domestic product, volume, market prices & see text \\
\hline Real Private Consumption & $\mathrm{CPV}$ & Private final consumption expenditure, volume & see text \\
\hline Real Total Investment & ITISKV & Gross capital formation chained/constant prices & see text \\
\hline Real Government Consumption & CGV & Government final consumption expenditure, volume & see text \\
\hline Real Government Investment & IGV & Government gross fixed capital formation, volume & see text \\
\hline Real Imports & MGSV & Imports of goods and services, volume, national accounts basis & see text \\
\hline Real Exports & XGSV & Exports of goods and services, volume, national accounts basis & see text \\
\hline GDP Deflator & PGDP & Gross domestic product, deflator, market prices & see text \\
\hline Private Consumption Deflator & $\mathrm{PCP}$ & Private final consumption expenditure, deflator & see text \\
\hline Total Investment Deflator & PITISK & Gross capital formation, deflator & see text \\
\hline Government Investment Deflator & PIG & Government fixed capital formation, deflator & see text \\
\hline Total Fixed Investment Deflator & PIT & Gross total fixed capital formation, deflator & see text \\
\hline Nominal Gross Domestic Product & GDP & Gross domestic product, value, market prices & see text \\
\hline Nominal Total Investment & ITISK & Gross capital formation, current prices & see text \\
\hline Nominal Government Investment & IG & Government gross fixed capital formation, value & see text \\
\hline Short-term interest rate & IRS & Short-term interest rate, percentage points & $1 / 30 / 2018$ \\
\hline Nominal effective exchange rate & EXCHEB & Nominal effective exchange rate, chain-linked, overall weights & see text \\
\hline Real effective exchange rate & EXCHER & Real effective exchange rate, constant trade weights & see text \\
\hline Unemployment rate & UNR & Unemployment rate & see text \\
\hline Total Government Revenues & YRGT & Total receipts, general government value & see text \\
\hline Total Government Transfers & SSPG & Social security benefits paid by general government, value & see text \\
\hline Population & POP & Total Population & $1 / 17 / 2018$ \\
\hline
\end{tabular}

Notes: All data are quarterly with two exceptions. First, total population is available only at an annual frequency. I interpolate the population linearly between quarters. Second, total government revenues and total government transfers are available at a quarterly level only for about half of the observations. When not available, I take annual data and interpolate linearly between quarters. 


\section{Additional Results}

\section{C.1 Additional tables and figures}

Figure C1: Histograms of shocks
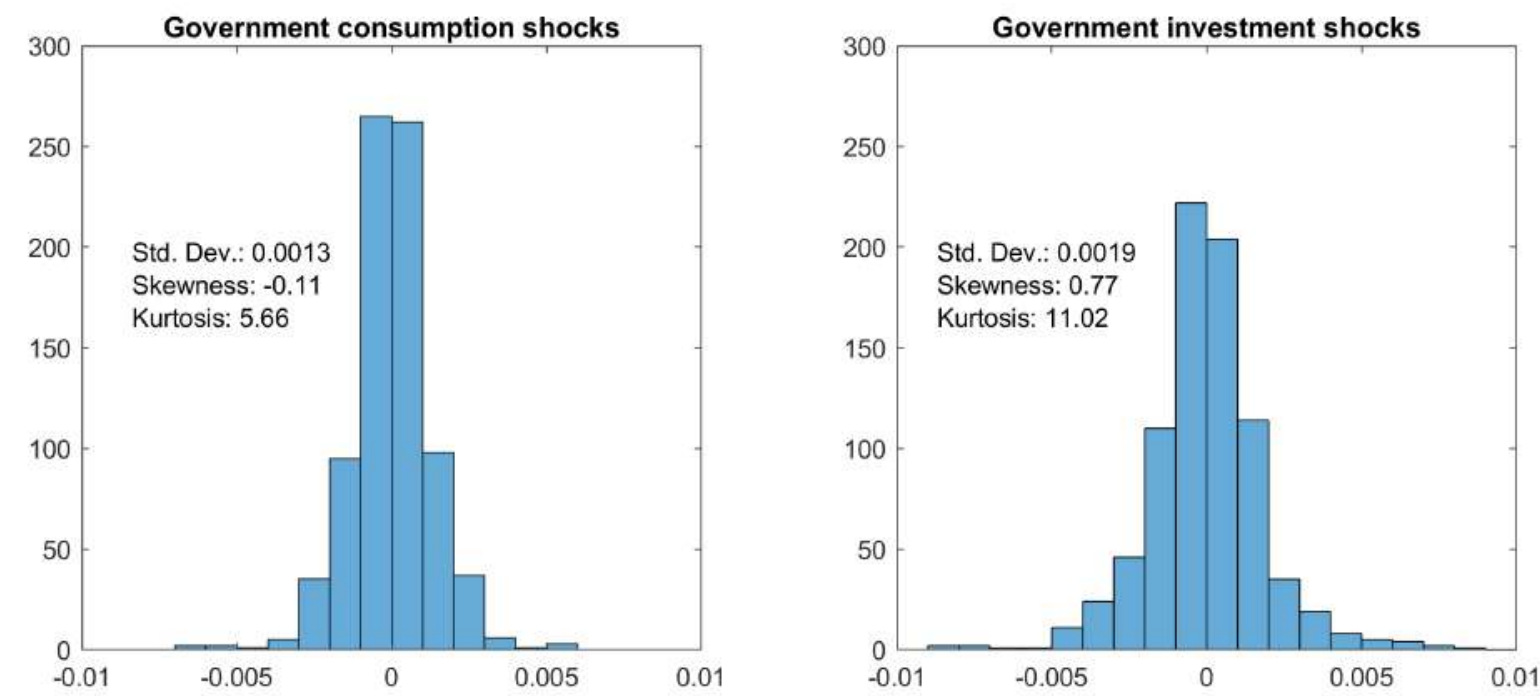

Notes: The histograms show the distribution of residuals from regression equation (22). For these illustrations I truncate the distributions below -0.01 and above 0.01 . 
Figure C2: Impulse response functions for government revenues net of transfers

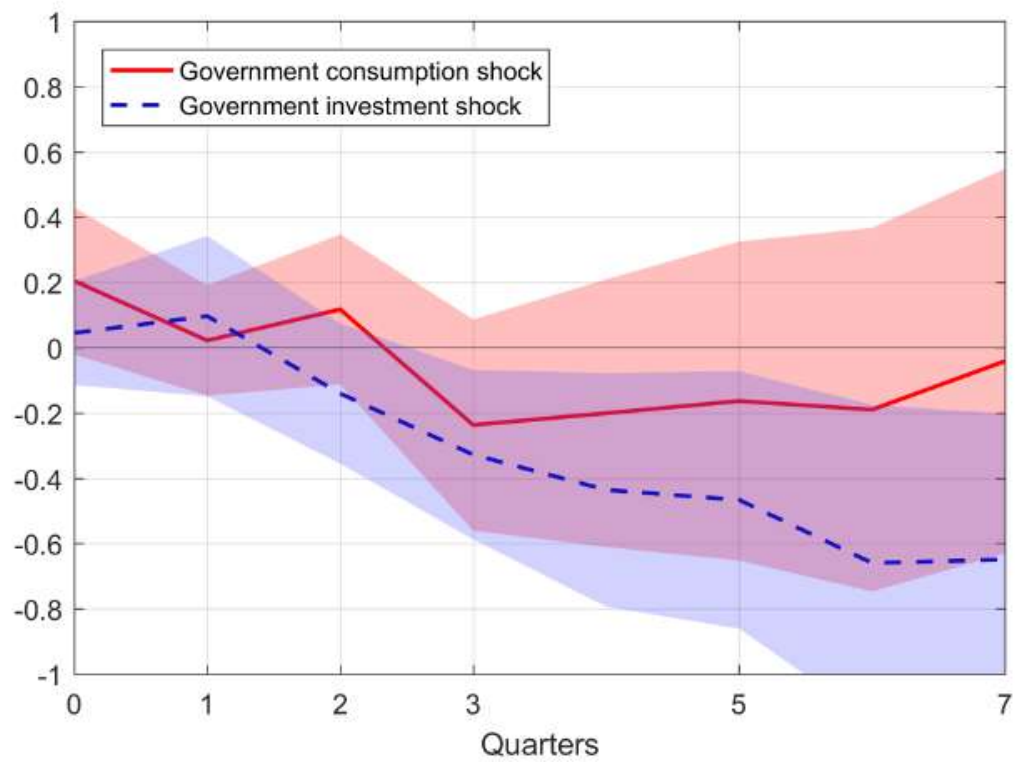

Notes: These estimates are based on specification (23) after replacing the left hand side with the $h$-quarter difference in nominal revenues net of transfers divided by lagged nominal GDP. The controls include the baseline controls as well as government transfers per GDP. The shaded areas are 90 percent confidence bands based on Driscoll-Kraay standard errors.

Figure C3: Impulse response functions for the nominal short rate

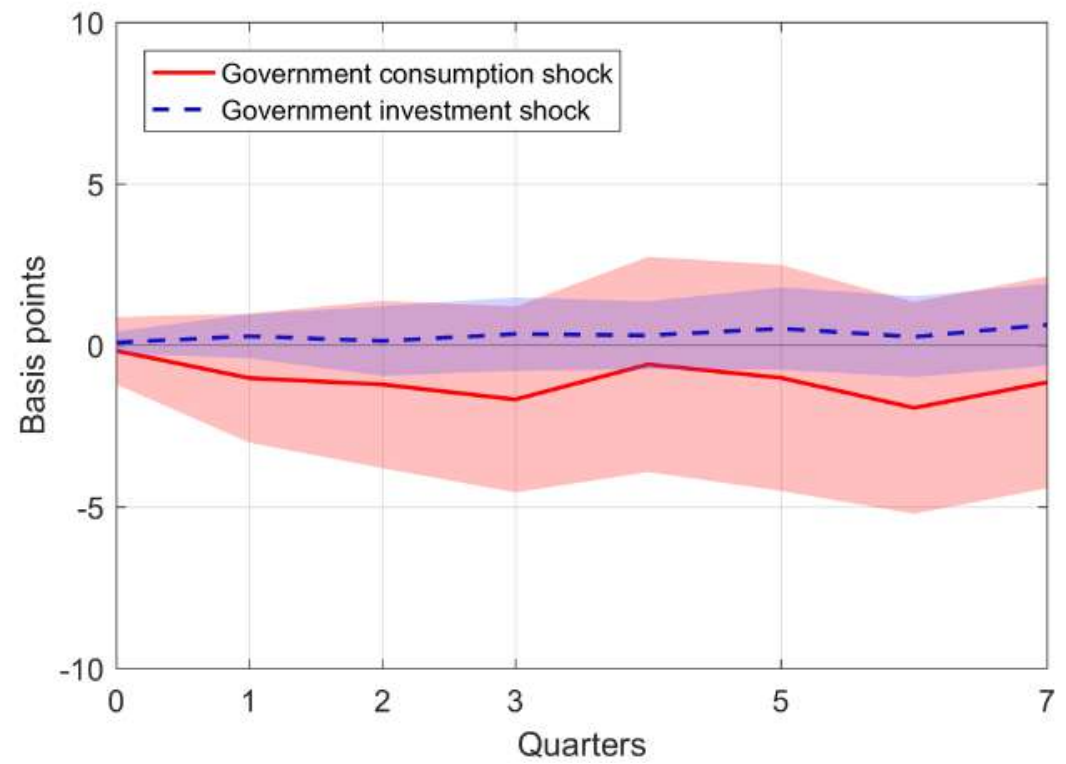

Notes: These estimates are based on specification (23) after replacing the left hand side with the $h$-quarter difference of the nominal short rate. The controls include the baseline controls as well as four lags of the first difference of the nominal short rate. The impulse response functions are scaled to reflect a one standard deviation change in the respective measure of spending. The shaded areas are 90 percent confidence bands based on Driscoll-Kraay standard errors. 
Figure C4: Impulse response functions for effective exchange rates
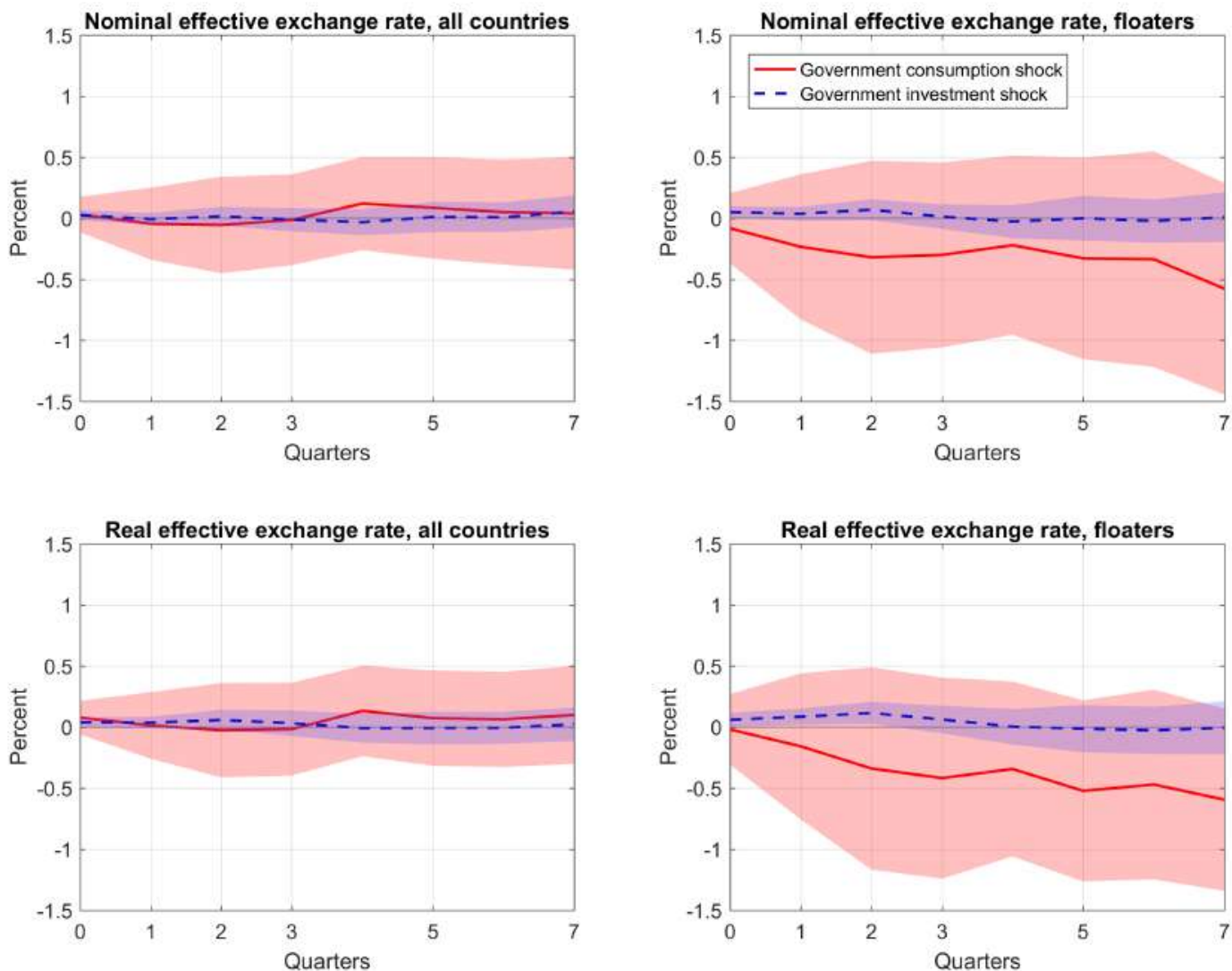

Notes: The estimates are based on specification (23) after replacing the left hand side with the $h$-quarter difference of the relevant effective exchange rate. The underlying exchange rates are denominated in U.S. Dollars per national currency unit, i.e. increases in the figure reflect appreciations. The controls include the baseline controls as well as four lags of the first difference of the respective exchange rate. Floaters are classified according to the coarse classification in Ilzetzki, Reinhart, and Rogoff (2017): Categories 1 and 2 are defined as fixed and 3, 4, and 5 as floating. The impulse response functions are scaled to reflect a one standard deviation change in the respective measure of spending. The shaded areas are 90 percent confidence bands based on Driscoll-Kraay standard errors. 
Figure C5: Leave-one-out estimation
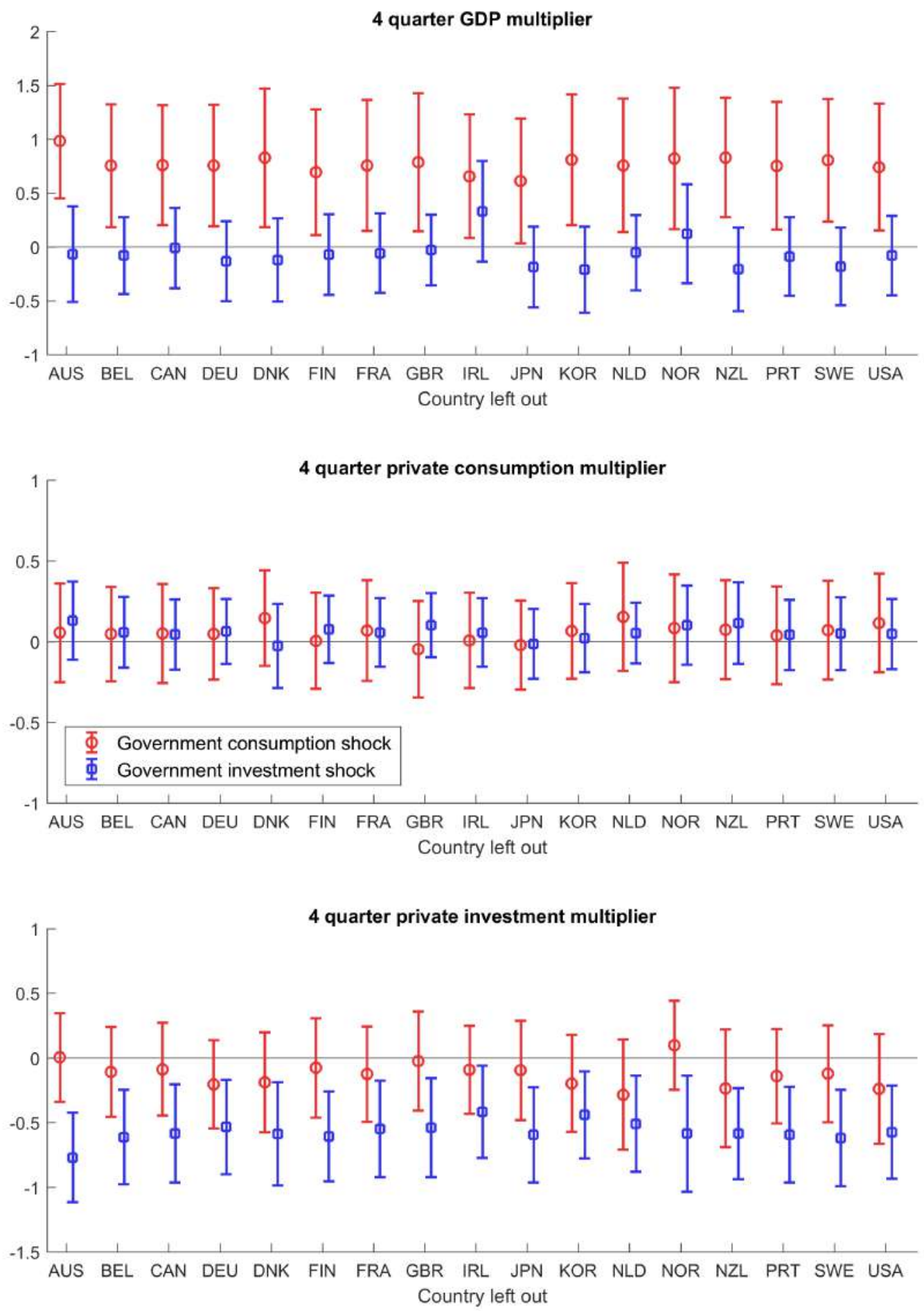

Notes: These estimates are based on specification (24) using the baseline sample, but dropping one country at a time. The vertical bars are 90 percent confidence intervals based on Driscoll-Kraay standard errors. 
Figure C6: Impulse response functions of prices at the zero lower bound
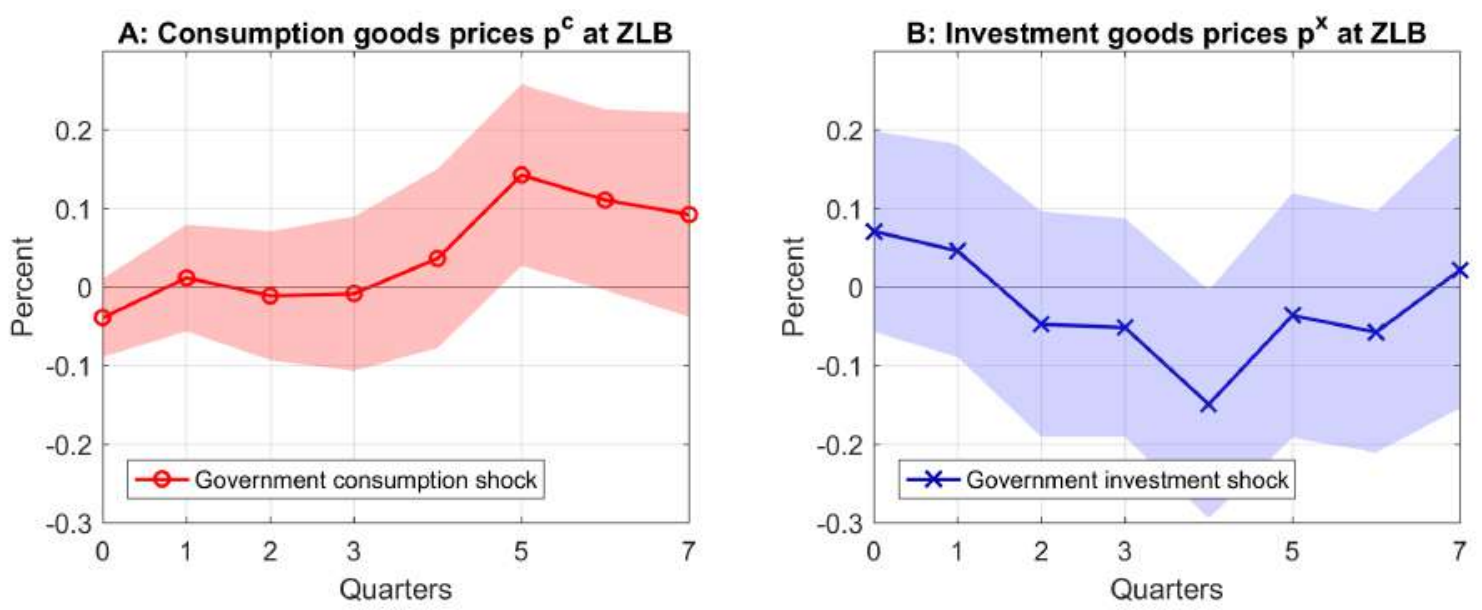

Notes: The impulse response functions are estimated based on equation (23) after replacing the left hand side with the percent change in prices $\left(p_{i, t+h}^{s}-p_{i, t-1}^{s}\right) / p_{i, t-1}^{s}, s \in\{c, x\}$. The controls include the baseline controls as well as four lags of the change in the relevant price. The sample is limited to observations at the zero lower bound and the impulse response functions are scaled to reflect a one standard deviation change in the respective measure of spending. Shaded areas are 90 percent confidence bands based on Driscoll-Kraay standard errors. 
Table C1: Comparison of multiplier estimates, standard Blanchard-Perotti identification, extended sample

\begin{tabular}{|c|c|c|c|c|c|c|}
\hline \multirow[b]{3}{*}{ Horizon (quarters) } & \multicolumn{4}{|c|}{ Panel A: Multiplier estimates } & & \\
\hline & \multicolumn{2}{|c|}{$\begin{array}{l}\text { Government } \\
\text { consumption }\end{array}$} & \multicolumn{2}{|c|}{$\begin{array}{l}\text { Government } \\
\text { investment }\end{array}$} & \multicolumn{2}{|c|}{$\begin{array}{c}\text { Total } \\
\text { purchases }\end{array}$} \\
\hline & 4 & 8 & 4 & 8 & 4 & 8 \\
\hline multiplier & $\begin{array}{c}0.72^{* * *} \\
(0.16)\end{array}$ & $\begin{array}{c}0.88^{* * *} \\
(0.21)\end{array}$ & $\begin{array}{c}0.20 \\
(0.16)\end{array}$ & $\begin{array}{c}0.10 \\
(0.26)\end{array}$ & $\begin{array}{c}0.51^{* * *} \\
(0.12)\end{array}$ & $\begin{array}{c}0.58^{* * *} \\
(0.16)\end{array}$ \\
\hline First stage F-statistic & 868.2 & 459.1 & 295.6 & 178.0 & 318.2 & 217.8 \\
\hline Observations & 2116 & 2048 & 2116 & 2048 & 2116 & 2048 \\
\hline
\end{tabular}

Panel B: Multipliers constructed from approximation (30)

\begin{tabular}{lcccccc} 
& \multicolumn{2}{c}{$\omega_{c}$} & \multicolumn{2}{c}{$\omega_{x}$} & \multicolumn{2}{c}{ Total } \\
Horizon (quarters) & 4 & 8 & 4 & 8 & 4 & 8 \\
\hline Weights & 0.414 & 0.446 & 0.482 & 0.431 & & \\
GDP multiplier & & & & & 0.39 & 0.44 \\
\hline
\end{tabular}

Notes: The estimates in Panel A are based on specification (24), but use the non-purified changes in purchases, $\left(c_{i, t}^{g}-c_{i, t-1}^{g}\right) / y_{i, t-1}$ and $\left(x_{i, t}^{g}-x_{i, t-1}^{g}\right) / y_{i, t-1}$, as instruments. The sample includes the same countries as those listed in Table 2, but spans the years 1980 to 2016. Panel B reports the weights as stated in (31) and constructs the multiplier for total purchases from the government consumption and investment multipliers as reported in Panel A, using approximation (30). Driscoll-Kraay standard errors are reported in parentheses. ${ }^{* * *}$ denotes significance at the 1 percent level. 


\section{C.2 The state of the business cycle}

In this Appendix, I explore the possibility that fiscal multipliers depend on the state of the business cycle (Auerbach and Gorodnichenko, 2012, 2013). Before proceeding, I note that the results I report below depend on how I measure the state of the business cycle. Reflecting the disagreement in the literature, alternative measures of slack yield different results. ${ }^{21}$

As a benchmark I measure the state of the business cycle as in Ramey and Zubairy (2017). That is, I use an indicator function which takes the value one if the unemployment rate is above the country-specific median. I call this measure slack ${ }_{i, t}$. The identification proceeds analogous to the procedure described in Section 3.2. To allow for state-dependent responses to shocks, I now interact all variables with slack ${ }_{i, t}$ and 1 - slack $_{i, t}$ prior to estimating specifications (22), (23), and (24). I also add a main effect of $\operatorname{slack}_{i, t}$ to the control variables.

The point estimates suggest a modest degree of state dependence in both multipliers (Table C2). The government consumption multiplier is slightly larger during slumps, but I cannot reject the null hypothesis of equal consumption multipliers over the business cycle. The government investment multiplier is smaller in episodes of slack, and this difference is significant at conventional levels. Further, the drop in private investment is striking during slumps. Although these findings are similar to Berger and Vavra (2014), I again caution that these estimates are dependent on how the state of the business cycle is measured. I next report results for an alternative measure of slack.

An alternative measure of slack Table C3 reports state-dependent estimates of multipliers for an alternative measure of slack $_{i, t}$. I construct slack ${ }_{i, t}$ as follows. First, I subtract from the unemployment rate the country-specific median. I then calculate the empirical counter-cumulative distribution function from this measure to map it into the unit interval. This mapping is almost identical to using the inverse logit specification in Auerbach and Gorodnichenko $(2012,2013)$, but avoids the choice of the parameter ( $\gamma$ in their case). The remainder of the estimation proceeds as described above. The key conclusion from these estimates is that, unlike the estimates reported above (Table $\mathrm{C} 2$ ), the government investment multiplier is no longer smaller in episodes of slack. For government consumption, the point estimates do not display large differences over the cycle. Clearly, the precise measure for slack strongly affects the results.

\footnotetext{
${ }^{21}$ Boehm and Pandalai-Nayar (2018) develop a model to motivate capacity utilization as a measure of slack.
} 
Table C2: State-dependent multipliers

\begin{tabular}{|c|c|c|c|c|c|c|}
\hline \multirow[b]{3}{*}{ LHS variable } & \multicolumn{4}{|c|}{ Panel A: High unemployment state $\left(\operatorname{slack}_{i, t}=1\right)$} & & \\
\hline & \multicolumn{2}{|c|}{ Government consumption } & \multicolumn{2}{|c|}{ Government investment } & \multicolumn{2}{|c|}{$\mathrm{p}$-value of difference $\dagger$} \\
\hline & 4 quarters & 8 quarters & 4 quarters & 8 quarters & 4 quart. & 8 quart. \\
\hline Gross domestic product & $\begin{array}{c}0.87^{* *} \\
(0.38)\end{array}$ & $\begin{array}{c}1.12^{* *} \\
(0.56)\end{array}$ & $\begin{array}{c}-0.56^{* *} \\
(0.24)\end{array}$ & $\begin{array}{c}-0.81^{* *} \\
(0.36)\end{array}$ & 0.002 & 0.011 \\
\hline Private consumption & $\begin{array}{c}0.09 \\
(0.19)\end{array}$ & $\begin{array}{c}0.39 \\
(0.27)\end{array}$ & $\begin{array}{c}-0.18 \\
(0.14)\end{array}$ & $\begin{array}{c}-0.42 \\
(0.25)\end{array}$ & 0.328 & 0.071 \\
\hline Private investment & $\begin{array}{c}0.16 \\
(0.28)\end{array}$ & $\begin{array}{c}0.68 \\
(0.50)\end{array}$ & $\begin{array}{c}-0.94^{* * *} \\
(0.28)\end{array}$ & $\begin{array}{c}-1.81^{* * *} \\
(0.44)\end{array}$ & 0.013 & 0.003 \\
\hline First stage AP F & 263.2 & 75.1 & 143.5 & 105.2 & & \\
\hline \multirow[t]{3}{*}{ Observations } & 762 & 697 & 762 & 697 & & \\
\hline & \multicolumn{4}{|c|}{ Panel B: Low unemployment state $\left(\operatorname{slack}_{i, t}=0\right)$} & & \\
\hline & \multicolumn{2}{|c|}{ Government consumption } & \multicolumn{2}{|c|}{ Government investment } & \multicolumn{2}{|c|}{ p-value of difference $\dagger$} \\
\hline LHS variable & 4 quarters & 8 quarters & 4 quarters & 8 quarters & 4 quart. & 8 quart. \\
\hline Gross domestic product & $\begin{array}{c}0.66 \\
(0.53)\end{array}$ & $\begin{array}{l}0.69^{*} \\
(0.40)\end{array}$ & $\begin{array}{c}0.20 \\
(0.27)\end{array}$ & $\begin{array}{c}0.14 \\
(0.43)\end{array}$ & 0.459 & 0.335 \\
\hline Private consumption & $\begin{array}{l}-0.02 \\
(0.28)\end{array}$ & $\begin{array}{l}-0.03 \\
(0.31)\end{array}$ & $\begin{array}{c}0.12 \\
(0.18)\end{array}$ & $\begin{array}{l}-0.17 \\
(0.29)\end{array}$ & 0.714 & 0.788 \\
\hline Private investment & $\begin{array}{l}-0.47 \\
(0.31)\end{array}$ & $\begin{array}{l}-0.32 \\
(0.27)\end{array}$ & $\begin{array}{l}-0.45^{*} \\
(0.26)\end{array}$ & $\begin{array}{l}-0.59 \\
(0.38)\end{array}$ & 0.960 & 0.575 \\
\hline First stage AP F & 217.9 & 188.3 & 215.1 & 76.2 & & \\
\hline Observations & 762 & 697 & 762 & 697 & & \\
\hline
\end{tabular}

Panel C: p-value (H0: Equal multipliers over the business cycle)

\begin{tabular}{lcccc} 
& \multicolumn{2}{c}{ Government } & consumption & \multicolumn{2}{c}{ Government investment } \\
& 4 quarters & 8 quarters & 4 quarters & 8 quarters \\
\hline Gross domestic product & 0.746 & 0.539 & 0.016 & 0.055 \\
Private consumption & 0.700 & 0.228 & 0.085 & 0.353 \\
Private investment & 0.107 & 0.079 & 0.152 & 0.016 \\
\hline
\end{tabular}

Notes: Estimates are obtained as described in text. AB abbreviates Angrist-Pischke. Driscoll-Kraay standard errors are reported in parentheses. ${ }^{* * *},{ }^{* *}$, and ${ }^{*}$ denote significance at the 1,5 , and 10 percent level.

$\dagger$ : The null hypothesis is that the government consumption and investment multipliers are equal. 
Table C3: Robustness: State-dependent multipliers

\begin{tabular}{|c|c|c|c|c|c|c|}
\hline \multirow[b]{3}{*}{ LHS variable } & \multicolumn{4}{|c|}{ Panel A: High unemployment state $\left(\operatorname{slack}_{i, t}=1\right)$} & & \\
\hline & \multicolumn{2}{|c|}{ Government consumption } & \multicolumn{2}{|c|}{ Government investment } & \multicolumn{2}{|c|}{ p-value of difference $\dagger$} \\
\hline & 4 quarters & 8 quarters & 4 quarters & 8 quarters & 4 quart. & 8 quart. \\
\hline Gross domestic product & $\begin{array}{c}0.78 \\
(0.77)\end{array}$ & $\begin{array}{c}0.61 \\
(0.58)\end{array}$ & $\begin{array}{c}0.17 \\
(0.39)\end{array}$ & $\begin{array}{c}0.28 \\
(0.68)\end{array}$ & 0.465 & 0.682 \\
\hline Private consumption & $\begin{array}{c}0.04 \\
(0.37)\end{array}$ & $\begin{array}{l}-0.13 \\
(0.42)\end{array}$ & $\begin{array}{c}0.14 \\
(0.24)\end{array}$ & $\begin{array}{l}-0.18 \\
(0.34)\end{array}$ & 0.852 & 0.937 \\
\hline Private investment & $\begin{array}{l}-0.64 \\
(0.43)\end{array}$ & $\begin{array}{l}-0.46 \\
(0.45)\end{array}$ & $\begin{array}{l}-0.62^{*} \\
(0.37)\end{array}$ & $\begin{array}{l}-0.58 \\
(0.56)\end{array}$ & 0.970 & 0.866 \\
\hline First stage AP F & 228.6 & 215.4 & 127.7 & 40.8 & & \\
\hline \multirow[t]{3}{*}{ Observations } & 762 & 697 & 762 & 697 & & \\
\hline & \multicolumn{4}{|c|}{ Panel B: Low unemployment state $\left(\operatorname{slack}_{i, t}=0\right)$} & & \\
\hline & \multicolumn{2}{|c|}{ Government consumption } & \multicolumn{2}{|c|}{ Government investment } & \multicolumn{2}{|c|}{ p-value of difference $\dagger$} \\
\hline LHS variable & 4 quarters & 8 quarters & 4 quarters & 8 quarters & 4 quart. & 8 quart. \\
\hline Gross domestic product & $\begin{array}{c}0.59 \\
(0.50)\end{array}$ & $\begin{array}{l}1.00 * \\
(0.63)\end{array}$ & $\begin{array}{l}-0.07 \\
(0.46)\end{array}$ & $\begin{array}{l}-0.24 \\
(0.71)\end{array}$ & 0.355 & 0.229 \\
\hline Private consumption & $\begin{array}{c}0.07 \\
(0.25)\end{array}$ & $\begin{array}{c}0.47 \\
(0.31)\end{array}$ & $\begin{array}{l}-0.07 \\
(0.24)\end{array}$ & $\begin{array}{l}-0.16 \\
(0.39)\end{array}$ & 0.720 & 0.276 \\
\hline Private investment & $\begin{array}{c}0.23 \\
(0.35)\end{array}$ & $\begin{array}{c}0.84 \\
(0.52)\end{array}$ & $\begin{array}{l}-0.62 \\
(0.42)\end{array}$ & $\begin{array}{c}-1.41^{* *} \\
(0.64)\end{array}$ & 0.162 & 0.023 \\
\hline First stage AP F & 393.3 & 148.5 & 183.5 & 99.7 & & \\
\hline Observations & 762 & 697 & 762 & 697 & & \\
\hline
\end{tabular}

Panel C: p-value (H0: Equal multipliers over the business cycle)

Government consumption Government investment

4 quarters 8 quarters 4 quarters 8 quarters

\begin{tabular}{lllll} 
Gross domestic product & 0.863 & 0.707 & 0.741 & 0.661 \\
Private consumption & 0.958 & 0.311 & 0.591 & 0.960 \\
Private investment & 0.192 & 0.125 & 1.000 & 0.417 \\
\hline
\end{tabular}

Notes: Estimates are obtained as described in text, but use the alternative measure of slack $_{i, t}$. AP abbreviates AngristPischke. Driscoll-Kraay standard errors are reported in parentheses. ${ }^{* * *},{ }^{* *}$, and ${ }^{*}$ denote significance at the 1,5 , and 10 percent level.

$\dagger$ : The null hypothesis is that the government consumption and investment multipliers are equal. 


\section{Decomposition of total purchases multiplier}

This appendix provides additional details on the relationship between the estimated multiplier for total government purchases and the multipliers for government consumption and investment as presented in Section 4.

Proposition. Consider the three models

$$
\begin{aligned}
& y_{i, t}=m_{g} g_{i, t}+q_{i, t}^{\prime} \beta_{g}+\varepsilon_{i, t}^{g}, \\
& y_{i, t}=m_{x} x_{i, t}^{g}+q_{i, t}^{\prime} \beta_{x}+\varepsilon_{i, t}^{x}, \\
& y_{i, t}=m_{c} c_{i, t}^{g}+q_{i, t}^{\prime} \beta_{c}+\varepsilon_{i, t}^{c},
\end{aligned}
$$

where $y_{i, t}$ is a common left hand side variable, $q_{i, t}$ a common vector of control variables, and

$$
g_{i, t}=x_{i, t}^{g}+c_{i, t}^{g}
$$

There are instruments $z_{i, t}^{g}$ for $g_{i, t}, z_{i, t}^{x}$ for $x_{i, t}^{g}$, and $z_{i, t}^{c}$ for $c_{i, t}^{g}$, such that

$$
z_{i, t}^{g}=z_{i, t}^{x}+z_{i, t}^{c}
$$

Then the exactly identified instrumental variable (IV) estimators satisfy

$$
\hat{m}_{g}=\omega_{x} \hat{m}_{x}+\omega_{c} \hat{m}_{c}
$$

where

$$
\omega_{x}=\frac{\left(M_{Q} z^{x}\right)^{\prime} M_{Q} x^{g}}{\left(M_{Q} z^{g}\right)^{\prime} M_{Q} g}, \quad \omega_{c}=\frac{\left(M_{Q} z^{c}\right)^{\prime} M_{Q} c^{g}}{\left(M_{Q} z^{g}\right)^{\prime} M_{Q} g},
$$

and $M_{Q}=I-Q\left(Q^{\prime} Q\right)^{-1} Q^{\prime}$.

Proof. The proof is an application of the Frisch-Waugh-Lovell theorem. Begin with writing (25) in stacked (matrix) form

$$
y=m_{g} g+Q \beta_{g}+\varepsilon^{g} .
$$

The moment conditions, split into $g$ and $Q$, for the exactly identified IV estimator are

$$
\begin{aligned}
z^{\prime}\left(y-\hat{m}_{g} g-Q \hat{\beta}_{g}\right) & =0 \\
Q^{\prime}\left(y-\hat{m}_{g} g-Q \hat{\beta}_{g}\right) & =0
\end{aligned}
$$

and these can be solved for

$$
\hat{\beta}_{g}=\left(Q^{\prime} Q\right)^{-1} Q^{\prime}\left(y-\hat{m}_{g} g\right)
$$

and hence

$$
\hat{m}_{g}=\frac{\left(M_{Q} z\right)^{\prime} M_{Q} y}{\left(M_{Q} z\right)^{\prime} M_{Q} g}
$$


where the matrix

$$
M_{Q}=I-Q\left(Q^{\prime} Q\right)^{-1} Q^{\prime}
$$

is indempotent and symmetric. (This matrix residualizes with respect to $Q$.)

Then simple algebra gives

$$
\begin{aligned}
\hat{m}_{g} & =\frac{\left(M_{Q} z^{c}\right)^{\prime} M_{Q} y+\left(M_{Q} z^{x}\right)^{\prime} M_{Q} y}{\left(M_{Q} z^{g}\right)^{\prime} M_{Q} g} \\
& =\frac{\left(M_{Q} z^{c}\right)^{\prime} M_{Q} c^{g}}{\left(M_{Q} z^{g}\right)^{\prime} M_{Q} g} \frac{\left(M_{Q} z^{c}\right)^{\prime} M_{Q} y}{\left(M_{Q} z^{c}\right)^{\prime} M_{Q} c^{g}}+\frac{\left(M_{Q} z^{x}\right)^{\prime} M_{Q} x^{g}}{\left(M_{Q} z^{g}\right)^{\prime} M_{Q} g} \frac{\left(M_{Q} z^{x}\right)^{\prime} M_{Q} y}{\left(M_{Q} z^{x}\right)^{\prime} M_{Q} x^{g}} .
\end{aligned}
$$

Now note that

$$
\hat{m}_{x}=\frac{\left(M_{Q} z^{x}\right)^{\prime} M_{Q} y}{\left(M_{Q} z^{x}\right)^{\prime} M_{Q} x^{g}} \quad \text { and } \quad \hat{m}_{c}=\frac{\left(M_{Q} z^{c}\right)^{\prime} M_{Q} y}{\left(M_{Q} z^{c}\right)^{\prime} M_{Q} c^{g}}
$$

are the IV estimates of $m_{x}$ and $m_{c}$ in equations (26) and (27). Further,

$$
\omega_{x}=\frac{\left(M_{Q} z^{x}\right)^{\prime} M_{Q} x^{g}}{\left(M_{Q} z^{g}\right)^{\prime} M_{Q} g} \quad \text { and } \quad \omega_{c}=\frac{\left(M_{Q} z^{c}\right)^{\prime} M_{Q} c^{g}}{\left(M_{Q} z^{g}\right)^{\prime} M_{Q} g} .
$$

The claim now follows immediately.

I add three remarks. First, this proposition requires no assumption on the true underlying model. Under the stated conditions it holds exactly in the data. Second, the weights do not sum to one, due to cross terms

$$
1-\omega_{x}-\omega_{c}=\frac{\left(M_{Q} z^{c}\right)^{\prime} M_{Q} x^{g}+\left(M_{Q} z^{x}\right)^{\prime} M_{Q} c^{g}}{\left(M_{Q} z^{g}\right)^{\prime} M_{Q} g} .
$$

Third, replacing the instruments with the endogenous variables gives the result for the ordinary least squares (OLS) estimator.

In the text, I apply this formula after replacing $y$ with $\Delta y$, the vector of $\sum_{j=0}^{h} \frac{y_{i, t+j}-y_{i, t-1}}{y_{i, t-1}}$, $g$ with $\Delta g$, the vector of $\sum_{j=0}^{h} \frac{g_{i, t+j}-g_{i, t-1}}{y_{i, t-1}}, x^{g}$ with $\Delta x^{g}$, the vector of $\sum_{j=0}^{h} \frac{x_{i, t+j}^{g}-x_{i, t-1}^{g}}{y_{i, t-1}}, c^{g}$ with $\Delta c^{g}$, the vector of $\sum_{j=0}^{h} \frac{c_{i, t+j}^{g}-c_{i, t-1}^{g}}{y_{i, t-1}}, z^{x}$ with the vector of residuals $\hat{u}^{x}$ from equation (22), $z^{c}$ with the vector of residuals $\hat{u}^{c}$ (also equation 22), and $z^{g}$ with the vector of residuals $\hat{u}^{g}=\hat{u}^{c}+\hat{u}^{x}$.

Finally note that this formula is not exact in the data for two reasons. First, chained indexes are not additive, so that equation (29) does not hold due to statistical discrepancy (see Whelan, 2000). Second, I prefer to estimate the government consumption multiplier while controlling for government investment shocks and the government investment multiplier while controlling for government consumption shocks. In other words, I add an additional control to equation (26) and (27). As I established in Section 3, these controls have little effect on the estimates, but break the identity in equation (30). As a result, we 
have

$$
\hat{m}_{g} \approx \omega_{x} \hat{m}_{x}+\omega_{c} \hat{m}_{c} .
$$

Table D1 shows this breakdown numerically. In the table, the term additive indicates that I impose additivity by constructing total purchases as the sum of government consumption and investment. This is not in general a permissible operation with chained indexes, but the statistical discrepancy is small here. Further, with controls indicates that I control for the government investment shock when estimating the government consumption multiplier and that I control for the government consumption shock when estimating the government investment multiplier.

Panel A shows the baseline estimates as reported in Table 8. Panel B adds additivity by constructing total purchases as the sum of government consumption and investment. As a result, the multiplier for total purchases changes moderately. In Panel C, I drop the other spending shock as a control which mildly affects the government consumption and investment multiplier. When combined with the weights in Panel D, the estimates for the government consumption and investment multipliers in Panel C exactly aggregate into the multiplier for total purchases (equation 30). 
Table D1: Breakdown of total purchases multiplier

\begin{tabular}{|c|c|c|c|c|c|c|}
\hline \multirow[b]{3}{*}{ Horizon (quarters) } & \multicolumn{6}{|c|}{ Panel A: Baseline estimates: not additive, with controls } \\
\hline & \multicolumn{2}{|c|}{ Gov. consumption } & \multicolumn{2}{|c|}{ Gov. investment } & \multicolumn{2}{|c|}{ Total purchases } \\
\hline & 4 & 8 & 4 & 8 & 4 & 8 \\
\hline \multirow[t]{3}{*}{ GDP multiplier } & 0.765 & 0.851 & -0.077 & -0.063 & 0.248 & 0.341 \\
\hline & \multicolumn{6}{|c|}{ Panel B: additive, with controls } \\
\hline & \multicolumn{2}{|c|}{ Gov. consumption } & \multicolumn{2}{|c|}{ Gov. investment } & \multicolumn{2}{|c|}{ Total purchases } \\
\hline Horizon (quarters) & 4 & 8 & 4 & 8 & 4 & 8 \\
\hline \multirow[t]{3}{*}{ GDP multiplier } & 0.765 & 0.851 & -0.077 & -0.063 & 0.220 & 0.302 \\
\hline & \multicolumn{6}{|c|}{ Panel C: Exact decomposition: additive, without controls } \\
\hline & \multicolumn{2}{|c|}{ Gov. consumption } & \multicolumn{2}{|c|}{ Gov. investment } & \multicolumn{2}{|c|}{ Total purchases } \\
\hline Horizon (quarters) & 4 & 8 & 4 & 8 & 4 & 8 \\
\hline \multirow[t]{2}{*}{ GDP multiplier } & 0.751 & 0.841 & -0.030 & -0.001 & 0.220 & 0.302 \\
\hline & \multicolumn{6}{|c|}{ Panel D: Weights } \\
\hline & \multicolumn{2}{|c|}{$\omega_{c}$} & \multicolumn{2}{|c|}{$\omega_{x}$} & \multicolumn{2}{|c|}{$1-\omega_{c}-\omega_{x}$} \\
\hline Horizon (quarters) & 4 & 8 & 4 & 8 & 4 & 8 \\
\hline Weight & 0.317 & 0.360 & 0.591 & 0.544 & 0.092 & 0.096 \\
\hline
\end{tabular}

Notes: See text for details. 